\title{
Examining Factors of Physical Activity Participation in Youth with Spina Bifida using the Theoretical Domains Framework
}

by

\author{
Zlata Volfson
}

A thesis submitted in conformity with the requirements

for the degree of Masters of Science

Graduate Department of Exercise Science

University of Toronto

(C) Copyright by Zlata Volfson 2016 


\title{
Examining Factors of Physical Activity Participation in Youth with Spina Bifida using the Theoretical Domains Framework
}

\author{
Zlata Volfson \\ Masters of Science \\ Exercise Science \\ University of Toronto
}

2016

\begin{abstract}
Spina Bifida (SB) is a congenital neural tube defect that involves the incomplete development of the spinal cord, resulting in varying health ailments. Given the high rate of inactivity reported for youth with SB and using the Theoretical Domains Framework as a guide, the purpose of this study was to explore the physical, psychological, social and environmental factors influencing physical activity (PA) participation in this population. Nine eligible youth (6 females; mean age $=15.9$ years) took part in one, semi-structured individual interview. The most commonly reported perceived PA facilitators were: self-efficacy, positive consequences of PA, positive affect, and social influences. Lack of knowledge and independence, pain/fatigue, limited control over decision processes, and inaccessible environmental resources were the most commonly reported barriers to PA. These findings can be used to direct further research, testing the theoretical correlates that are most amenable to change in order to promote PA within this population.
\end{abstract}




\section{Acknowledgments}

First off, I wish to thank my Master's supervisor, Dr. Kelly Arbour-Nicitopoulos for your continued support, guidance and patience throughout this entire project and for never giving up on me. You have provided me with an opportunity to explore a great passion of mine, and given me a platform to make a difference. The skills and lessons I have learned from you are invaluable and which I will never forget.

A special thank you to Dr. Amy McPherson, for your continuous guidance and support. I greatly appreciate all the knowledge you have given me on all things related to Spina Bifida, and for allowing me to share in your passion.

To the remainder of my committee and external reviewer, Dr. Guy Fulkner, Dr. Jennifer Tomasone and Dr. Heather Gainforth. Thank you for your invaluable suggestions and insights into the various topics my thesis covered. Thank you for challenging me, you have developed my critical thinking and for that I thank you.

I would also like to acknowledge and thank the care team at the Spina Bifida Clinic at Holland Bloorview Rehabilitation Hospital. Thank you for providing me with the opportunity to conduct research within the clinic. I am so grateful for all your help fine tuning the interview guide and with recruitment. As well as special thank you to all the participants who took the time share your experiences with me. You have opened my eyes in more ways than one.

Thank you to all my wonderful friends within the Faculty of Kinesiology and Physical Education for your friendship, support, and guidance. It has meant more than you know.

Lastly, I would like to thank my brother and sister, for always being my first participants, and allowing me to develop as a researcher. Finally, the biggest thank you to my parents for allowing me to follow my dreams and passions (even though you are not sure what they are). Thank you for teaching me to never give up at any sign of hardship and to fight even harder to achieve my goals. 


\section{Table of Contents}

Acknowledgments ............................................................................................ iii

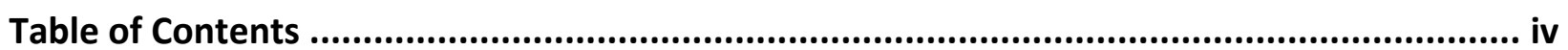

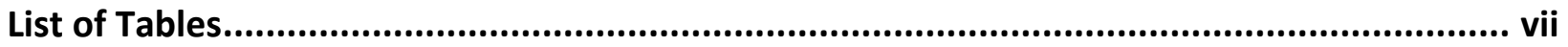

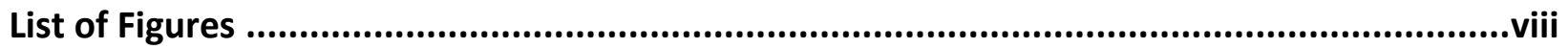

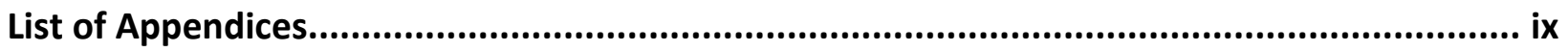

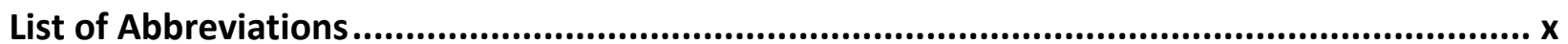

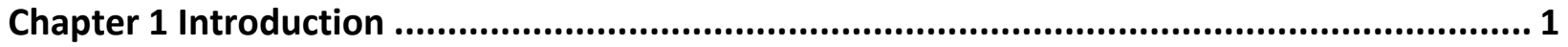

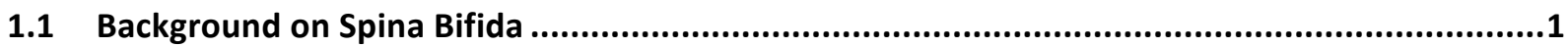

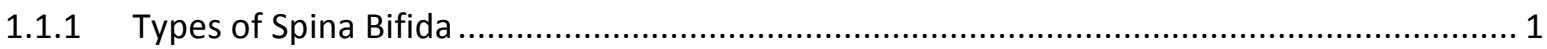

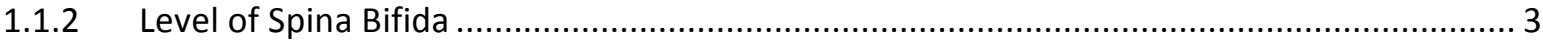

1.1.3 Spina Bifida and Associated Neurological Conditions .................................................... 3

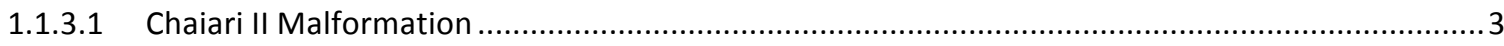

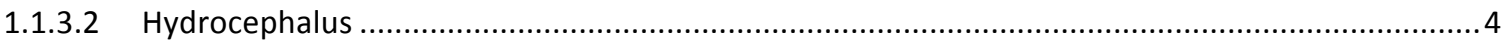

1.1.4 Secondary Conditions in Persons with Spina Bifida .......................................................... 4

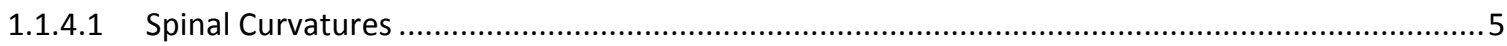

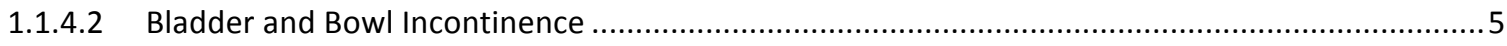

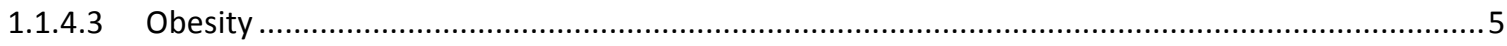

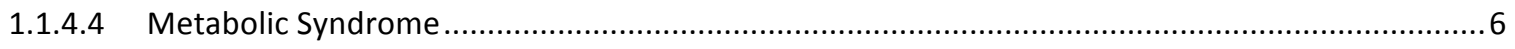

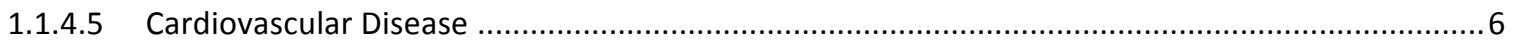

1.1.4.6 Other Complications ……......................................................................................................

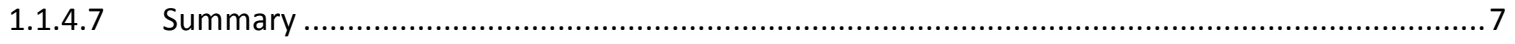

1.1.5 Youth with Spina Bifida - A Priority Group .................................................................. 7

1.1.6 Overall Summary on Secondary Health Complications.................................................... 8

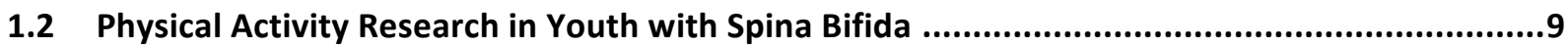

1.2.1 Benefits of Physical Activity for Youth with Physical Disabilities ........................................ 9

1.2.2 Barriers and Facilitators to PA participation in Youth with Physical Disabilities ..................... 12

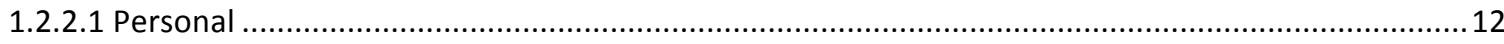

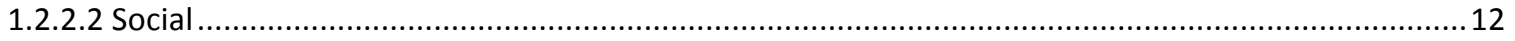




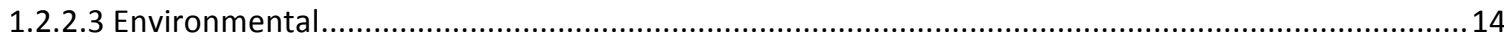

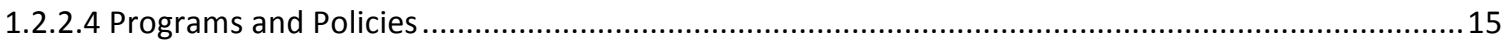

1.2.3 Barriers and Facilitators to Physical Activity Participation in Youth with Spina Bifida ............ 15

1.2.4 Correlates of PA Participation for Youth with Spina Bifida ............................................ 16

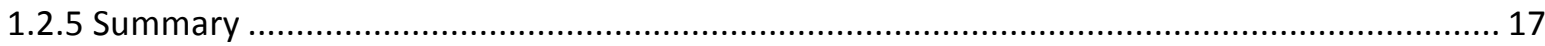

1.3 The Theoretical Domains Framework (TDF) .............................................................18

1.3.1 TDF - A Useful Framework for Exploring Factors that Influence PA Behaviour in Youth with

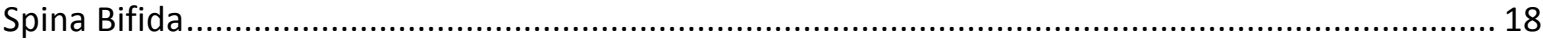

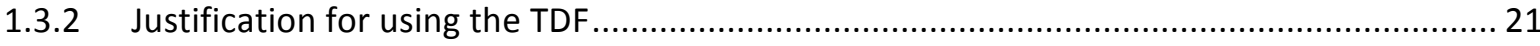

Chapter 2 Objectives and Hypotheses......................................................................... 23

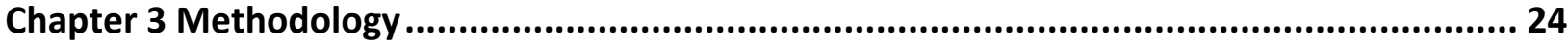

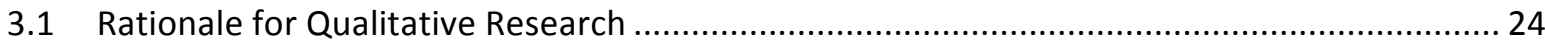

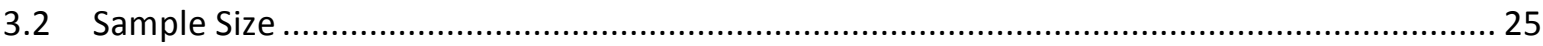

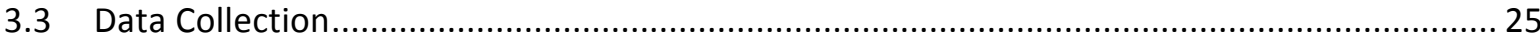

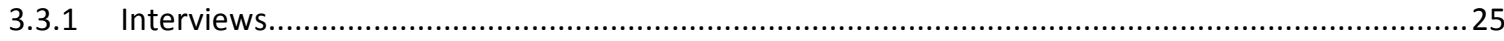

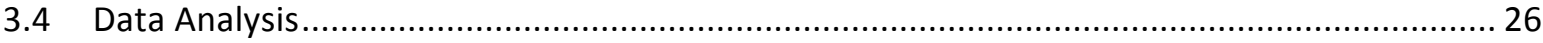

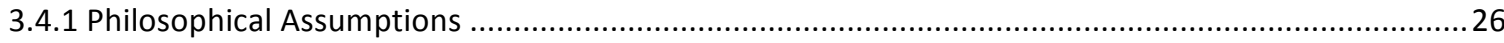

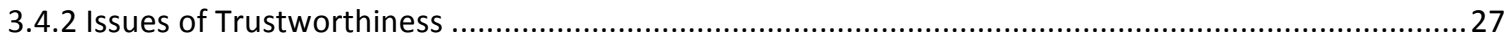

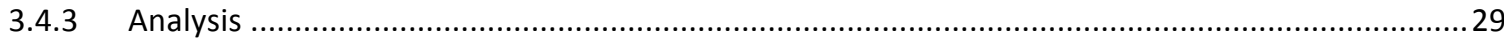

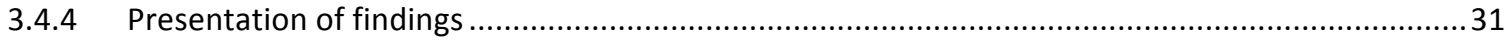

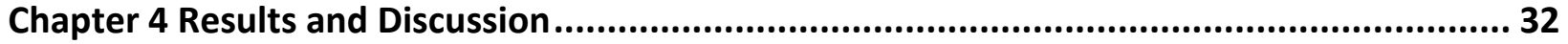

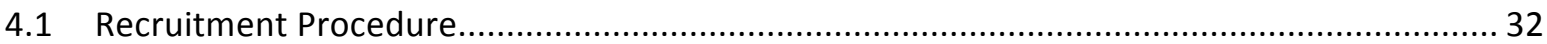

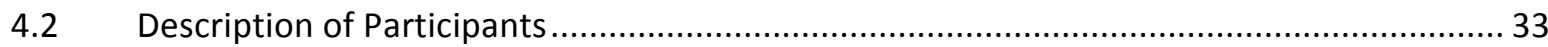

4.3 Theoretical Domains Framework Domains ....................................................... 34

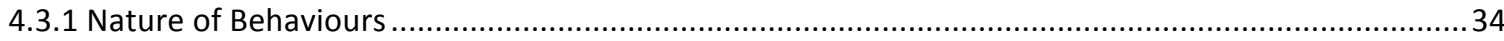

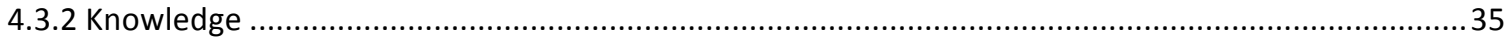

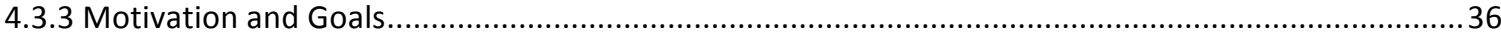

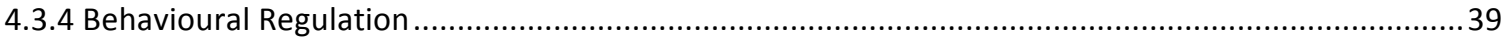

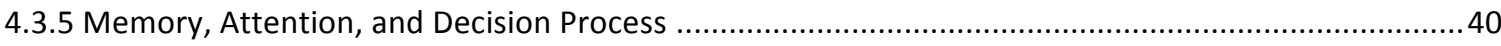

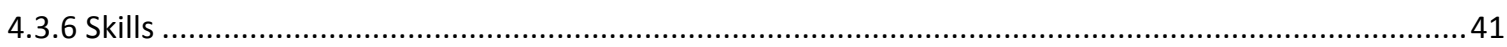

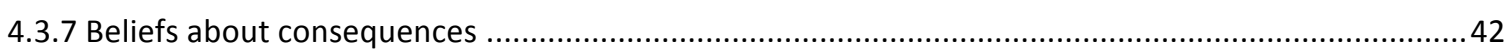

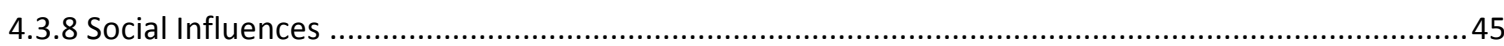

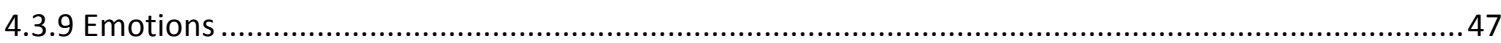




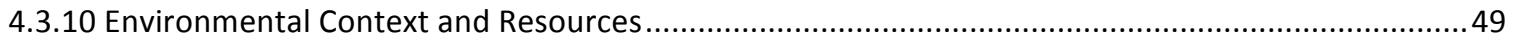

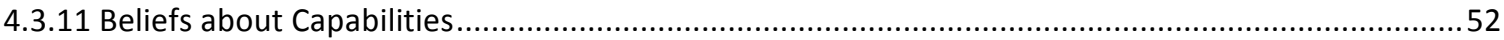

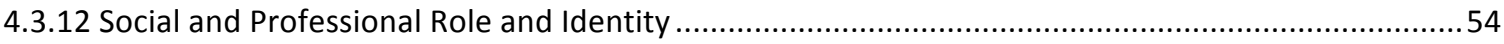

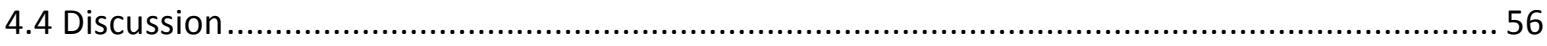

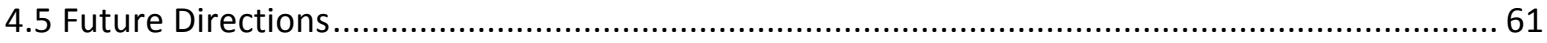

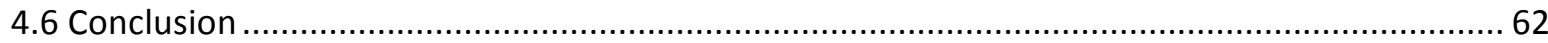

Chapter 5 Considerations, Strengths and Personal Reflections...................................... 64

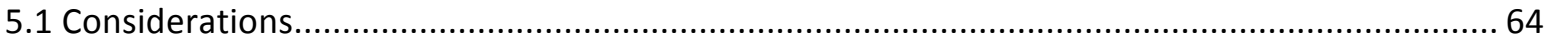

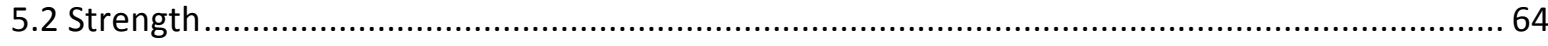

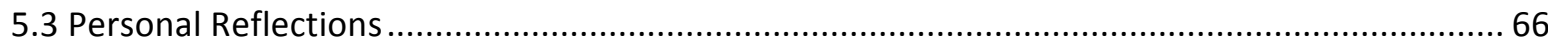

6.1 Appendix A.............................................................................................68

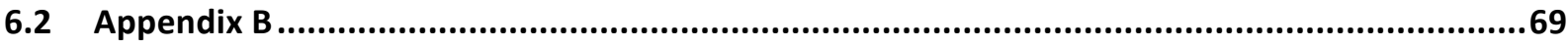

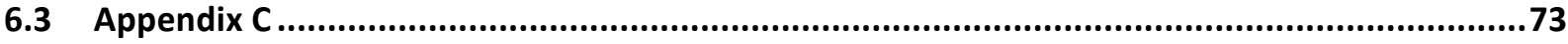

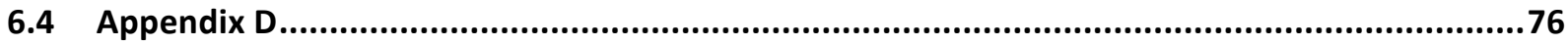

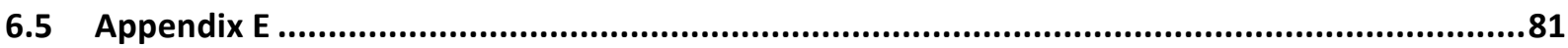

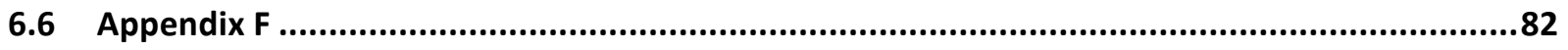

References.................................................................................................... 83 


\section{List of Tables}

Table 1: Literature Examining PA in Youth with SB................................... 11

Table 2: Summary of the Theoretical Domains Framework............................20

Table 3: Youth Demographic Information......................................... 33

Table 4: Perceived Influence of TDF domains on PA behaviour.........................63 


\section{List of Figures}

FIgURE 1-1: SPINA BIFIDA IN COMPARISON TO NORMAL SPINE. 1) SPINA BIFIDA OCCULTA (CLOSED SPINA BIFIDA) 2) MENINGOCELE (OPEN SPINA BIFIDA) 3) MYELOMENINGOCELE (OPEN SPINA BIFIDA)..............2 


\section{List of Appendices}

Appendix A: Cover Letter ....................................................68

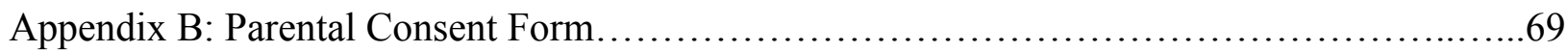

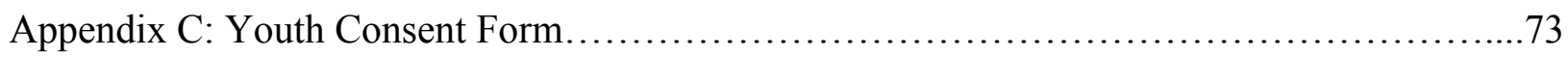

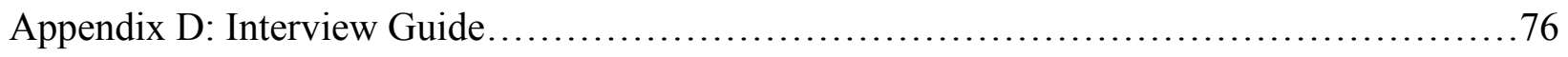

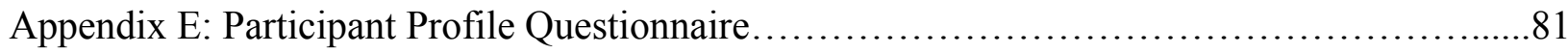

Appendix F: Example of Mapping Behaviour Change Techniques.......................82 


\section{List of Abbreviations}

NTD

PA

SB

TDF

TD

LMMC

MMC

SCI

CVD

HRQoL
Neural Tube Defects

Physical Activity

Spina Bifida

Theoretical Domains Framework

Typically Developing

Lipomyelomeningocele

Myelomeningocele

Spinal Cord Injury

Cardiovascular Disease

Health Related Quality of Life 


\section{Chapter 1}

\section{Introduction}

\subsection{Background on Spina Bifida}

Neural tube defects (NTD) are a group of conditions that occur in utero, which involve malformations of the spinal cord or the brain. The two most common types of NTD are anencephaly (the incomplete development of the brain) and spina bifida (SB; the incomplete development of the spinal cord or its coverings). SB is the result of the improper caudal development of the vertebral bodies and spinal cord during the first 28 days of pregnancy. This may result in varying degrees of permanent damage to the spinal cord and nervous system, with problems arising in the central nervous system, the urogenital system, the musculoskeletal system, and/or the skin (Botto, Moore, Khoury \& Erickson, 1999). The prevalence and incidence rate of SB, as well as other types of NTD have declined since the late $20^{\text {th }}$ century, due to the widespread availability of prenatal diagnostic services, improved nutrition among pregnant women, and foods fortified with folic acid. Research indicates that folate can reduce the incidence of NTD by $46 \%$, and decrease the severity of defects when they do occur (De Wals et al., 2007). However, the average worldwide incidence of SB is still 4.7 per 10,000 births (Botto et al., 1999), while in Canada, NTD [including SB] occur at a frequency of 4.0 per 10,000 births (Public Health Agency of Canada, 2013). In the United States, the incidence of SB is higher among White and Hispanic populations (3.4 and 4.2, respectively, per 10,000 live births) than among the Black population (2.9 per 10,000 live births; Boulet, Gambrell, Shin, Honein \& Mathews, 2009). SB remains a common birth defect, leading to childhood-onset physical disability (defined as a limitation to musculoskeletal and/or neurological body systems influencing functional abilities; ICF, 2001), and affecting the individual over the course of his or her lifetime.

\subsubsection{Types of Spina Bifida}

Spina bifida can be categorized as either open SB or closed SB. Infants born with closed SB will have one or more vertebrae in the spine that is not properly formed, the split in the vertebrae is so small that the spinal cord does not protrude and a layer of skin covers the malformation. 
Closed SB is less severe than open SB and is often present without neurological symptoms but the skin overlying the defect may be dimpled, thickened, or pigmented along the midline of the back (See Figure 1-1). The most common type of closed SB is lipomyelomeningocele, where a collection of fatty tissue is attached to the end of the spinal cord, presenting often as a bulge or dimple on the back of a child (Lutkenhoff, 2008). The incidence rate of lipomyelomeningocele is 0.5 per 10,000 births (De Wals et al., 2008).
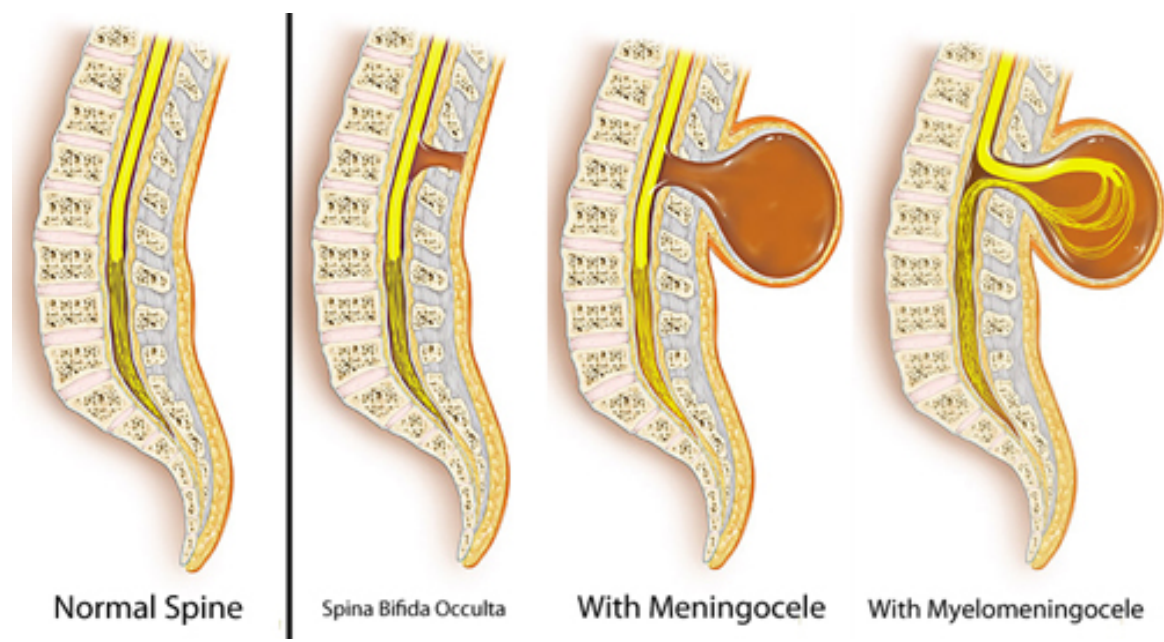

Figure 1-1: Spina bifida in comparison to normal spine. 1) Spina bifida Occulta (closed spina bifida) 2) Meningocele (open spina bifida) 3) Myelomeningocele (open spina bifida).

Meanwhile, open SB is considered more severe than closed SB as a layer of skin does not cover the malformation. Myelomeningocele $(\mathrm{MMC})$ is the most severe and most common $(\sim 1.8$ per 10,000 live births; Rothenberg et al., 2008) form of open SB, resulting in an open lesion that contains portions of the spinal cord, nerve roots, meninges, and vertebral bodies (see Figure 1-1). Most infants born with MMC have significant spinal cord dysfunction, with impaired neurological function below the anatomical level of the lesion (Oakeshott \& Hunt, 2003). The second type of open SB, meningocele, is less severe than MMC, because the spinal cord develops normally. In this case, only the meninges (i.e. the protective covering of the spinal cord) protrude from the opening created by a damaged or missing vertebrae, often resulting in a bulge or lump in the midline of the back. The prevalence of meningocele is approximately 5\% of all cases; (Rothenberg et al., 2004). Meningocele is often associated with less nerve damage than $\mathrm{MMC}$, although problems may develop later in life due to tethering of 
the spinal cord. Tethering of the spinal cord occurs when scar tissue attaches itself to the spinal cord and causes pulling on the spinal cord, resulting in secondary health complications including back pain, difficulty walking, scoliosis, and changes in bladder or bowel function (Lutkenhoff, 2008).

\subsubsection{Level of Spina Bifida}

An infant born with open SB requires surgery within the first 24 to 72 hours following their birth. The surgery required covers the lesion including the spinal cord and its nerve roots with lateral muscles and skin. The location of the lesion along the spinal cord, often acts as a predictor of the degree of impairment a child will experience. Generally, the lower the defect is on the spinal cord, the less loss of function there will be. The point at which function is affected is referred to as the level of $\mathbf{S B}$, and is subdivided into four categories: 1) cervical: the nerves from the neck region are affected; 2) thoracic: the nerves from the upper part of the body are affected; 3) lumbar: the nerves from the lower part of the body, which control the feet, ankles, knees, thighs and hips, are affected; and 4) sacral: only the nerves at the very end of the spinal cord which control the bladder and bowel are affected (Lutkenhoff, 2008).

\subsubsection{Spina Bifida and Associated Neurological Conditions}

Infants born with SB may be at risk of experiencing two types of neurological conditions hydrocephalus and Chaiari II malformation. These conditions are discussed below.

\subsubsection{Chaiari II Malformation}

Chaiari II malformation affects approximately $80 \%$ of children born with SB (Hunt \& Poulton, 1995). Furthermore, a Chaiari II malformation is observed in almost all ( $\sim 98 \%)$ infants born with MMC (Zimmerman et al., 1979). This malformation results in a structural difference of the lower brainstem, upper spinal cord, and the lowermost part of the cerebellum. Normally, the cerebellum and part of the brainstem sit in a space at the lower rear end of the skull above the opening to the spinal canal. When the lowermost part of the cerebellum is located below the opening to the spinal canal this results in a Chaiari II malformation. The brainstem and cerebellum are often pushed down and compression may occur due to the lack of space. Health complications that can arise from this type of malformation include: respiratory distress, apnea, high pitch noisy breathing, an inability to swallow resulting in difficulty feeding and handling of 
fluids, and upper extremity weakness and numbing (Lutkenhoff, 2008). The high prevalence of a Chaiari II malformation among youth with SB makes this a neurological condition that must be considered when working with individuals with MMC

\subsubsection{Hydrocephalus}

Hydrocephalus is a neurological concern that is almost exclusively related to the existence of a Chaiari II malformation. Hydrocephalus may arise in as many as $85 \%$ to $90 \%$ of babies born with open SB but more commonly occurs in those children born with MMC. Hydrocephalus may occur if, a) there is an excessive amount of cerebrospinal fluid (CSF) stored in the brain or, b) there is deficient absorption of the CSF due to abnormal circulation (Botto et al., 1999). The higher the level of lesion within the spinal cord, the greater the incidence of hydrocephalus: $97 \%$ of patients with a lesion at the thoracic level are shown to have hydrocephalus versus $87 \%$ and $37 \%$, respectively, of patients with either a lumbar or sacral level lesion (Ritouel et al., 2002). The most common symptoms of hydrocephalus during infancy are vomiting, fatigue, seizures and a rapid increase in head circumference. Hydrocephalus symptoms can vary with age because the skull of an infant may expand to accommodate the build-up of CSF, since the fibrous joints that connect the bones of the skull have not yet closed. As a child ages, the brain cannot expand to accommodate the build-up of CSF, and therefore hydrocephalus can also develop later in life. Symptoms among older children and adults include headaches, vomiting, nausea, blurred vision, gait disturbance, incontinence, and lethargy.

Hydrocephalus is often treated by inserting a shunt into the fluid cavities of the brain and connecting it to a catheter that runs under the skin all the way into either the, abdominal cavity, or the atrium of the heart. This allows excess CSF to drain from the brain, reducing pressure and the risk of possible brain damage. Individuals with SB require lifelong monitoring of this shunt. Some complications that may occur as a result of this shunt include: mechanical failure of the device, infections, and the need to replace or lengthen the catheter into the abdominal cavity or heart. If left untreated, progressive hydrocephalus may be fatal (Lutkenhoff, 2008).

\subsubsection{Secondary Conditions in Persons with Spina Bifida}

Surgical treatment of SB has become more sophisticated over time, resulting in increased survival rates. Current estimates indicate that approximately $90 \%$ of infants born with SB will 
live well into their adult years (Bowman et al., 2001; Oakeshott \& Hunt, 2003; Spina Bifida Association, 2011). However, most children and youth with SB will face a variety of secondary health complications across their lifespan. A more detailed overview of the most prevalent secondary health complications is discussed in the sections below.

\subsubsection{Spinal Curvatures}

Almost $90 \%$ of children with SB have some form of abnormal spinal curvatures (Simeonsson et al., 2002). Scoliosis (i.e., abnormal lateral curvature of the spine) is a frequent complication and significant concern for individuals living with SB - its prevalence is estimated at approximately $50 \%$ among this population (Wai et al., 2000). Scoliosis may result in back pain and/or difficulty with performing physical activities, thus increasing the risk of a sedentary lifestyle.

\subsubsection{Bladder and Bowl Incontinence}

Bladder and bowel incontinence affects almost all individuals with SB (Lutkenhoff, 2008). Abnormal development of the spinal cord may lead to the neurologic denervation of the smooth muscle and urethral sphincter. Debilitating issues such as urinary incontinence, urinary tract infections, vesicoureteral reflux (i.e., the abnormal backward movement of urine from the bladder into the ureters or the kidneys), as well as chronic renal failure, can be complications of neurogenic bladder dysfunction for persons with SB. Most infants ( 80\%) with MMC will have a neurogenic bladder and often experience a lack of sphincter control (Simeonsson et al., 2002). As well, many patients with SB require catheterization at frequent intervals to avoid bladder desensitization, and to ensure infections do not occur (Phillips et al., 1990). Several studies have shown impaired self-esteem and a decrease in health-related quality of life (HRQoL) among TD youth with different types of incontinence (Equitt, Hübner \& von Gontard, 2014).

\subsubsection{Obesity}

Obesity rates within the SB population range from $28 \%$ to $50 \%$ among children and $34 \%$ to 64\% in youth and adults (Spina Bifida Association, 2011). Non-ambulatory status combined with a sedentary lifestyle may be a contributor to higher levels of obesity in youth with SB. In a recent Canadian study, estimates of obesity were as high as $41 \%$ among a sample of children and youth (ages 2 to 18 years) with SB (McPherson et al., 2013). Additionally, metabolic studies using peak aerobic capacity tests have documented that youth (ages 14 to 26 years) with 
SB have a higher percentage of body fat and lower basal metabolic rate than their peers (Van den Berg-Emmons et al., 2003). The level of SB may affect a youth's risk of obesity whereby; youth who have lower lesions (i.e., at the sacral segments of the spinal cord) are estimated to have double the risk of obesity compared to those youth with higher-level lesions (Dosa et al., 2009). Given the increased risk of childhood obesity within this population, early dietary intervention and regular physical activity are recommended for prevention of obesity in children and youth with SB. Adverse health consequences of obesity for those with SB include diabetes, pressure ulcers, gastro-esophageal reflux disease, metabolic syndrome, along with social isolation and depression (Dosa et al., 2009). Furthermore, excess weight can cause difficulties with manual wheelchair propulsion or it can place pressure on one's knees and hips and can cause pain when walking (Crytzer, Dicianno, \& Kapoor, 2013). Often, leading to a further deterioration in function and ambulatory status within the SB population.

\subsubsection{Metabolic Syndrome}

In addition to a higher prevalence of obesity, individuals with SB are at a greater risk of developing type II diabetes and metabolic syndrome. Metabolic syndrome is a clustering of conditions (i.e., increased blood pressure, high blood sugar levels, excess body fat around the waist, and abnormal cholesterol levels), which occur together and can increase the risk of heart disease, stroke, and diabetes (Isomma et al., 2001). Prevalence of metabolic syndrome is high among youth with SB. For example, Nelson et al. (2007) examined 11 to 20 year olds with SB and found that $32 \%$ of youth had metabolic syndrome and of those, $46 \%$ were obese. How these rates project into adulthood for youth with SB, is yet to be determined. However, within the general population, it is known that childhood obesity increases the risk of developing metabolic syndrome in adulthood (Vanhala, Vanhala, Kumpusalo, Halonen, \& Takala, 1998).

\subsubsection{Cardiovascular Disease}

A hypoactive lifestyle coupled with high obesity rates among youth may be linked to an increased chance of developing cardiovascular disease (CVD) later in life. Currently, there is no specific data examining the CVD profile of individuals with SB. However, there is data examining CVD profiles among individuals living with a spinal cord injury (SCI), and although the aetiology of a SCI is different from SB (congenital vs. acquired), individuals with SB may face many of the same health concerns as individuals with limited functional mobility due to a 
SCI. These health concerns can include obesity, diabetes and metabolic syndrome (Janssen et al., 1997). Even further, SCI is associated with significantly increased odds of heart disease (adjusted odds ratio $[\mathrm{OR}]=2.72$ ) and stroke (adjusted $\mathrm{OR}=3.72$; Cragg, Noonan, Krassioukov, \& Borisoff, 2013). CVD profiles in individuals with a SCI have been associated with an inactive lifestyle and lower aerobic fitness (Janssen et al., 1997). Studies have shown that CVD is one of the leading causes of death in individuals with a SCI (Lidal et al., 2007; DeVivo et al., 1999), with annual mortality rates for the SCI population being approximately 1.6 times higher than the general population (Whiteneck et al., 1992). Since individuals with a SCI typically experience their injuries during late adolescence or early adulthood (Farry \& Baxter, 2010), CVD may be of greater concern for individuals with SB compared to those with SCI, due to the earlier exposure of an inactive lifestyle because of limited functional mobility, low aerobic fitness levels, (Van den Berg-Emons et al., 2001; Short and Frimberger, 2012), increased prevalence of secondary health complications such as scoliosis (Simeonsson et al., 2002), and obesity (McPherson et al., 2013).

\subsubsection{Other Complications}

SB can be associated with a variety of other complications including foot deformities, fractures, contractures, degenerative joint disease, as well as complications that often involve difficulties with mobility, self-care skills, dressing, bathing, communication and learning (Verhoef et al., 2004).

\subsubsection{Summary}

As a result of these aforementioned associated secondary health complications, individuals with SB are often at an increased risk of developing an inactive lifestyle. Given the detrimental health effects related to decreased physical activity and increased sedentary activities, it is of great importance to target health promotion efforts towards the SB population as early as possible.

\subsubsection{Youth with Spina Bifida - A Priority Group}

Not only are youth with SB at an increased risk of developing chronic health conditions, they also face a number of challenges which can impair their quality of life, during both adolescence and adulthood. Health-related quality of life (HRQoL) refers to an individual's perception of various aspects of his/her life, related to physical, mental, emotional, and social functioning 
(Buffart et al., 2008). Some studies have shown that youth with SB perceive lower levels of HRQoL compared to their TD peers, particularly related to aspects of physical functioning (i.e., self-care, continence, mobility), emotional, and social/school domains (Abresch et el., 2007; Buffart et al., 2009; Verhoef et al., 2007). Notably, active adults with SB report more functional independence and higher quality of life compared to those with SB who are inactive (Buffart et al., 2009). This suggests that adolescence is a critical period for building PA into the daily routines of individuals with SB in an effort to preserve overall life satisfaction (Rimmer \& Rowland, 2008). Parents have reported concerns with decreases in PA participation, particularly as their children enter adolescence when they develop a fear towards PA and reject involvement in adapted PA programs (Luther et al., 2010). Given the early onset of physical inactivity noted among youth with SB and other physical disabilities (Brunton \& Barlett, 2010; Law et al., 2004; Maher et al., 2007; Telama et al., 2005), there is a need for specific PA promotion efforts to target youth living with SB. These efforts would help prevent secondary complications associated with inactivity (i.e., obesity, metabolic syndrome, cardiovascular disease; Buffart et al., 2009; Rimmer et al., 2010; Simeonsson et al., 2002) as individuals with SB enter adulthood.

\subsubsection{Overall Summary on Secondary Health Complications}

This section outlines why increased PA participation may be even more important for youth with SB than their TD peers. Youth with SB are at an increased risk of developing an inactive lifestyle leading to obesity, metabolic syndrome, CVD, functional impairments, and reduced quality of life (Buffart, Van den Berg-Emons, Meeteren, Stam \& Roebroeck, 2009). PA may be one of the key components to enable youth with SB to self-manage such secondary health conditions. Prior to employing health promotion efforts to increase PA participation for youth with SB, it is important to examine PA experiences of these youth. The following section will explore current levels of PA among youth with SB, as well as the factors that affect their participation. SB is considered to be a physical disability and since there is such a sparse body of literature available for youth with SB, there is benefit to exploring these topics for youth with physical disabilities as well. 


\subsection{Physical Activity Research in Youth with Spina Bifida}

\subsubsection{Benefits of Physical Activity for Youth with Physical Disabilities}

The health benefits of PA are universal for both TD youth and those with physical disabilities (Janssen \& LeBlanc, 2010; Paffenbarger, Hyde, Wing \&, Hsieh, 1986). Murphy and Carbone (2008) report that participation in PA and sport for youth with physical disabilities can have multiple positive effects, including improving overall health, slowing the progression of secondary health conditions such as diabetes, decreasing complications of immobility, and improving physical and social functioning. A recent systematic review of 20 cross-sectional studies on the topic of physical fitness and exercise training in individuals with SB (ages 1 to 30 years) showed that: a strength and aerobic training program is a safe and effective way of improving cardiorespiratory endurance (effect sizes ranged from 0.78 to 1.40 , all considered to be large effects; Cohen et al., 1992) and muscular strength (effect sizes ranged from 0 to 0.59 , indicating small to moderate effects; Cohen et al., 1992) in individuals with SB (Oliveira, Jácome \& Marques, 2014). This increased physical fitness may play an important protective role in preventing secondary health conditions associated with SB (see section 1.1.4).

In addition to the associated fitness benefits, PA also enhances the psychological well-being of youth with physical disabilities [including SB], such as providing opportunities to form friendships, express creativity, develop self-identity and foster meaning in life (Dykens, Rosner, \& Butterbaugh,1998). Additionally, regular PA participation can foster independence, coping abilities, competitiveness and teamwork (Patel \& Greydanus, 2002). Overall, PA provides many physical, psychological and social benefits to youth with physical disabilities like SB.

Despite the benefits PA offers youth with SB, inactivity levels remain a concern. Currently, there is no national data published on the PA levels of youth with physical disabilities in general, and SB more specifically. This scarcity of literature may be attributed to the challenges for quantifying PA behaviour among youth with physical disabilities due to the lack of valid and reliable PA instruments available for use within this population (White, Volfson, Faulkner, \& Arbour-Nicitopoulos, 2015). There is a limited body of research $(n=4)$ that has focused on quantifying PA levels in youth with SB (Buffart et al., 2008; Pan et al., 2006; Schoenmakers et al., 2009; Van den Berg-Emons et al., 2001; see table 1 for an overview of each of the studies). This limited body of literature suggests that youth with SB are even more inactive than their TD 
peers (where national data indicates only $5 \%$ of Canadian youth accumulate the recommended 60 minutes of daily moderate-to-vigorous PA; Tremblay et al., 2012). For example, youth with MMC report spending an average of 91 minutes/24 hour monitoring period engaged in dynamic activities (i.e. movement) compared to 178 minutes/24 hour monitoring period in the healthy control group (Van den Berg-Emons et al., 2001).

In summary, the PA research that has been conducted for youth with SB suggests that inactivity within this population is of great concern, despite the many physical, psychological and social benefits that PA has to offer. The reported low PA levels among youth with SB shows that greater attention must be focused on ways to facilitate PA participation within this population. 
Table 1: Literature Examining PA in Youth with SB

\begin{tabular}{|c|c|c|}
\hline $\begin{array}{l}\text { Author; Year; Country; } \\
\text { Study Design }\end{array}$ & $\begin{array}{l}\text { Sample } \\
(N \text {; age; gender; functioning) }\end{array}$ & \\
\hline $\begin{array}{l}\text { Buffart et al. (2008) } \\
\text { Netherlands } \\
\text { Cross-sectional }\end{array}$ & $\begin{array}{l}N=51 \\
\text { Age: } 16 \text { to } 30 \text { years } \\
\text { Mean: } 21.1 \pm 4.5 \text { years } \\
\text { Gender: } \\
\text { Female: } n=25 \\
\text { Male: } n=26 \\
\text { Functioning: } \mathrm{N} / \mathrm{A}^{1}\end{array}$ & $\begin{array}{l}\text { Instrument: Activity Monitor (Accelerometer) } \\
\text { Results: Youth with } \mathrm{MMC}^{2} \text { spent } 81 \pm 62 \text { minutes per a } 48 \text {-hour period } \\
\text { on physical activities compared to } 63 \pm 62 \text { minutes per a } 48 \text {-hour period } \\
\text { in } \mathrm{TD}^{3} \text { peers } \\
\text { - } \quad 39 \% \text { of participants were classified as inactive } \\
\text { - } \quad 37 \% \text { of participants were classified as extremely inactive } \\
\text { - } \quad \text { Aerobic fitness of youth with MMC was } 42 \% \text { lower than TD peers. }\end{array}$ \\
\hline $\begin{array}{l}\text { Pan et al. (2005) } \\
\text { Canada } \\
\text { Cross-sectional }\end{array}$ & $\begin{array}{l}N=256 \\
\text { Age: } 6 \text { to } 18 \text { years } \\
\text { Mean: } 11.8 \pm 3.22 \text { years } \\
\text { Gender: } \\
\text { Female: } n=120 \\
\text { Male: } n=136 \\
\text { Functioning: } \\
\text { cerebral palsy } n=151 \\
\text { head injury: } n=31 \\
\text { spina bifida: } n=49 \\
\text { muscular dystrophy: } n=17\end{array}$ & $\begin{array}{l}\text { Instrument: Modified version of the Canadian Fitness Survey } \\
\text { Results: } \\
\text { - Youth with disabilities reported to be sedentary for } 37 \% \text { to } 40 \% \text { of } \\
\text { the day compared to } 18 \% \text { of TD youth }\end{array}$ \\
\hline $\begin{array}{l}\text { Schoenmakers et al. }(2009)^{4} \\
\text { Netherlands } \\
\text { Cross-sectional }\end{array}$ & $\begin{array}{l}N=23 \\
\text { Age: } 6 \text { to } 18 \text { years } \\
\text { Mean Age: } 10.4 \pm 3.1 \text { years } \\
\text { Gender: } \\
\text { Female: } n=10 \\
\text { Male: } n=13 \\
\text { Functioning: } \\
\text { MMC: } n=16 \\
\text { LMMC }:=7^{5}:=1\end{array}$ & $\begin{array}{l}\text { Instrument: Physical Activity Diary } \\
\text { Results: } \\
\text { - } \quad \text { No significant differences between LMMC and MMC group for } \\
\text { PA } \\
\text { - } \quad \text { engaged in dynamic activities on average of } 2.8 \text { hours/day } \\
\text { - } \quad 57 \% \text { used active transportation to school }(33 \% \text { biked; } 22 \% \text { walked) } \\
\text { - } \quad E^{6} \text { significantly lower for both groups compared to healthy peers }\end{array}$ \\
\hline $\begin{array}{l}\text { Van den Berg-Emons et al. } \\
(2001) \\
\text { Netherlands } \\
\text { Cross Sectional }\end{array}$ & $\begin{array}{l}N=14 \\
\text { Age: } 14 \text { to } 26 \text { years } \\
\text { Mean Age: } \mathrm{DNR}^{7} \\
\text { Gender: } \\
\text { Female: } n=6 \\
\text { Male: } n=8 \\
\text { Functioning: } \\
\text { Non-ambulatory: } n=5 \\
\text { Household ambulators: } n=6 \\
\text { Community ambulators: } n=3\end{array}$ & $\begin{array}{l}\text { Instrument: Activity monitor (accelerometer) } \\
\text { Results: } \\
\text { - } \quad \text { Mean duration of dynamic activities was less in youth with SB }(6.5 \\
\pm 2.3 \% \text { / day) than in healthy age matched controls }(12.7 \pm \\
4.3 \% / \text { day) } \\
\text { Average duration of dynamic activities was } 91 \text { minutes } / 23.4 \text { hour } \\
\text { monitoring period in youth with SB compared to } 178 \text { minutes/23.4 } \\
\text { hour monitoring period in healthy control } \\
\text { Time spent in dynamic activities was correlated with ambulatory } \\
\text { status }(r \mathrm{~s}=0.55, p<0.05)\end{array}$ \\
\hline
\end{tabular}

Notes: ${ }^{1}$ Not Available; ${ }^{2}$ Myelomeningocele; ${ }^{3}$ Typically Developing; ${ }^{4}$ Total EE was compared to healthy peers' predicted values of EE matched for height, sex, age; ${ }^{5}$ Lipomyelomeningocele; ${ }^{6}$ Energy Expenditure; ${ }^{7}$ Did not report 


\subsubsection{Barriers and Facilitators to PA participation in Youth with Physical Disabilities}

As discussed in section 1.2.1, youth with physical disabilities (including those with SB) have been shown to engage in low levels of PA. One potential reason for these lower participation levels may be due to the numerous barriers to PA that youth with SB encounter. The following section will outline the various barriers to PA that have been examined for youth with physical disabilities. These barriers and facilitators have been divided within the literature into four categories: personal, social, environmental, and policy/program. As such, this section will provide a discussion on the PA barriers and facilitators specific to youth with physical disabilities based on these four categories.

\subsubsection{Personal}

Within the literature, four types of personal barriers have been identified for youth with physical disabilities: (a) lack of skills (physical and social) including: feelings of embarrassment, lack of confidence, inability to navigate unfamiliar areas, lack of athletic ability and coordination; (b) preference for sedentary activities; (c) fear of being stigmatized or teased (d) fear of injury or incontinence; and (e) lack of knowledge including not knowing what to do, and not knowing how to use the equipment (Shields, Synnot \& Barr, 2012). Children with a physical disability dislike having to deal with the negative stigma of disability, even reporting that having to use assistive devices in a PA context is associated with feelings of distress (Hutzler et al., 2002).

Within the literature three personal facilitators have been identified for youth with physical disabilities: (a) a desire to be fit and healthy (b) practice to gain sports skills and competence, and (c) perceptions of PA as being fun, and gaining confidence (Shields et al., 2012). Children and youth with disabilities (i.e., physical disabilities, visual impairments, cognitive disabilities) report that having fun, increasing fitness and achievement were the main reasons for their engagement in PA (Sit et al., 2002).

\subsubsection{Social}

In addition to personal barriers, a lack of social support is a frequently reported barrier to PA for youth with disabilities. Such limitations in social support include (a) parental actions such as: 
(i) refusing to register a child for a program, (ii) being overprotective (i.e., fear that their child will be isolated) and (iii) time or financial constraints. Parents of youth with a physical disability often display a lack of knowledge regarding the benefits of PA for their child. For example, over one-fifth $(21 \%)$ of parents thought PA was more important for those without a disability than for their child with SB (Field and Oates, 2001). Those same parents reported the lack of knowledge about PA opportunities available for their child with SB as a barrier to registering their child for organized sports programs (Field and Oates, 2001).

Other social support barriers include (b) lack of friends to participate in PA with, (c) unsupportive peers, and (d) negative societal attitudes (Shields et al., 2011). Parents of children with physical disabilities have often reported the general public's attitude is a significant factor influencing their child's participation in recreational and leisure activities (Law et al., 1999; Law et al., 2007). For example, Kirchner et al. (2008) reported that about 50\% of their participants with disabilities cited public attitude as a factor affecting their PA participation within their neighbourhoods. A parent of a child with cerebral palsy may prefer that their child stay at home to avoid dealing with people commenting on or staring at their child because of his or her behaviours or physical appearance (Bauman, 2005).

Finally, (e) a lack of program staff support and attitudinal barriers from coaching staff may limit sport and recreation opportunities for this population (Rimmer \& Rowland, 2008). There is often an absence of information and training provided to support staff on specific considerations for individuals with physical disabilities, including how to adapt PA programs. Furthermore, many staff at recreational facilities report that they feel overwhelmed when working with youth who have a disability, and some fear legal implications of an accident when delivering integrated PA programs (Rimmer, 2005; Rimmer, Riley, Wang, \& Rauworth, 2005).

A lack of social support from peers, parents or support staff/coaches have been reported as a barrier to PA for youth with physical disabilities. However, receiving support (physical or social), being provided with the opportunity to make friends, along with the positive attitudes of schoolmates, teachers and other people (i.e., coaches) have all been seen to positively influence PA participation within this target population (Shields et al., 2011). For example, youth with a physical disability were more likely to participate in physical activities that included interaction, encouragement, and assistance from their peers, friends and/or siblings. Parents and siblings 
have also been seen to facilitate involvement in PA by modeling and participating in PA themselves. (Shields et al., 2012).

\subsubsection{Environmental}

Along with personal and social barriers, the lack of accessibility has been shown to be a major environmental barrier to PA for youth with physical disabilities (Petersen \& Piletic, 2006; Rimmer et al., 2005). The presence of environmental barriers (i.e., broken sidewalks, narrow hallways, inaccessible equipment, small bathrooms, and the presence of stairs) may be a primary reason for the lack of PA participation among youth with physical disabilities (French \& Hainsworth, 2001; Law et al., 1999; Murphy et al., 2008; Rimmer, 2005; Rimmer \& Rowland, 2008). The presence of structural barriers in local fitness facilities may limit access to; entryways to and from the facility (e.g., parking lots), activity spaces within the facility (e.g., swimming pools or weight rooms), and locker rooms or bathrooms within the facility; Petersen $\&$ Piletic, 2006). These structural barriers serve to discourage youth from participating in PA. Individuals with disabilities consider most local pools, fitness centres, and other recreation facilities as "unfriendly" due to accessibility-related barriers (Rimmer, 2005). Parents of youth with a physical disability have often reported facilities as inaccessible for their child, due to: lack of adaptive equipment, locations that are inconvenient or too far away, or physical obstacles at the facility that make it a challenge for their child to use the space (Shields et al., 2012; Buffart et al., 2008). For example, the lack of accessible facilities and/or programs has been reported as a major barrier for PA participation among youth with cerebral palsy (Fowler et al., 2007).

Having access to facilities (both indoor and outdoor) that provide adapted programs, have adapted equipment, and are within one's neighbourhood are all reported as important factors for facilitating PA engagement among youth with a physical disability (Shields et al., 2011). Additionally, the most prominent accessibility features of fitness and recreation facilities proven to facilitate PA include: (a) nonslip floors, (b) ample accessible parking space, (c) the availability of automatic doors, and (d) the availability of family change rooms (Rimmer et al., 2005). Youth with SB who are able to independently overcome barriers in their communities and receive help to negotiate their physical environment are shown to be able to participate in any PA they desire (Luther et al., 2010). 


\subsubsection{Programs and Policies}

Finally, the literature shows that the absence of appropriate PA programs with respect to: (a) variety, (b) involvement with the whole family, (c) opportunities for facilitating social relations with peers, and (d) easing the transition from a rehabilitation to a community setting, are all common program-related PA barriers for youth with physical disabilities (Shields et al., 2012). After examining 33 ambulatory youth with cerebral palsy and their parents, Verschuren et al. (2012) noted a number of concerns with PA programs. For example, parents stated that the sports teams were too big, there were long wait-lists, the child's abilities were being underestimated or the child was not allowed to play in matches. These program and policyrelated barriers have placed youth with physical disabilities at a disadvantage in their ability to participate in PA, and therefore youth with physical disabilities such as SB, are less likely to accrue the health benefits most commonly associated with PA.

The most prominent policy or program-related PA facilitators that have been identified among youth with physical disabilities include: (a) having a variety of non-competitive, small-sized, age-appropriate, community-based PA programs for youth of all abilities; and (b) having knowledgeable staff delivering these programs who know how to modify activities so that children and youth with physical disabilities can be fully included (Shields et al., 2012; Rimmer et al., 2005).

\subsubsection{Barriers and Facilitators to Physical Activity Participation in Youth with Spina Bifida}

Much of the available literature on barriers and facilitators to PA for youth with physical disabilities includes samples of both children and youth who have a variety of disabilities. For example, Shields and colleagues (2012) examined barriers and facilitators to PA in children and youth (aged 0 to 18 years) with any type of disability (physical, intellectual, or sensory), which makes it difficult to understand whether the factors affecting PA participation would differ between specific diagnoses or across age groups (Buffart et al., 2008; Shields et al., 2012). To date, there has been only one study, using qualitative methodology, that specifically examined personal and environmental factors that influence PA participation in youth with SB (Bloeman et al., 2015). In total, eleven semi-structured interviews were conducted with parents of children with SB (ages 4 to 7 years) and nine focus groups with youth (ages 8 to 18 years) with SB ( $n=$ 
31). Data showed that youth with SB encountered both personal and environmental factors that were associated with participation (or lack there of) in PA. Some of the major personal barriers and facilitators that emerged included: bowel and bladder care, skill competency, sufficient fitness, medical events, and self-efficacy for engaging in PA. Major environmental barriers and facilitators that emerged included: contact with and support from other people, the use of assistive devices for mobility and care, adequate information regarding opportunities for adapted sport participation, and accessibility to playgrounds and sports facilities.

Looking beyond barriers and facilitators, it is important to understand the relationship and association between (a) these personal, social and environmental variables that are said to affect PA participation, and (b) actual PA levels in this group. Establishing this relationship will allow future research to closely examine those behaviours that have the most influence on PA, and thereby, help increase PA levels in this population.

\subsubsection{Correlates of PA Participation for Youth with Spina Bifida}

Research examining the correlates of PA for TD youth has increased over the past two decades (e.g., Bauman et al., 2012; Kirchner et al., 2008; Washburn et al., 2002). Researchers have identified several personal (i.e., intention), social (i.e., peer support), and environmental (i.e., availability of programs, area of residence) factors that are known to influence PA participation among TD youth (Gordon-Lasen, McMurray, \& Popkin, 2000; Lindquist et al., 1999; Sallis \& Saelens, 2000; Trost et al., 2002). Within Sallis et al.'s (2000) review of PA correlates for TD children and youth (ages 3 to 18 years), the most consistent factors related to PA participation were gender, intentions, and previous experience with PA. Other factors that were identified as important, yet exhibited fewer consistent relationships with PA behaviour included: age, perceived competence, opportunities to participate in PA, level of sedentary behaviour, parental support, PA levels of siblings and socioeconomic status.

In contrast to the large body of PA correlate literature available for TD youth, little is known about PA correlates for youth with physical disabilities (King et al., 2003; Kirchner et al., 2008). However, it cannot be assumed that the PA correlates identified as important for TD youth will play a similar influence on the PA participation of youth with physical disabilities (Van der Ploeg et al., 2004). In order to enhance PA participation among youth who have a physical 
disability such as SB, researchers need to target their efforts to identify and understand the specific factors that influence PA participation for youth with SB (Law et al., 2007).

To date, there have been two studies examining correlates of PA in youth with SB. The first of these studies (Buffart et al., 2008) examined the correlates of sport participation among a sample of 51 youth (ages 16 to 30 years) with MMC. Within this study, sport participants reported more positive perceptions of self-efficacy, exercise enjoyment, and physical appearance, as well as greater social support from family than non-sport participants. However, sport participation is a planned and structured sub-category of PA, and therefore, conclusions cannot be generalized to daily PA for youth with SB.

Exploring beyond sport participation, Marques et al. (2014) expanded on Buffart et al.'s (2008) earlier findings, using a self-report questionnaire to collect data on PA behaviour, demographics and psychosocial variables (i.e., attitudes, sport goal-orientation and perceptions) among a sample of 31 youth aged 10 to 17 years. Researchers found that approximately $38.7 \%$ of the sample reported participating in organized and non-organized PA. Using a regression analysis, the authors found only one of the nine psychosocial variables examined (i.e., perceived competence; $\mathrm{OR}=9.55,1.06-85.99, p<0.05$ ) was positively associated with participation in non-organized PA. Therefore, more studies are needed to identify the factors that predict physical activity participation among youth with SB.

\subsubsection{Summary}

As outlined in this chapter, there are few studies available on the barriers and facilitators, as well as correlates of PA that are specific to youth with SB. (e.g., Bloeman et al., 2015; Buffart et al., 2008; Marques et al., 2014). All of the literature that has explored the PA behaviour for youth with SB has been atheoretical in nature. Using a theoretical approach to explore the underlying factors of PA participation has numerous benefits given theories are formulated to explain, predict, and understand behaviour on the basis of previous scientific inquiry. One particular theoretical framework to consider is the Theoretical Domains Framework (TDF; Michie et al., 2005). The following section will explore the TDF to demonstrate its utility for this study. 


\subsection{The Theoretical Domains Framework (TDF)}

\subsubsection{TDF - A Useful Framework for Exploring Factors that Influence PA Behaviour in Youth with Spina Bifida}

Theoretical frameworks provide a validated blueprint for researchers to better understand the factors that are most strongly associated with health behaviours, such as PA, for a particular population. This information can then be used to identify areas to target in future behaviour change interventions within a specific population. In the general population, theory-based PA interventions have been shown to be more effective at increasing PA behaviour than those that are atheoretical (Noar, Benac, \& Harris, 2007). There have been an abundance of behaviour change theories developed; many of which include overlapping constructs and each with its own strengths and limitations. The most common social cognitive theories and models used to provide researchers with a structured approach to understand and predict PA behaviour have been the Theory of Planned Behaviour (TPB; Ajzen, 1991), Health Belief Model (HBM; Becker et al., 1974), Transtheoretical Model (TTM; DiClemente \& Prochaska, 1998), SelfDetermination Theory (SDT; Deci \& Ryan, 2000), Social Cognitive Theory (SCT; Bandura, 1989), and Theory of Reasoned Action (Ajzen and Fishbein, 1979). Choosing one theory from the vast array of theoretical frameworks of behaviour change can be challenging for many researchers, often leaving researchers to question if some key behaviour predicting factors have been left out. Currently, there is no systematic way to identify the most salient theory for changing a particular behaviour (Francis et al., 2009), nor is it possible to apply all the potentially relevant theoretical frameworks to change a particular behaviour.

Overall, the majority of social cognitive theories and models that have been used to understand and predict the PA behaviour of TD youth have performed quite poorly (Plotnikoff et al., 2013). Within a systematic review, Plotnikoff and colleagues revealed that these theories and models were only able to account for $33 \%$ of the variance in the PA behaviour of TD youth, and had a high variability in terms of which construct was most strongly associated with the PA behaviour in this population. It has been suggested that future studies employ a multi-theory approach, using integrated social cognitive models, as this may be more useful for explaining behaviour within the PA domain (Hagger, Chatzisarantis, \& Biddle, 2002). 
To maximize the utility of social cognitive theories to understand and predict the health behaviour of a particular population, Michie and colleagues (2005) mapped 128 constructs from 33 psychological theories and identified 12 discrete domains. These 12 domains, known as the Theoretical Domains Framework (TDF), are labelled as (1) Knowledge (i.e., What do you know about PA); (2) Skills (i.e., What types of skills do you need to participate in PA); (3) Social/Professional Role and Identity (i.e., How important do you think it is to take part in PA?, For you and/or for others with SB?); (4) Beliefs about Capabilities (i.e., How easy or difficult is it for you to participate in PA?); (5) Beliefs about Consequences (i.e., What are some of the good and bad things about taking part in PA?); (6) Motivation and Goals (i.e., What makes you want to (or not) take part in PA); (7) Memory, Attention, and Decision Processes (i.e., What do you think about when deciding if you are going to participate in PA?); (8) Environmental Context and Resources (i.e., Thinking about where you live, where can you participate in PA?); (9) Social Influences (i.e., Do your family or friends do PA?); (10) Emotion (i.e., What do you feel when you take part in PA?); (11) Behavioural Regulation (i.e., How do you get ready to take part in PA?); and (12) Nature of the Behaviours (i.e., What do you currently do in terms of PA?). The TDF covers a broad spectrum of theories; thereby limiting the risk of omitting important factors that may influence decision-making (Francis, O'Connor \& Curran, 2012), and therefore making it a useful framework to use for this study. 
Table 2: Summary of the Theoretical Domains Framework

TDF Domain

Knowledge

Skills

Social Role and Identity

Beliefs about Capabilities

Beliefs about Consequences

Motivation and Goals

Memory, Attention, and Decision Processes

Environmental Context and Resources

Social Influences

Emotion

Behavioural Regulation
Definition

An awareness of the existence of something.

An ability or proficiency acquired through practice.

A coherent set of behaviours and displayed personal qualities of an individual in a social setting.

Acceptance of the truth, reality, or validity about an ability, talent, or facility that a person can put to constructive use.

Acceptance of the truth, reality, or validity about outcomes of a behaviour in a given situation.

Mental representation of outcomes or end states that an individual wants to achieve.

The ability to retain information, focus selectively on aspects of the environment, and choose between two or more alternatives.

Any circumstance of a person's situation or environment that discourages or encourages the development of skills and abilities, independence, social competence, and adaptive behaviour.

Those interpersonal processes that can cause individuals to change their thoughts, feelings, or behaviours.

A complex reaction pattern, involving experiential, behavioural, and physiological elements, by which the individual attempts to deal with a personally significant matter or event.

Anything aimed at managing or changing objectively observed or measured actions.
Sample Question from Interview Guide

What do you know about physical activity?

How much PA do you think you should you be doing every day?

What types of skills do you think you need to have to participate in PA?

Why do you think you need these skills?

How important do you think it is to take part in PA? For you? For other people with spina bifida?

How easy or difficult is it for you to participate in PA?

What do you think are some of the good things about taking part in physical activity? What might some bad things be?

What makes you want to (or not) take part in physical activity?

What motivates you to do physical activity?

What do you think about when deciding if you are going to participate in PA?

Is there anything in your environment that has helped you or made it difficult for you to participate in PA?

Are there any times that someone has made you feel like you shouldn't be physically active?

How do you feel when you take part in PA?

How do you get ready to take part in PA? If you wanted to start doing PA/increasing your PA, describe how you would go about doing this.

What do you currently do in terms of your PA? 


\subsubsection{Justification for using the TDF}

Prior to developing a complex, theory-driven intervention, the Medical Research Council framework (Craig et al., 2008) encourages researchers to engage in preliminary work (i.e., interviews with those who are the intended targets of a future intervention). This ensures that interventions target areas of concern relevant to the intended users. The TDF provides comprehensive coverage of potential factors that have been shown to be determinants of a variety of health behaviours (Francis, O'Connor \& Curran, 2012; Francis et al., 2009). The TDF has been used in exploratory interviews to identify barriers and facilitators for the uptake of a particular guideline such areas as immunization (Helms et al., 2011), hand hygiene (Dyson et al., 2012), and the promotion of physical health in youth mental health services (Hetrick et al., 2010). To date, there has been only one published study that has applied the TDF to examine PA behaviours within any population. In this study, Nicholson and colleagues (2014) used the TDF to conduct semi-structured individual interviews with 13 stroke survivors to explore the perceived barriers and facilitators that influence their PA participation. The most commonly reported TDF domains to influence PA within this group were beliefs about capabilities (i.e., the belief that one can successfully perform the behaviours necessary to achieve an outcome such as walking a given distance), environmental context and resources (i.e., transportation problems, program cost and a lack of knowledge of services), and social influences (i.e., both personal and professional interactions that influenced participants' PA uptake after stroke). No study has used the TDF to examine the factors associated with PA in youth with SB.

As explored in sections 1.2.3 and 1.2.5, the limited research examining the PA behaviour of youth with SB suggests that a more exploratory approach needs to be taken to better understand the factors associated with PA participation in this population. The TDF is an ideal framework to use, given its comprehensive approach to identifying salient theoretical constructs that hinder and/or facilitate the uptake of PA behaviour in a specific group (Francis, O'Connor \& Curran 2012). The TDF also takes into consideration personal, social, and environmental influences of an intended behaviour, further contributing to its utility in the context of PA in youth with SB. Additionally, the TDF explores concepts related to physical literacy (defined as "the motivation,

confidence, physical competence, understanding and knowledge to maintain PA at an individually appropriate level, throughout life"; Whitehead, 2001), which is a salient issue for 
youth particularly youth with disabilities. Furthermore, Michie et al. (2008) developed a model to inform the selection of behaviour change techniques (known as 'intervention mapping') that target the domains described in the TDF. The approach to mapping behaviour change techniques to TDF domains has been incorporated into protocols for the development of complex interventions, such as tobacco counseling in dentistry (Amemori et al., 2011), and management of low back pain (French et al., 2012). Together, these strengths provide a strong rationale for using the 12 domains of the TDF as a blueprint for theory-based PA research among youth with SB.

In 2012, the TDF was further refined into 14 domains and 84 constructs (Cane, O'Connor and Michie, 2012). This revision involved the "motivation and goals" domain of the original 12domain model to be further divided into two domains consisting of intentions and goals. Intentions are concerned with the determination to initiate or terminate behaviour, while goals are concerned with the end state or the outcome of the behaviour. The second revision consisted of separating the "beliefs about consequences" domain into two subdomains -- reinforcement and beliefs about consequences -- where the former refers to constructs of associative learning and the latter refers to beliefs. There was also a further division of the "beliefs about capabilities" domain into a separate optimism domain which concerns one's general disposition rather than specific capabilities required to achieve an outcome. The refined 14-domain TDF are labeled as: (1) Knowledge, (2) Skills, (3) Social/Professional Role and Identity, (4) Beliefs about Capabilities, (5) Optimism, (6) Beliefs about Consequences, (7) Reinforcement, (8) intentions, (8) Goals, (9) Memory, Attention, and Decision Processes,(10) Environmental Context and Resources, (11) Social Influences, (12) Emotion, (13) Behavioural Regulation, and (14) Nature of the Behaviours. Unlike the 12-domain TDF, the 14-domain TDF has not been mapped out onto a matrix of behaviour change; rather the refined TDF has been mapped onto the Behaviour Change Wheel (BCW; Michie, van Stralen, \& West, 2011) whereby the target behaviour is categorized in terms of capability, opportunity, and motivation (COM-B). This COM-B model may help to identify the TDF domains that are likely to be important in changing behaviour (Cane, O’Connor and Michie, 2012). A key difference between the systematic intervention mapping technique that is used with the 12-domain TDF and the BCW approach that is used with the 14-doamin TDF is that intervention mapping aims to map behaviour onto its theoretical determinants in order to identify potential correlates to intervene upon, whereas the $\mathrm{BCW}$ approach recognizes that the target behaviours can in principle arise 
from a combination of the capability, opportunity or motivation model (Cane, O'Connor and Michie, 2012).

The 12-domain TDF was found to be the most appropriate framework for the current study given that one aim of this thesis was to understand the theoretical components of PA behaviour in this population. Any future research resulting from this thesis can therefore use the intervention mapping technique (Michie et al., 2008) to integrate theory, empirical findings from the literature and, and information collected from the target population in order to design an effective behaviour change intervention.

\section{Chapter 2}

\section{Objectives and Hypotheses}

Taking into consideration the discussions highlighted within Chapter 1 on the need to increase $\mathrm{PA}$ in youth with $\mathrm{SB}$, and the limited research exploring the theoretical factors that affect PA participation in this target group, the purpose of this current study is to qualitatively explore the personal, social, and environmental factors influencing PA participation among youth (ages 1217 years) with SB. In particular, this thesis involved qualitative interviews with youth, using the TDF as a guiding framework to explore PA knowledge and underlying beliefs around PA behaviour. The aim of this work is to provide a foundation for guiding future theory-based PA research within the SB population. Given the exploratory nature of this research, no hypotheses were generated. 


\section{Chapter 3}

\section{Methodology}

\subsection{Rationale for Qualitative Research}

Vanderbook and colleagues (2014) conducted a review that incorporated Sallis et al.'s (2000) Behavioural Epidemiological Framework to identify and classify the current state of PA research among individuals with SB. This review produced 77 studies for which $43 \%$ were classified as being in Phase I (linking PA to health), 32\% were classified as Phase II (developing methods for measuring PA behaviour), 32\% in Phase III (identifying correlates of PA), and 4\% of the studies were identified as Phase IV research (evaluating PA interventions). None of the 77 studies were in Phase V (translating research into practice). Based on these classifications, it is evident that the majority of the research examining PA in the SB population is still in its early stages of development (i.e., Phases I and II). Therefore, the focus of this present study was to move beyond Phase I and direct research efforts towards the later stages, specifically Phase III (i.e., examining factors that affect PA participation specific to the SB population).

Drawing upon Vanderbook et al.'s (2014) conclusion, it may be asked which methodology would be the best option for eliciting information on factors that influence PA behaviours among youth with SB. Qualitative inquiry may be the optimal choice as it allows for a deeper understanding of the significance of a particular experience, through the perspectives of the individuals who are involved in the research (Esterberg, 2002). Previous research has demonstrated that PA levels are lower for youth with SB than their TD peers (i.e., Buffart et al., 2008; Shoenmakers et al., 2009; see Table 1). However, there is a gap within the literature in terms of understanding the reasons behind these lowered levels of PA for youth with SB. A qualitative approach provides youth with SB the opportunity to discuss their thoughts and feelings towards their experiences with PA, which provides the researcher with an in-depth exploration of the participants' subjective world, and provides detail rich data (Charmaz, 2006). This allows researchers to better understand the factors associated with PA behaviour within this understudied population.

Over the past 15 years, there has been increased interest among researchers on how to optimize

youth engagement in the research process, where youth are seen as active and competent 
participants in the research process, capable of speaking for themselves and shedding light on their own lives (France, Bendelow, \& Williams, 2000). To date, research that has employed qualitative methods to examine PA barriers and facilitators for youth with disabilities, including SB, has been mainly from a parental perspective (i.e., Shields et al., 2012) or has been atheoretical in nature (Bloeman et al., 2015). Examining theoretical influences of youth's PA behaviour from their perspective, is warranted and a novel contribution to the literature.

\subsection{Sample Size}

Twelve youth ages 12 to 17 years were recruited from Holland Bloorview Kids Rehabilitation Hospital's Spina Bifida Outpatient clinic. Holland Bloorview is Canada's largest children's rehabilitation teaching hospital and provides specialized programs and clinical care for children and youth with disabilities and special needs. This age range was chosen in order to stay consistent with the current Canadian Physical Activity Guidelines that were designed for youth 12 to 17 years of age (CSEP, 2011). Based on previous qualitative literature that employed interviews with children who have physical disabilities, a sample size of 12 was adequate for the study to reach data saturation (i.e., the point where the data collection does not generate any new knowledge and the perspectives seem to be completely covered; Lincoln \& Guba, 1985; Bloemen et al., 2015).

The following inclusion criteria were required for participation in this study: (a) between the ages of 12 to 17 years; (b) diagnosed with SB, any spinal level, with or without hydrocephalus; (c) able to understand, write and speak in English; and (d) able to participate in a verbal interview. No participants were excluded on the basis of gender or socio-economic status.

\subsection{Data Collection}

\subsubsection{Interviews}

In person and telephone, semi-structured individual interviews were conducted to elicit youth's thoughts and experiences about PA. Prior to the start of each interview, the information letter (Appendix A and B) and study details were discussed in detail in a conversation with both the youth and parent. The youth and parent were encouraged to ask any questions, and any 
information that was not clear was further explained. Through this conversation, the youth's capacity to consent was determined. All youth $(n=9)$ demonstrated capacity to consent and signed their own consent form (Appendix C).

Appendix D outlines the interview guide that was used for the semi-structured interviews. On average, the interviews lasted between 45 to 60 minutes. Each interview was audio-recorded and thorough field notes were taken both during and following the interview. Interviews began with the student investigator asking participants to describe themselves including their age, ethnic background, type of SB, as well as their level of mobility (Appendix E). Participants were then asked questions about their experiences with PA participation related to the 12 domains associated with the TDF (Michie et al., 2005). Utilizing open-ended questions, participants were asked to discuss their knowledge, skill level, self-efficacy, anticipated outcomes, intentions, decisional balance, environmental constraints, social norms, emotions, and behavioural regulations as they related to their participation in PA. The TDF questions were modified based on previous research that has used the TDF to examine guideline implementation (Patey et al., 2012; Team, 2012; Tavender et al., 2014). Additionally, the TDF questions were reviewed by a nurse from the spina bifida care team (JL), in order to ensure that the language was ageappropriate. Utilizing open-ended questions allowed participants to share significant experiences that they encountered. Probing techniques were also used in order for participants to elaborate or clarify on specific experiences (Wolf, 2012). After completion of the interview, each participant was given a $\$ 20.00$ gift card as a small token of appreciation for participating in the study. Their travel costs, including parking cost or transit fares, were also reimbursed. A lay summary was prepared once all the data was analyzed, providing a summary of the findings and potential future research directions. This summary was emailed out to each participant, as well as presented to the Spina Bifida care team at Holland Bloorview Kids Rehabilitation Hospital.

\subsection{Data Analysis}

\subsubsection{Philosophical Assumptions}

When qualitative researchers engage in inquiry, it is important that they are clear about their own beliefs and assumptions. Paradigms guide qualitative inquiry and are defined as the "basic 
belief system or worldview that guides the investigator" (Guba \& Lincoln, 1994, p. 105). Guba and Lincoln break down paradigms into two components - ontology and epistemology. Ontology describes the form and nature of reality. A realist ontological lens assumes that a single uniform and objective reality exists externally and independent from the person, while a relativist ontological stance conceives of social reality as humanly constructed and shaped in ways that make it fluid and multifaceted (Sparkes and Smith, 2013). For this thesis, I used a relativist ontological position to interpret and understand the meaning of the youths' subjective experiences of participating in PA. Through a relativist lens it is understood that realities exist in the form of multiple, intangible, mental constructions, that are socially and experientially based, and dependent for their form and content on the individual holding the constructions.

Epistemology considers the nature of the relationship between the knower or would-be knower (i.e., the researcher) and those involved in the study (Guba \& Lincoln, 2005; Hesse-Biber \& Leavy, 2004). Essentially, does the knower need to be "objective" and affect the outcome as little as possible (i.e., a dualist and objectivist epistemological approach), or does the knower actively co-construct knowledge with others (i.e., a subjectivist, transactional and constructionist epistemological stance) (Sparkes and Smith, 2013). To interpret and understand the meaning of an individual's, especially youths', subjective experiences participating in PA, a constructivist epistemological paradigm was undertaken for this thesis. This means that it was understood that myself (i.e. the researcher) and the participants were linked, and therefore the findings that emerge are the creation of a process of interaction between the two (Guba and Lincoln, 2005).

\subsubsection{Issues of Trustworthiness}

Trustworthiness is recognized as one fundamental avenue to critically evaluate qualitative research (Lincoln and Guba, 1985). For knowledge to be evaluated as "trustworthy", it must meet the following criteria: 1) credibility; 2) transferability; 3) dependability; and 4) confirmability; Lincoln \& Guba 1985; Mackey, 2012). To enhance the credibility of the data that were collected through the interviews with the youth, I engaged in reflexive practice and logged my experiences and thoughts regarding each interview. Reflexivity is the immediate, conscious, subjective self-awareness in which researchers acknowledge that they are a fundamental part of the research project (Finlay, 2002; Wolf, 2012). With this comes the understanding that the researcher's assumptions and perspectives on the research topic will ultimately influence the interpretation of data (Finlay, 2002). I was aware of the assumptions 
and preconceived notions that guided the research questions, laying open pre-conceptions and becoming aware of dynamics in which the interviewer and interviewee are jointly involved in the production of knowledge and I reflected upon my subjective opinions that may influence the data collection and interpretation of it. I was consciously aware of my social background including my age, gender, ability level, religion, and social class. Moreover, as a swim instructor for children with a variety of disabilities and an active member of the Holland Bloorview community, I have preconceived notions about how swimming, and more broadly PA, can provide a positive experience and of the benefits that children gain from active participation in PA. As a swim instructor, I have witnessed the enjoyable, fun activities that children engage in and the social interactions that occur in a PA setting. I have seen children and youth with or without disabilities push their limits in terms of their physical capabilities and interactions with others. I also recognize how swimming and PA can improve children's self-confidence, behavioural functioning and self-perceptions. By keeping a reflexive journal throughout the research process, I was able to maintain an open-minded stance about the PA experience, specifically for those who had negative experiences with PA. My subjective positions regarding the benefits of PA were acknowledged throughout the research process so that the participants' voices drove the research findings.

To ensure the dependability of the data, I kept an audit trail during the research process. In order to recognize the impact that the participants and myself had upon the research, field notes were taken throughout the research process. Descriptive field notes were kept to recall detailed and accurate descriptions of what was seen, heard, and experienced in each interview with each participant. For example, a detailed description of the interview room was written, to paint a picture of how the room was set up and where was I sitting in relation to the participant. For interviews conducted over the phone, a detailed description of the telephone room I was using, any background noise I may have heard, and where the participant may have been taking the phone call. This detailed account was a way to interpret my experience and learning through my ongoing inquiry. In addition to a description of the setting, a detailed description of the participants was recorded. For example, a detailed description about their appearance and mannerisms, or for those interviews conducted over the phone, a participant's style of talking was noted. These notes also included non-verbal communications, such as a participant's body language or vocal inflections, which provided context for understanding the emotional and circumstantial settings for interpreting the content of oral dialogue. 
Paying close attention to not only what participants said orally but also how they said it with their emotions and bodies in a holistic manner, allowed for a more open and accurate interpretation of what I heard. Finally, I noted descriptions of adjustments to the design of the study, sampling decisions, problems that were dealt with in conducting the study, and comments on how I was developing relationships with participants.

In addition to descriptive field notes, reflective field notes were taken to build upon the descriptive field notes to explain what I was personally learning. These notes go beyond the descriptions presented above, to include my speculations, feelings, problems, ideas, hunches, impressions, prejudices, analyses, plans for future inquiry, clarifications, syntheses, connections, and other ideas about what I was learning in the inquiry phase. This process helped to clarify what I was thinking and experiencing during the inquiry phase. This written record of my reflections provided a contextual framework for interpreting my descriptive field notes.

These notes were all used to help guide data analysis, to assist in the interpretation of each quote, and to help understand each participant's point of view. As well, critical self-reflection had an effect on the research process whereby iterative changes were made to the language of the interview guide, as well as impacting the approach taken when discussing PA with those individuals who did not participate in PA.

\subsubsection{Analysis}

Interviews were audiotaped and transcribed verbatim by the student investigator. Transcribing interviews consisted of listening to the audiotape recordings and typing what was being stated. Data processing software (NVivo ${ }^{\circledR}$ ) was used to transform raw textual material (i.e., transcripts) into a format for analysis by classifying, sorting, and arranging quotations into labeled categories. The software was used to categorize emerging themes.

Thematic analysis was used in analyzing the data and is a foundational and flexible research method utilized for a qualitative analysis. Thematic analysis is a tool that helps researchers identify, analyze, and report on themes that have emerged from within the data, with themes representing a reoccurring pattern that identifies something significant about the data (Braun \& Clarke, 2006). Thematic analysis can be conducted using either a deductive or an inductive approach. Deductive content analysis was used in the primary analysis of the data, where the first level of coding mapped references to each TDF domain. First, the transcribed data was 
thoroughly and repeatedly read in its entirety. Each transcribed document was then read line by line, and a log of initial ideas and overarching themes were kept to help guide the formal coding process. Text that emerged from the data were categorized into one of the 12 TDF domains. This aligned well with the deductive approach given that such an approach begins with preconceived categories derived from prior relevant theory, research, and/or literature (Cavanagh, 1997; Kondracki, Wellman, \& Amundson, 2002). The deductive approach was appropriate to use given that one of the objectives of this study was to explore an existing theory (i.e., the TDF) in a new context (i.e., PA). The TDF provided the variables of interest to determine the initial coding scheme. Due to the overlapping nature of numerous domains, (e.g., beliefs about consequences, and motivation and goals), participants were prompted with key words and phrases (i.e., outcomes vs. motivation), giving the coder the ability to distinguish between which domain the quotation fell under. For example, to explore the ' beliefs about consequences' domain, participants were asked to describe some good and bad things that they maybe have experienced while participating in PA. On the other hand, to explore the motivation and goals domain participants were asked to describe what motivates them to be active. In cases where participants described a consequences of PA as a motivator to be active, the factor was included in both domains.

Inductive analysis is the process of coding data that is not guided by a pre-existing coding framework, to ensure that the themes are strongly linked to the data itself (Braun \& Clarke, 2006). Upon initially categorizing the data into the 12 domains, an inductive approach was then used to analyze the data to determine any subthemes that emerged from each TDF domain. For example, in examining the TDF domain of 'motivation and goals', participants were asked to describe anything that makes them want to stay or become physically active. Participants described how they generally enjoyed being physically active, they enjoyed having friends and teammates, and they personally felt physical benefits of being physically active. These statements were coded into three units -- 'enjoyment of PA', 'social contact', and 'benefits of PA' -- and were then reviewed again to confirm they accurately depicted the construct of 'motivation and goals'. 
The student investigator $(\mathrm{ZV})$ reviewed the transcripts in their entirety, while any uncertainties related to interpretations of specific phrases were discussed with a second person (KAN). A second coder was not used given how the concept of inter-rater reliability underpins the (realist) assumption that there is an accurate reality in the data that can be captured through coding (Sparkes and Smith, 2013). Undertaking a relativist ontological position, thematic coding is seen as flexible and organic, and is an active and reflexive process that bears the mark of the researcher. From a relativist lens it is understood that there is no one-way to code the data. Therefore, the need for additional coders is not salient.

Finally, for each participant, the total statements relevant to each domain were assigned $+/-$ or 0 , depending on whether the domain was perceived by the participant as being an overall positive, negative or neutral influencer of PA. The assignment was based on the researchers general impression relevant to each domain. After identifying relevant domains for each participant, the results were tabulated to identify the most frequently occurring domains, which could be positive, negative or neutral influencers of PA.

\subsubsection{Presentation of findings}

The findings from this study are presented below with a detailed explanation of the themes that both deductively and inductively emerged from the data. TDF domains are presented as the section heading. Subthemes are presented within each TDF domain to better describe and illuminate the findings from each domain. Furthermore, original direct quotations from the youth interviews are inserted into the text to illustrate their experiences. Links are presented between the data and previous literature, in order to contextualize each theme more broadly. Pseudonyms have been used to maintain confidentiality of the participant. 


\section{Chapter 4 \\ Results and Discussion}

\subsection{Recruitment Procedure}

Purposive sampling was used to recruit youth with SB, aged 12 to 17 years (Lincoln \& Guba, 1985; Patton, 1990). This approach results in participants who can illuminate the research questions by providing in-depth descriptions of their PA experiences (Patton, 2002). In July 2015, the decision support team at Holland Bloorview Kid's Rehabilitation Hospital provided contact information for all clients who met the aforementioned eligibility criteria (see section 3.2) and attended the Spina Bifida Outpatient clinic $(n=69)$. The list of client names was subject to secondary screening by a nurse at the clinic who was familiar with the clientele. This secondary check was done in order to eliminate youth who were no longer active clients $(n=2)$, had a diagnosis of Autism Spectrum Disorder $(n=1)$, or who did not have a diagnosis of SB $(n=$ 24). After screening, a total of 42 information packages were mailed out to families. The mail out contained a cover letter signed by a nurse in the client's circle of care (Appendix A), as well as a detailed information letter for parents (Appendix B) and youth (Appendix C) outlining the research purpose, research design, the location of the study, and a request for voluntary participation. Parents and youth who were not interested in participating in the study were given 10 days to call a confidential voicemail to opt out of study participation $(n=2)$. Otherwise, follow-up phone-calls were made to families to inquire about their interest in participating and to answer any questions they had about the study $(n=40)$. Of these 40 clients, nine $(23 \%)$ agreed to schedule an individual interview. Families were given the option to set up a face-to-face meeting at Holland Bloorview $(n=1)$, or if participants lived too far away and travelling to Holland Bloorview was inconvenient, a telephone interview was scheduled $(n=8)$. Although a total sample size of nine is smaller then the anticipated sample size of 12, no new information emerged after the eighth interview. At this time, data saturation was reached and there was no need to recruit additional participants to reach the planned sample size of 12 (Lincoln \& Guba, 1985). 


\subsection{Description of Participants}

Nine eligible youth (6 females) between the ages of 13 and 17 years (mean age of 15.9 years) took part in a semi-structured individual interview. Interviews were held between August 2015 and November 2015. Details of demographic characteristics of the sample are provided in Table 3. The majority of participants $(n=7)$ were unable to identify the type of SB they were diagnosed with, although four youth reported having hydrocephalus. Most youth reported using a mobility device, which they used on either a part-time or full-time basis. The majority of youth self-identified as being of "white" ethnicity.

Table 3: Youth Demographic Information

\begin{tabular}{|c|c|c|c|c|c|c|c|c|}
\hline Participant $^{1}$ & Gender & Age & $\begin{array}{c}\text { Ethnic } \\
\text { Background }\end{array}$ & $\begin{array}{c}\text { Type of } \\
\text { SB }\end{array}$ & Hydrocephalus & Mobility Aid & $\begin{array}{c}\text { Type of } \\
\text { Mobility } \\
\text { Aid } \\
\end{array}$ & Frequency \\
\hline Jennifer & Female & 15 & White & Unknown & No & Yes & $\begin{array}{c}\text { Manual } \\
\text { Wheelchair }\end{array}$ & Part time \\
\hline Siranush & Female & 15 & Armenian & Unknown & $\begin{array}{l}\text { Yes - with } \\
\text { shunt }\end{array}$ & Yes & $\begin{array}{c}\text { Manual } \\
\text { Wheelchair }\end{array}$ & Full time \\
\hline Dina & Female & 17 & White & $\mathrm{LMC}^{2}$ & No & No & & \\
\hline Kaitlin & Female & 16 & White & Unknown & No & No & & \\
\hline Nelly & Female & 16 & White & $\mathrm{MMC}^{3}$ & No & Yes & $\begin{array}{c}\text { Manual } \\
\text { Wheelchair }\end{array}$ & Part time \\
\hline Maha & Female & 14 & Indian & Unknown & $\begin{array}{c}\text { Yes - with } \\
\text { shunt }\end{array}$ & Yes & Walker & Full time \\
\hline Hussein & Male & 17 & Egyptian & Unknown & $\begin{array}{c}\text { Yes - with } \\
\text { shunt }\end{array}$ & Yes & $\begin{array}{c}\text { Manual } \\
\text { Wheelchair }\end{array}$ & Part time \\
\hline Patrick & Male & 17 & Filipino & Unknown & No & No & & \\
\hline Greg & Male & 16 & White & Unknown & $\begin{array}{c}\text { Yes - with } \\
\text { shunt }\end{array}$ & No & & \\
\hline
\end{tabular}

Note: ${ }^{1}$ Pseudonyms have been used to protect the identity of all participants. ${ }^{2}$ Lipomyelomeningocele. ${ }^{3}$ Myelomeningocele 


\subsection{Theoretical Domains Framework Domains}

The current study was conducted to explore the theoretical factors associated with participation in PA in a sample of youth who have been diagnosed with SB. Using the TDF (Michie et al., 2005) as a guiding framework, a variety of personal, social, and environmental factors were shown to have a positive, negative, or neutral influence on the PA behaviour of youth with SB. This study is the first to use qualitative methodology to explore theoretical factors of PA behaviour in youth with SB using the TDF. Implementing the TDF ensured a wide range of personal and environmental influences were investigated and categorizing participants' responses to meaningful theoretical domains. As described below, 11 out of the 12 TDF domains were found to be relevant when discussing factors affecting PA participation in the sample of youth that was studied. The domain "Nature of Behaviours" was found to be neither a barrier nor a facilitator for the youth's PA behaviour. No other themes emerged outside of the 12 TDF. The main sub-themes emerging within each of the 12 domains are described below.

\subsubsection{Nature of Behaviours}

The nature of behaviour domain refers to a youth's daily routine and PA behaviour. Some of the activities/hobbies that the youth reported engaging in during their spare time comprised of sedentary activities such as surfing the internet, spending time on Instagram or Facebook, watching television, and playing computer games. For those participants who reported engaging in recreational screen time, they often reported participating for more than the recommended two hours per day (Canadian Physical Activity Guidelines; CSEP, 2011). For example: "like when I get home, I go on my iPad a lot... I don't do it all at once so maybe two hours" (Nelly).

In terms of PA-related hobbies, youth reported participating in organized sports (e.g., softball, ringette, wheelchair basketball, sledge hockey), as well as unstructured physical activities such as swimming, biking, and leisure walking or wheeling. When asked about their level of involvement in these different physical activities, the frequency, time, and intensity varied considerably between organized (i.e., sports) versus leisure forms of PA such as walking or wheeling. Youth often recalled the exact amount of time they spent in organized PA, but lacked any knowledge of time they spent in unstructured activities. As Nelly describes: 
“[Wheelchair basketball happens] every Thursday... [Other PA] I don't know, I just wheel my chair between classes around 5 minutes, and I walk up and down the stairs in my house. When its warmer out, I ride my bike around 15 - 20 minutes'.

\subsubsection{Knowledge}

The knowledge domain refers to a youth's general understanding of the definition of PA, as well as the type, frequency, and duration of PA recommended for youth of a similar age (i.e., 12 to 17 years). Many of the youth reported a lack of knowledge about the different types of activities that are considered under the umbrella term 'physical activity'. For most of the participants, PA was often perceived as being related to organized sports. For example, "...like those that you have to get physical, like soccer and hockey and those kind of things." (Maha)

Most youth were aware that some sort of PA guidelines did exist for youth (e.g., "mmm...around an hour I think... maybe a little more" (Hussein), and reported hearing this information at school, from health care professionals, during television commercials, online and/or from their parents. However, youth did not know specifically what types of physical activities to undertake, nor did they know how often to participate in PA in order to meet the PA guidelines. Youth reported that their parents and health care professionals had encouraged them to be physically active, but they had not been given any specific instructions regarding the nature of PA to undertake. For example, when talking to his health care providers (i.e. doctors), Heussein often encountered general encouragement to be physically active, "they (health care professionals) encourage it obviously...but don't really give me routines but I guess they tell me teams and stuff I can join."

In the current study, youth with SB demonstrated a lack of knowledge about the recommended Canadian PA guidelines for youth, as well as uncertainty about the types of PA (i.e., sports, structured exercise, leisure time PA) they should be participating in. Additionally, youth lacked knowledge of how much unstructured PA they were currently engaging in (see section 4.1.1), making it difficult to determine whether the current sample of youth was meeting the recommended levels of PA for Canadian youth. Knowledge about PA (e.g., mode, intensity, duration) has been identified as a factor related to PA participation in TD youth (Sallis et al., 1992). Given that the youth in this sample described their primary health care providers of (e.g., 
doctors, physiotherapists) as a source of information in managing their SB, possible way to bridge this gap in PA knowledge is to have primary health care providers communicate these national PA guidelines to youth with $\mathrm{SB}$, as well as spend time to discussing the appropriate types/levels of PA for achieving health benefits among youth with SB (Exercise as Medicine)

\subsubsection{Motivation and Goals}

The motivation and goals domain refers to the reasons why youth with SB believe they are or are not physically active. Seven participants were motivated enough to be physically active, while two participants felt that a lack of motivation was a possible barrier for them to start engaging in PA on a regular basis. Three subthemes emerged from the youths' responses to the questions pertaining to their motivation to engage in PA including: enjoyment, social contact, and benefits of PA.

Firstly, youth revealed that participating in physical activities, which they found to be enjoyable had positively influenced their decision to continue their PA participation. Participants talked about the "fun factor" as one of the main reasons for adopting PA, as Patrick described:

"Cross country for me looked like fun...running with all these people... trying to win in your division looked like fun. So I kept going at it for several years...starting in high school. I still find it a lot of fun"

Secondly, youth felt that having social contact with others motivated them to be physically active. Participants often described how their family, friends and/or teammates increased their motivation for and adherence to PA. As Greg describes below, his sledge hockey team is the reason he continues to attend his weekly practices:

"I think a lot has to do with the team aspect...Just you get to be around a lot of different people and it is a really light atmosphere."

Those youth who lacked social contact often reported a lack of motivation to participate in PA. Siranush, a high school student, describes the reasons she does not want to participant community PA programming: 
"I don't do it...because I don't know anyone and stuff... if it [PA] was in school I would know and I would be with friends." (Siranush)

In addition to the enjoyment of PA and social contact opportunities, youth also revealed that knowing the benefits of PA, as well as actually experiencing the benefits of PA, such as losing weight and increased strength and endurance, positively influenced their motivation to engage in PA. These benefits of PA and their relation to the youths' motivation for being physically active are clearly illustrated by Maha and Patrick:

"What makes me want to do that [PA] is basically my mom tells me that if you want to grow up to be fit and look pretty and be thinner and stuff you have to work hard. That gives me motivation to do it. That makes me think that yes, I do want to look thinner and prettier so I will have to work hard and do this for it. Especially being a girl...it's important for girls, how they look and they should not be too fat and stuff and look ugly." (Maha)

"I can say there has been some moments where I can definitely do things now but before I couldn't. For example moving heavy boxes. If there were five objects and you asked me to carry one of them. Before I would be like "oh no"... right off the bat. But now if you ask me, I'll do it because I know I can [as a results of participating in PA]. " (Patrick)

In addition to increased motivation to participate in PA, youth reported how the beneficial effects of PA (i.e., reduction in back pain or discomfort commonly associated with secondary complications of $\mathrm{SB}$ ) increased their commitment to remain physically active, as Dina describes:

"My commitment to sport is probably a 9 or 10. Part of it is...it's always been something in my life. So it's just about having that constant thing...I know when I am physically active I am in less pain then I would be if I wasn't physically active, so it's kind of that. You know there is a little bit of pain and discomfort but it's not as bad as it could be if I wasn't physically active." (Dina)

For two participants, a lack of motivation was perceived as a barrier to being physically active. Participants who reported low motivation to becoming physically active often did so because they self identified as being a "lazy" person. For example: 
“...to be honest with you I am lazy most of the time as well, so at school I am really lazy sometimes I don't really do much if any. If it feels good when you do it and you want to do more but in reality I just don't." (Heussein)

In summary, youth discussed motivational themes that were both intrinsic and extrinsic in nature. Intrinsic motivators for PA included enjoyment of the activity itself, while extrinsic motivators consisted of losing weight, increasing strength, and having social contact with others. In some cases, participants revealed no motivation to be physically active. The three subthemes that emerged from the motivation and goal domain of the TDF have all been shown to be significant predictors of PA for TD youth. For example, the "fun factor" was mentioned in about half of the interviews. Participating in physical activities that were perceived as "fun" motivated the youth to be physically active. A similar finding can be seen among TD youth where a review of qualitative studies showed that "fun" and "enjoyment" were more often reported as stronger predictors of PA participation than the perceived health benefits of being physically active (Allender, Cowburn \& Foster, 2006). Given, that youth with SB have lowered levels of involvement in PA, it may be of even greater importance to promote the fun aspect of PA programs to youth with SB to maintain their levels of motivation.

The beneficial effect of PA also emerged as a motivator for youth with SB to participate in PA, which is consistent with previous research among women with physical disabilities. Women with cerebral palsy, acquired brain injury, and SCI identified losing physical functioning as a concern that may jeopardize their ability to be independent, therefore motivating them to stay physically active (Goodwin \& Compton, 2004). In the current study, eight of the nine participants expressed that overall health and wellness motivated them to stay active and they were very concerned with their future health and ability to maintain independence. Youth also regularly mentioned weight management as a health benefit associated with their PA participation. As previously discussed in Chapter 1, obesity is a major problem in the SB population, with estimates suggesting that $50 \%$ of children with SB are overweight, and by adulthood $50 \%$ will likely be obese (Spina Bifida Association, 2011). Youth in the current study were not asked to report on their height or weight so it is difficult to compare if the sample exhibited BMI and body composition levels consistent with this statistic. Nevertheless, the fact that more than half of the participants recognized the importance of weight management and associated their PA participation with overall health (i.e., independence) is encouraging. However, an area of concern was raised when 
some participants mentioned wanting to lose weight for physical appearance (i.e., wanting to look thin or pretty), as opposed to health maintenance. Previous studies suggest that body image and physical appearance may influence health perceptions among TD youth. Adolescence is a period of increased awareness of bodily cues and self-reflection, including evaluation of one's appearance (Melan, Haugland \& Breidablin, 2007). Youth who are dissatisfied with their bodies are more likely to perceive their health as fair or poor and more likely to show depression, low self-esteem and low social functioning (Melan et al., 2007). A future focus on promoting a positive body image in youth with SB may be an area of exploration.

\subsubsection{Behavioural Regulation}

The behavioral regulation domain refers to the planned processes youth adopt while choosing to participate in PA. It was evident that the youth did not plan their PA. Rather, their parents took on this role, which consisted of scheduling and providing the youth with transportation to and from their activities. As Dina and Maha revealed, it was often their mothers who played this planning role in their PA participation:

"Well I have always been involved in things outside of school whether it's girl guides or playing soccer when I was younger. It was just, if I wanted to do it, my mom would try and sign me up in whatever way she could. So that I could try it." (Dina)

"I am actually starting to join the gym and club that they have at [a recreational facility]. That gym program that they have and that is something my mom will put me into." (Maha)

Most youth did not know where, when, or how they could be physically active. Youth were not able to discuss any self-regulatory strategies that they could adopt or had used in the past to remain committed to their PA. Youth lacked the ability to make a PA plan, set goals, and manage their time to participate in PA. This suggests that this domain may pose a barrier for at least some youth. Among TD youth, goal-setting has been related to increases in PA behaviour (Shilts et al., 2004), and motivation for PA (Pemberton \& McSweigen, 1989). When goals are lacking, not believed in, and/or not valued, there is little motivation to accomplish the task at hand (Jackson \& Csikszntmihalyi, 1999). These self-regulatory skills (i.e., goal-setting, time 
management) will likely be essential for youth with SB to maintain a healthy, active lifestyle as they transition away from parental supervision into adulthood.

\subsubsection{Memory, Attention, and Decision Process}

The memory, attention, and decision process domain refers to the ability to retain information, focus selectively on aspects of the environment, and choose between two or more alternatives. It was difficult to judge whether the youth had problems with this domain. Six youth reported that it was "easy" to decide whether to engage in PA, while three youth found it "difficult" to decide whether to engage in PA. Two subthemes emerged from this domain -- mood and lack of control.

First, youth often reported a daily fluctuation with their mood, which influenced their ability to choose between two or more alternatives. Being in a good mood made youth want to be active, making PA an easy choice, while if in bad mood they reported it was difficult to participate in any activity. As Patrick, an avid runner, describes:

“...umm I mean like I said before it depends [on] my mood. The feelings. So sometimes it could be yah! I feel like I'm going to go for a run today. I feel like a million bucks, and other days I will just be like really into my thoughts or tired, and just really not in the mood for anything." (Patrick)

Secondly, a number of youth reported that they experienced a lack of control over what types of PA they could choose to do. This lack of control was often the result of the youth feeling that their parents, in particular mothers, made decisions for them. As Maha and Nelly describe:

“Well my mom just signed me up for para swimming... I didn't want to, my mom forced me." (Nelly)

"Well, I've never made a decision on my own. People have always made decisions for me, so it gets difficult sometimes. And sometimes I want to make decisions on my own... I wanted to do bollywood dancing because that is something I wanted to do. But she [mom] said you have to do this [wheelchair tennis] if you want to do that [Bollywood dancing]." (Maha) 
Within this domain, the youth spoke primarily of the decision-making process as a barrier to their PA behaviour. In particular, many participants mentioned daily fluctuations in mood and heightened parental control over PA pursuits as negatively influencing the ability to make their own decisions regarding their PA behaviour. There is evidence to support that youth with disabilities, in general, lack decisive power over their own lives. For example, patients with a disability often report feeling 'talked over' as decisions regarding their health are directed to a third party, such as their parents or caregivers (Myerscough \& Ford, 1996). While research into the perceptions and experiences of parents of children with disabilities has been valuable, the child's right to express opinions about issues affecting him/her and having these views heard has often been overlooked (Morrow \& Richards, 1996). There is a need for parents, health care providers, and researchers to involve youth in the decision-making process, and conversations regarding their health. Perhaps once youth feel invested in the decision of where, when, or how they will participate in PA, they may feel a stronger sense of commitment to become, or remain physically active.

\subsubsection{Skills}

Skills referred to the types of fundamental movement skills that the youth perceived to be essential for participating in different types of PA. These skills include: throwing, catching, jumping, striking, running, kicking, agility, balance, and coordination. Which are critical to the acquisition of physical literacy (defined as "the development of fundamental movement and sport skills, that permit a youth to move confidently and with control in a wide range of physical activities"; Physical \& Health Education Canada, 2016). Physical literacy is a critical skill that is often associated with life-long enjoyment and engagement in PA (Higgs et al., 2005). Physically literate youth can, not only execute the movement, but also understand the vocabulary to describe the movement, which requires them to comprehend and express movement terminology. All youth in the study lacked the ability to describe fundamental movement skills involved with PA, and instead discussed the cognitive and/or behavioural strategies and techniques they used to maintain their PA behavior (i.e. dedication, motivation). This was exemplified by Nelly and Dina: 
"I guess...they [other youth with SB] need some motivation and um... they need to know a little bit about how to use things and do things properly and what's good for different areas of your body." (Nelly)

"I think the biggest skills someone needs to have is an understanding that at the beginning of the season or the first time we are doing something, it will be difficult. And there is a lot to learn if you stick with it... almost perseverance and then dedication and more of the sports sense. Once you are on a team, you make a commitment to that team. You're saying to that team 'hey I will be at any practices or games I can be at' and its kind of, you know helping the team...I think its just the patience aspect and understanding it may be difficult and there may be some discomfort or pain. But if you work at it a little bit, that discomfort or pain will lessen." (Dina)

Physical literacy is a critical skill that provides youth with the building blocks for enabling them to engage in a variety of physical activities over their lifetime (Physical \& Health Education Canada, 2016). The past few years has involved heightened interest among educators on the importance of incorporating physical literacy to enhance opportunities into PA programming for TD children and youth. However, there has been less focus on the physical literacy needs in such programming for children and youth with disabilities. Based on the conversations with the youth in the current study, physical literacy-enhancing programs for youth with SB should provide them with the ability to learn and practice a variety of fundamental movement skills (e.g., running, jumping, hoping), thereby increasing their physical literacy, and potentially, facilitating life-long engagement in PA.

\subsubsection{Beliefs about consequences}

The beliefs about consequences domain refers to the positive and/or negative expectations youth associated with engaging in PA. Youth described positive consequences of PA that were related to increases in their general and mental health, while the negative consequences of PA they raised included competing demands on time, immediate adverse responses to PA, and experiencing pain and/or fatigue.

All of the participants, whether they engaged in PA regularly or not, were able to identify the link between PA and health. Two participants mentioned health in their definition of PA, such as 
Dina who described PA as, "the kind of things that get you active and keep you healthy". Being healthy acted as a motivator for Dina to be physically active (see section 4.3.3). Participants also believed that PA improved their general health and the management of their secondary health problems such as pain and weight management:

"I just feel better when I do that [PA]... I feel better...my knees don't hurt... when I get older my bones, they won't be as strong so it's better to start now... It actually helps me go to the bathroom because I am moving around a lot and it helps me go more often." (Kaitlin)

“Yah, I think that's important because I can't be carrying all this weight. I would not be able to do all this stuff and it will slowly get difficult to do things...walking around. If I keep on increasing weight." (Maha)

Participants also reported that PA helped to improve their mental health, with many of them focusing on the positive mental health benefits of PA. Participants often discussed how they felt "happy", "less stressed", and "relaxed" when they participated in PA:

"In a way it's almost a stress reliever at the end of the week. If I'm having a busy week at school but I know I have practice at some point that week. I know that there is that hour of practice where I can just go and do whatever." (Dina)

The youths' recognition of the mental health benefits that PA provides an important finding within the current study. The positive effects of PA on mental health have been shown across a variety of populations (i.e., Paluska \& Schwenk, 2000). Given the high rates of depression reported for young adults with SB (Bellin et al., 2010), the responses of participants in the current study are encouraging since the risk for depressive symptomology may occur as these youth transition into young adulthood, and the important role PA can play in preventing or managing it.

Despite the positive health consequences of PA mentioned by participants, many youth also addressed the perceived negative consequences of PA. Firstly, youth reported having a number of competing interests, obligations and commitments that placed demands on the time they could 
devote to participating in PA. They reported that PA was a time-consuming activity and often prevented them from doing something more productive such as homework. As Patrick describes:

“...like running could take the stress off me for a bit and it could also add stress to me. In a way I feel like I can be spending that time doing something more productive rather then for the sake of being active... its been pretty busy at school to be honest."

Similar time demands have been noted for the TD youth population, where social hobbies such as reading and surfing the Internet, as well as obligations to family and friends, and school commitments significantly reduced the time youth perceive as available for engaging in PA (Stankov, Olds \& Cardo, 2012).

Secondly, youth often spoke of their concerns with experiencing an immediate adverse physical response to PA. Examples of the physical responses mentioned included sore muscles and joints, and breathlessness. These immediate adverse consequences did not seem to prevent the youth from engaging in PA, nor did they appear to influence their overall decision on whether to participate in PA:

\footnotetext{
"Well sometimes I am a little bit out of breath, but it was fun and I'm kind of sad to leave." (Nelly)

“...the soreness...yah that's annoying...but that's normal I have gotten used to that." (Hussein)
}

Finally, the majority of youth reported that pain and fatigue made it difficult for them to be physically active. While immediate adverse physical effects (i.e., sore muscles, joint and breathlessness) did not seem to impact PA participation, pain and fatigue were identified by many youth, such as Maha and Kaitlin, as a barrier:

"It depends how many times I do it [walk up and down the stairs]. If it... just takes me about 2 or 3 minutes.... but if it takes me 5, 10 and if it's more I have to rest and then go up again..." (Maha) 
"Well, some things I can't really do...[because] my knees hurt ...It can be a throbbing pain or it can really hurt. I just have to sit to make it go away...for like 30 minutes." (Kaitlin)

As discussed in Chapter 1, SB is often associated with secondary health complications such as scoliosis, which increase the presence of chronic pain. In a sample of 68 youth diagnosed with SB between the ages of 8 and 19 years, $56 \%$ of participants reported experiencing pain at least once a week, particularly in the head, back, abdomen, neck, shoulders, legs, and hands (Clancy, McGrath \& Oddson, 2005). Research has shown that various physical discomforts reported by TD youth, including breathlessness and sharp chest pains have a negative influence on their participation in PA (Stankov et al., 2012). However, this was not reinforced in the current study. Having an increased exposure to chronic pain may provide youth in this study a heightened ability to differentiate "normal" (e.g., increased heart rate, muscle soreness) versus "abnormal" (e.g., pain) physiological responses to PA, whereas TD youth are less likely to experience chronic pain. The youth interviewed did not appear to be deterred from PA by 'normal' physiological responses to PA. Rather, pain and fatigue -- two secondary health complications associated with SB - were reported to negatively influence their PA behaviour. Those youth who reported experiencing SB-related pain had coping strategies in place (e.g., resting, Tylenol @) to help ease the pain so they could continue PA participation, as exemplified by Dina:

“...but still being aware if there is back pain... how much of it. Do I need to talk to my coach to see if they need to put someone one. Sometimes they will have another goalie on my team...so they have to put her in... I take some Tylenol if it gets really bad...I have a heating pad that I will lay on or well put muscle rub on my back before some games." (Dina)

\subsubsection{Social Influences}

The social influences domain refers to the social interactions that affect the youths' PA participation. The most commonly reported social influences were personal influences such as family and friends, as well as professional influences such as coaches and health care professionals. 
Family members and friends or teammates were the two sources of personal social influences identified. Family members had both a positive (e.g. encouraging, supporting) and/or negative (e.g. no encouragement or discouraging) impact on youths' PA participation. Friends and teammates were perceived to have an overall positive social influence on the youth's PA participation.

Family members showed positive support to youth in the form of emotional support. Parents often facilitated the youths' involvement in PA by modeling and participating with the youth in PA. As Maha tells about her experience with her grandfather:

"We used to live in downtown Toronto and we moved to Mississauga... when we moved, my grandparents were here so sometimes with my grandfather I used to go for walks around our block, around our neighborhood...that's something that has helped me stay physically active." (Maha)

In addition to emotional support, youth often spoke of other instrumental support that family members provided, such as transportation and physical help with equipment:

“Well my parents usually drive me... for sledge hockey for some of my equipment I need help putting it on and my dad usually comes in to help, although my dad is usually on the ice as well, he helps out at the practices." (Greg)

Only two participants described their family members as discouraging them from being physically active, because of concerns related to their SB:

"My aunts are always telling me to sit down and take a break....they just baby me." (Nelly)

"I mean it's like my parents will mention [my SB] to me and we will go here [name of rehabilitation centre] always for appointments and then I'm reminded of it. But in reality when I go out there [and run] it's not a bother at all." (Patrick)

On the other hand, all participants reported that friends and teammates had a positive influence on their PA behaviour by providing emotional and companionship support: 
"My friends...my friend and I were video chatting and she was doing it [sit-ups]. and that's what really got me to start doing it." (Siranush)

"Sometimes when you run...I don't really want to run alone and sometimes when I run and I don't want to be by myself.... as long as there are people that are supportive enough. As long as they are overall friendly and nice people, and that of itself is enough to motivate me. For me to get out there and be active." (Patrick)

Finally, youth spoke about the positive social influence that coaches had on their PA behaviour. Coaches were often described as providing informational support by giving advice, guidance, suggestions, or useful information to help the youth problem solve, such as Nelly's wheelchair basketball coach:

"My coach is pretty cool... he used to coach the Canadian men's national team. So he knows what he's talking about. He's always giving me tips and stuff and he says he likes me because I always listen to him. He says I am very coachable." (Nelly)

As noted above, a variety of sources and types of social support were identified that play an influential role in the youths' PA behaviour. The main sources of support included family members, friends and teammates who provided the youth with emotional and instrumental social support, and professional relationships (i.e., coaches) who provided the youth with informational support. Previous research has shown that, youth with SB who report receiving social support from their family and friends to have a greater likelihood of participating in sports (Buffart et al., 2008). This supportive role from family, and particularly friends and teammates, was highlighted by youth in the current study, suggesting the importance of incorporating activities that promote friendships and social interactions into youths' PA experience. The presence of positive social interactions during PA may help to increase youth's motivation to adopt and maintain PA participation.

\subsubsection{Emotions}

The emotions domain referred to the youths' positive and/or negative affective responses to participating in PA. Many participants experienced feelings of positive affect after completing a 
bout of PA. For Dina and Patrick, this positive affect-PA relationship was reported through feelings of happiness and relaxation both during and immediately following a session of PA:

"For me PA is a really big stress reliever and I think in many situations. A lot of the girls who have played on my previous teams look at it [PA] as a stress reliever too so you know we are all aware when we go there we blow off stress." (Dina)

“When I run I don't usually think about all that...it's just for that half an hour for that 45 minutes, I can let everything go...just focus on where I am going...from point A to point B” (Patrick)

On the other hand, there were several participants who described experiencing negative affect while participating in PA. For example, Nelly described her experience in a PA program as "boring":

"Whenever I got into a program, like wheelchair, it was always little kids and I didn't challenge myself and it was really boring." (Nelly)

Affect and its relationship to both acute and longer-term PA are of increased interest within mainstream exercise psychology (Ekkekakis, Parfitt \& Petruzzello, 2011; Ekkekakis \& Petruzzello, 1999). Although still being explored, there is research to suggest that individuals who have a more positive affective response to an acute session of PA are more likely to engage in moderate to vigorous PA. For example, in a sample of 124 TD youth who completed two, 30minute aerobic PA tasks, those who displayed a more positive affective response during PA showed significant associations with greater participation in MVPA, when affective valence was assessed before, during, and after each task (Schneider, Dunn, \& Cooper, 2009). To date, there has been no literature examining the affective responses to acute PA and implications on future PA participation among youth with physical disabilities. Both positive and negative affective experiences were reported by the youth, which suggests that the emotion domain has both a positive and negative influence on the youths' PA participation. Creating fun, interesting, and challenging programs for youth with SB, may facilitate a positive affective experience during PA. 


\subsubsection{Environmental Context and Resources}

The environmental context and resources domain refers to personal and/or environmental situations that encourage or discourage the youths' PA behaviour. Three sub-themes were drawn from the youths' responses to the questions posed within this domain, which included access, cost, and experiences in physical education.

Contrary to past research conducted among youth with disabilities (Shields et al., 2011), participants in this study reported that they experienced few environmental barriers within their community and/or the recreational centres they frequently used. Youth did not find access to accessible recreational facilities, adapted programs, adapted equipment, and the proximity of facilities to be a problem in their communities. As Dina explains her experience with hockey rinks around her neighbourhoods:

"The one we practice at in [city A ] is very accessible because they have a ramp going into the building and once you are in the building. It's very flat... one level... and they have special areas for people with mobility issues. But some of the other arenas... well some of them are really old...so they are not designed properly. They have really narrow hallways and its difficult to get around but most of the arenas in [city A] and [city B] are easy to get around." (Dina)

This finding could be attributed to the fact that the youth in this study relied heavily on their parents to find programs, drive them to facilities, and facilitate their participation in the program (i.e., assist them in the pool and change facilities; see section 4.3.4).

While cost of PA programs is seen as a barrier to PA for those with and without disabilities (Shields et al., 2011), only one youth in this study reported cost as a possible factor that prevented him from being more physically active. Heussein was one of the oldest participants in the study and was starting to take more financial responsibility over his own life, as evidenced by the following:

"I don't really go to the gym outside of school. Going to the gym outside of school isn't really an option because memberships are sky rocket expensive." (Heussein) 
This new sense of financial responsibility likely made Heussein more aware of the personal costs associated with being physically active (such as memberships to recreational facilities), and therefore limited the choices available to him to be active within his community.

An environmental barrier that was frequently identified by youth was access to outdoor recreational facilities, such as parks and basketball courts. For participants who use a wheelchair as their primary mode of mobility, the terrain within these settings was often difficult to navigate, as exemplified by Siranush and Nelly;

"...[to access the park] is not that easy because the park was uphill and I was downhill." (Siranush)

"Well we [Youth and Parent] have to drive to the court....its really weird like there are pavement half way and then there is just grass one way. And then you go to sidewalks and then there's a parking lot but the parking lot is gravel. So we drive to make it easier, because you get stuck everywhere, and you have to get out and push it and it's awkward."(Nelly)

Finally, as previously discussed in Chapter 1, many individuals with SB have bladder and bowl management issues due to nerve damage from birth. Youth with SB often have a urologist as part of their clinical care team, who places them on a bowl continence program, which may involve emptying the bladder or bowls at a specific time in the day (Spina Bifida and Hydrocephalus Association of Ontario, 2016). Given this, youth with SB may need easy access to the bathroom. In the current study, youth reported inaccessibility of bathrooms as an issue they often have to be aware of when engaging in PA:

"I know in softball, the struggle that we have is the league gets a bunch of diamonds the year and then rotate your team and they schedule at whatever time...over the past years we have had to ensure there are bathroom access near the diamond. Whether it be at a building across the street we can go to, or a port-a-potty at the diamond. We have to do a little bit of fighting...to make sure there was a bathroom there and my team was at a diamond that had washroom access" (Dina) 
Within this domain, the youth also spoke of the lack of resources available to support their participation within physical educational settings. This theme was the most commonly mentioned barrier to PA within this domain. Participants often reported feeling excluded from their physical education classes, due to the lack of knowledge teachers have about adapting physical education for youth with a physical disability. This prevented the youth from participating with their peers in this particular setting:

" [when the class did dodge ball]. I usually sit out or he [PE teacher] told me I can do homework." (Greg)

"In elementary school they said I could be the referee, sometimes I did get to play, but I didn't like volley ball because I was scared of getting hit and it was embarrassing but in basketball, in stand up basketball, I never played because I couldn't run that fast." (Nelly)

Youth only reported positive experiences with physical education, when teachers were able to accommodate the planned activities to their specific physical needs. As described by Maha:

“... any activities I couldn't do. I used to go out for a walk with the ERW [educational resource worker] around school and I have another friend who has autism and he would come on a walk too, so we would walk around the school and do the stairs in my school." (Maha)

Overall, the youth spoke of unique experiences within their physical education classes. In some cases, the physical education teachers seemed to incorporate inclusive teaching practices where they found ways to involve youth with disabilities in their physical education lessons. Nelly reported:

"Well I had a really great teacher so she would always include me in everything. She modified things when I got tired. For volleyball I would play with one person... she would switch off people while they played a game. I remember one time I got to play ping pong with people instead." 
In other situations, physical education teachers lacked knowledge on how to incorporate the needs of the youth to support their participation in the physical education class and, instead had them sit out of the class all together. One participant was told she could not participate in physical education class with other students because of safety concerns:

“I didn't take gym or any sports after school. I wasn't able to do because that's the [school] rule... They say its not safe for the others. It's not really fair for the wheelchair people. The school board is not letting you play because you are in a wheelchair so what are you supposed to do?" (Siranush)

In general, research has shown that children and youth with SB seem to have lowered levels of active participation at school than their peers, particularly at recess or free time (PenyDahlstrand, Krumlinde-Sundholm \& Gosman-Hedstrom, 2013). Similar to the experiences noted by some youth in this study, many individuals with disabilities are still, to a large extent, socially segregated in physical education settings, leaving them with limited opportunities for participation in group-based PA (King et al., 2003). Based on the lived experiences of the youth in this study, it is evident that a significant need exists to educate highly qualified and effective physical education teachers, who are able to assess needs of youth with physical disabilities and implement adapted school-based PA programs. This is important for providing youth with SB an opportunity to enhance their physical literacy as early as possible, and therefore facilitate lifetime enjoyment and participation in PA (Physical \& Health Education Canada, 2016).

\subsubsection{Beliefs about Capabilities}

The beliefs about capabilities domain referred to the youths' feelings about their own abilities and their perceptions of control over their PA behaviour. Most of the youth were satisfied with the amount of PA they were involved in and had no interest in increasing their current levels of PA. All of the youth reported that having SB did not prevent them from being involved in PA. Youth noted that self-confidence in their abilities (i.e., self-efficacy) was a critical factor in recognizing their capacity to participate in PA. As Kaitlin, a long-time participant in PA explains: 
"It pretty easy because I've been doing it [phys-ed] since elementary school...I kind of learn from there... what is good for me and what I shouldn't do and what's hard for me. Things like that. The dodge ball thing happened in elementary school and when I got into high school I already knew I should stay away from that." (Kaitlin)

This finding is not surprising given the fact that self-efficacy has been shown to be strongly associated with both PA and sedentary behaviour in TD children and youth (Biddle et al., 2005; Horst, Paw, Twisk \& van Mechelen, 2007). Furthermore, self-efficacy is one of the only longitudinal determinants to be consistently associated with physical activity behaviours in the TD population (Craggs, Corder, van Sluijs \& Griffin, 2011). Similar to findings from this current study, Bandura (2004) proposed that self-efficacy influences how people perceive barriers and facilitators in their environment. For example those with low self-efficacy are more likely to have negative views of their environment, while people with high self-efficacy (as Kaitlin describes above) are more likely to have positive environmental perceptions. This concept was demonstrated, in a Canadian study of TD youth where, those with low self-efficacy were more likely to perceive fewer opportunities for PA in their school environment compared to an objective assessment of these same opportunities (Fein, Plotnikoff, Wild, \& Spence, 2005). Within the current PA correlate literature, self-efficacy is the most commonly studied factor (Kaczynski, Robertson-Wilson \& Decloe, 2012), therefore it can be hypothesized that selfefficacy may play a universal role for determining the PA behaviour for youth of all abilities. Future research should further examine this relationship among youth with physical disabilities including SB.

Self-efficacy can also be an important factor to target when designing future PA behaviour interventions for this population. There were three participants in the current study who were inactive and reported very low confidence in their ability to be active. Strategies to increase selfefficacy for this subgroup are needed. One potential way to increase youth's self-efficacy could be to increase their mastery and vicarious experiences (role modeling). A lack of mastery experiences may be a particular concern for individuals with SB, as previous research has demonstrated that individuals often have a lack of responsibility from a young age (i.e., behavioural regulation domain), leading to a lack of opportunities to master PA skills (Buran et al., 2004). Providing support and gradually teaching these youth fundamental movement and 
sports skills will lead to a greater sense of accomplishment. Learning and succeeding at a new skill is also likely to increase belief in their ability and increase future PA behaviour.

\subsubsection{Social and Professional Role and Identity}

The professional role and identity domain describes the youths' attitudes and beliefs in relation to their peer group. In this context, participants reported that it was important to be physically active, regardless of the presence or absence of a disability or one's ability level.

“It doesn't matter. Absolutely not, to me everyone should have and should get the same amount of $P A$ as the other, and an equal chance at getting into a physical activity program as another person." (Patrick)

However, some participants reported feelings of discomfort around others with disabilities, or with youth who are not in the same age or skill category, preventing them (at times) from participating in PA. For example, Maha described her fear of participating in PA with youth who were older than her:

"One time I was doing electric wheelchair hockey. I had to drop out half way because those kids who I was doing those sports with, they were much older then me so I couldn't. I was really scared."

Or as Nelly described her hesitation with playing wheelchair basketball with her friend who's skill level is not advanced as hers is:

"I have a friend down the street who plays wheelchair basketball with me... she has SB, hers is a little bit worse then mine... she needs assistance walking...she's not really at the level I am.... so she struggles a bit. That makes it a little bit more difficult because I don't want to exclude her but I want to get better myself. "(Nelly)

Finally, when asked if they want to be active with others who have a disability or those who don't, the majority of youth said they preferred to participate in PA with others who did not have a disability: 
"I would rather kids who don't have disabilities...because I don't want to be around people who have disabilities...I don't want people to think I'm the girl with the disability. Even though I am. I just want them to think that I am like any normal other kids. I don't want people to think that she's different because she is a disability. That's why I want to be around kids without disabilities" (Maha)

"Can I be honest.... without disabilities. Having a disability I find that for the most part I know what the person is going through and that gives me an odd feeling...I am sympathetic. For me I find that an overwhelming feeling, just to be around someone who I know similarly what they are going through. It's harder for me to interact with them than someone else outside."(Heussein)

However, the context did influence some of the youths' preferences to be active with others who have disabilities. For example, one youth who played on a competitive adapted sports team described his desire to compete with others who have a disability in order to make the level of competition more equal:

“ [I would prefer a league] geared towards people with disabilities... I think and this is coming from the more competitive aspect of it. I think it would be more fair for it to be a league with all people of disabilities" (Greg)

Social role and identity were perceived as barriers to PA for those youth who had difficulty identifying with the other participants in the group (i.e., older children, those who do not have a disability). While there is some research on intervention development for youth with physical disabilities (Durstien et al., 2000; Patel \& Grevdanus, 2002), little research has focused on the PA preferences of youth with SB, in terms of how and with whom they want to be physically active. Youth in this study expressed their dislike for segregated programs but the context did affect whom youth reported they wanted to be active with. In fact, research does show that there is merit to inclusive PA opportunities such as decreasing disability stereotypes and fostering an environment of acceptance (Schleien \& Miller, 2010). Regardless of the presence or absence of a disability, youth in this study who did not relate to the larger group did not want to be physically active. Several reasons can be offered to support the utilization of a group focus to improve the PA adherence of youth with SB. First, humans are stimulated by the activity of 
others and influenced by their behaviour (Latane \& Nida, 1980). Past research has demonstrated the relationship between groups and individuals, and it has been suggested that when individuals become members of a group, it can have a powerful impact on the individual (Shaw, 1981). Not surprisingly, this also applies in a PA setting as " peer groups" have been identified as one of the three dominant social influences, alongside exercise leaders and significant others, to impact an individual's level of PA (Carron, Hausenblas, \& Estabrooks, 1999). Understanding youth preferences when designing group PA interventions may have a powerful impact on adherence.

\subsection{Discussion}

This qualitative study explored theory-based factors that contribute to PA participation in youth with SB. Improving the health of youth with SB is of particular interest due to the combination of an aging disability population, and the increased risk of poor health and secondary health complications associated with SB (McPherson et al., 2013; Nelson et al., 2007) Identifying the specific factors that contribute to the PA behaviours of youth with SB is important to effectively target future efforts to increase PA participation and overall health within this population. Using the TDF as a guide, a variety of factors were identified to influence PA participation for youth with SB. A summary of the perceived influences of the 12 TDF domains on the PA behaviours of the youth interviewed is presented in Table 4. Some of the emergent factors had both positive and negative influences on the youths' PA behaviour (i.e., mood, family social support, affect, environmental resources). Others acted as perceived facilitators or motivators for PA (i.e., friends/teammates, coaches, enjoyment, beneficial effects of PA on general and mental health, self efficacy). The remaining emergent factors were perceived as barriers to PA (i.e., lack of knowledge of PA, lack of self-regulatory skills, lack of control over the PA decision-making process, competing demands on time, lack of skills, pain/fatigue, lack of environmental resources, lack of identity with peer groups in a PA context). Some subthemes that arose from each domain were found to overlap with one another, perhaps suggesting an intricate relationship between these theory-based factors and PA in youth with SB. Future research should focus on identifying the relationships between these modifiable factors and their outcomes on PA within youth with SB. For example, since the presence of social contact and the encouragement of family members, friends/teammates, and coaches had a positive influence on the PA 
participation in the current sample of youth, one future research direction can be to examine the relationship between social contact and its outcome on PA. If a relationship is established, then future behavioral interventions can be designed where such social relationships are targeted to meet the PA participation needs within this population.

There were many similarities drawn between the literature on the barriers and facilitators to PA for TD youth to those who were interviewed in the current study (see section 1.2.4). For example environmental barriers to PA (e.g., availability of program, area of residence), and the presence of peer support and parental support have been shown to be important barriers to consider for youth who are TD (Gordon-Lasen, McMurray, \& Popkin, 2000; Lindquist et al., 1999; Sallis \& Saelens, 2000; Trost et al., 2002) as well as for youth in the current study. A possible reason for this finding could be attributed to the fact that youth in this study had a high level of physical functioning with only two participants used a mobility aid on a full time basis. Environmental barriers discussed were regarding availability of programs as opposed to accessibility of those programs as seen in previous literature examining factors of participation affecting youth with disabilities (Shiels, Synott and Barr, 2011). Finally, parental support has been perviously identified as a strong correlate to PA in the TD population (Sallis et al., 2000). Therefore, it is not surprising, this was identified in this sample youth. These similarities in barriers and facilitators may suggest that, when designing PA interventions for the general population, messages regarding availability of programs or peer/parental support can be distributed to all youth regardless of ability level.

In addition to similarities drawn with TD youth, the current findings build upon the prior research examining PA in youth with SB. For example, positive health benefits (i.e., functional benefits), fatigue, amotivation, lack of information and/or knowledge, social support, skill competency, and self-efficacy (Bloeman et al., 2015; Buffart et al., 2008; Marques et al., 2014) have also been reflected in previous literature involving youth with SB. Additional factors that were not identified in the SB and PA literature, but were emergent modifiable factors that influenced the PA behaviour of youth in the current study included, behavioral regulation (i.e., goal setting ) and memory, attention, and decision processes domains (i.e., lack of decisive power). Within the current study, the youth identified a lack of control over the decision-making process related to their PA participation. These cognitive skills are critical for remaining active, particularly as the youth transition out of adolescence and into adulthood. These barriers not 
previously identified in the literature are a novel contribution to the literature and can be attributed to the use of the TDF. Using a comprehensive theoretical framework allowed for the broad exploration of topics affecting PA behaviour that may have been otherwise missed, such as the topic of youth's resiliency.

While the views of the parents on their role of their child's PA participation were beyond the scope of the current study, research suggests that parents play a key role in the development of their child's resiliency, this can be accomplished by assisting their child to identify and meet the challenges they face on a day-to-day basis, as well as within a PA context (Alvord and Grados, 2005). In the current study, the youth disclosed that their parents did not provide such resiliencebuilding opportunities. Rather, parents were perceived by the youth to facilitate every aspect of their PA (i.e., scheduling, locating programs, transportation). Behavioural strategies such as goal-setting and self-reflection play an important role in PA participation by enabling individuals to invest the time to practice, navigate distractions, and stay committed to PA throughout life (Giblin, Collins, \& Button, 2014). Research has shown that parents who build resiliency in a child are parents are warm, loving, and supportive and provide a cognitively stimulating environment. They are also demanding in that they apply rational, firm, and consistent, but not overbearing, control on their children and place high behavioral expectations on them (Baumrind, 1991). Although there has been no research addressing the topic of resiliency in youth with SB, other longitudinal studies have followed the outcome of individuals with learning disabilities and attention-deficit/hyperactivity disorder (ADHD) to determine those factors that contribute to their resilience (Gerber, Ginsburg, \& Reiff, 1990, and Spekman,Goldberg, \& Herman, 1992, as cited in Katz, 1997; Werner \&Smith, 2001). Studies reveal that resilient learning youth with disabilities search for personal control over their lives, possess a strong desire to succeed, set goals, demonstrate high levels of persistence, and are willing to seek out and accept support. Youth with various disabilities who display resilient characteristics report a better ability to identify their successes and unique strengths, and are more likely to report turning points in their lives as motivations to overcome their challenges, and show a stronger self-determination (Miller, 2002). Resiliency can be developed through successfully navigating challenging situations by trial and error, setting realistic goals, and successfully solving problems, all of which help youth to overcome adversity and everyday stresses (Brooks \& Goldstein, 2001). Taking initiative in one's own life and believing in one's own effectiveness, 
has been identified as a primary characteristic defining resilience in the literature. There were youth in the current study who were motivated and wanted to increase their PA, but were unable to make a plan on how to increase their PA, nor did not have the knowledge on how to schedule PA into their daily routines independently. Conducting future interventions that focus on developing self-regulatory skills (e.g., self-monitoring, goal-setting, planning, and overcoming barriers) in youth, as well as educating parents on the importance of providing resilient building opportunities for their youth by allowing youth to generate their own ideas and receive positive feedback will give youth a sense of empowerment and may be an effective way to increase PA in this group.

Another area for further exploration that was highlighted in the current study is the enhancement of physical literacy in youth with SB. The Canadian Sport for Life expert group strives to educate parents, coaches, teachers, and students about the importance of understanding physical literacy in TD children and youth (Higgs et al., 2008). The seven-stage Long-Term Athlete Development (LTAD) model is built on the foundation of fun, fitness, and movement skill development with the intent of translating sport science into community action (Balyi, Way, Cardinal, Norris, \& Higgs, 2008). The quest for physical literacy requires an early emphasis on learning proper movement skills along with the integration of cognitive, emotional, and social development (Whitehead, 2010). The LTAD model is composed of the following seven stages: (1) Active Start (males and females birth to 6 years) which focuses on learning fundamental movements and linking them together into play; (2) FUNdamentals (males ages 6 to 9 years and females ages 6 to 8 years) which focuses on learning all fundamental movement skills and building overall motor skills; (3) Learning to Train (males ages 9 to 12 years and females ages 8 to 11 years) which focuses on learning overall sport skills; (4) Training to Train (males ages 12 to 16 and females ages 11 to 15 ) which focuses on developing sport specific skills; (5) Training to Compete (males ages 16 to 23 and females ages 15 to 21) which optimizes event and position specific physical conditioning; (6) Training to Win (males ages $\geq 19$ years and females ages $\geq 18$ years) which focuses on podium performances and maximizes fitness preparation and sport, and (7) Active for Life (any age) which focuses on the smooth transition from an athlete's competitive career to lifelong PA and sport participation (Robertson \& Way, 2005). Physical literacy is developed during the first three stages of the LTAD model (i.e., from birth to the start of adolescence), but the model also specifies that athletic and recreational 
involvement in PA should be based on the individual's developmental stage, rather than on his or her chronological age (Canadian Sport for Life, 2016).

Recent research in the UK suggests that nearly half of TD youth leave school without the basic movement skills required to engage successfully in PA (Griffiths et al., 2013), however, there is no current research available evaluating the current state of physically literacy in youth with physical disabilities. Given the high rates of inactivity in youth with disabilities (Buffart et al., 2008; Pan et al., 2006; Schoenmakers et al., 2009; Van den Berg-Emons et al., 2001), it can be assumed that youth with disabilities may experience a similar, if not even greater, lack of fundamental movement skill development than their TD peers. Youth in the current study were often asked to sit out and not participate in physical education classes, and therefore were not given the opportunity to develop these movement skills that are essential to enhancing physical literacy. Developing physical literacy will allow youth to learn the importance of PA (i.e., knowledge domain of the TDF), as well as to gain the self-regulatory skills (i.e., behavioural regulation domain of the TDF) to make healthy lifestyle choices. A well-designed elementary school physical education program, focusing on the first three stages of the LTAD model will allow children and youth to focus on learning fundamental movement skills as well as build overall motor and sport skills. Without the development of the first three stages, youth will not be able to progress to the Active for Life stage. Through the progression of these first three stages, a child acquires the competence and confidence necessary to pursue more complicated life long fitness, sport, and PA (Atwater, Crowe, Deitz, \& Richardson, 1990). Based on the current study findings, there is an apparent gap among physical education specialists on the knowledge and skill set that are required to teach these fundamental movement skills, in a modified way, to meet the needs of students of all ability levels. Youth in this study who had positive experiences in physical education classes did so only because their teachers were passionate and knowledgeable about inclusive PA programming. It was evident, through the youths' experiences with physical education, that teaching professionals need to gain more knowledge about individuals, especially youth with physical disabilities, to better understand how to facilitate PA within the school setting which meets the needs of the target population. In order to foster continued PA participation for youth with SB, perhaps the focus of health promotion in this population should move towards promoting physical literacy. Enhancing youth with SB's physical literacy will allow them to learn fundamental movement and sport skills, 
develop the competency to read their environment and make appropriate decisions, and provide them with the opportunity to move confidently in a wide range of PA situations.

\subsection{Future Directions}

Although the TDF is a relatively new approach (Michie et al., 2005), this study has demonstrated its utility for understanding behaviour in a PA context. The TDF was chosen for this particular study in order to maximize the utility of social cognitive theories to the understanding of PA in youth with SB. Using the TDF permitted wider consideration for potential explanations than would be possible if only one theoretical model had been used (Francis et al., 2009). For example, the HBM and TPB only cover three domains of the TDF (i.e., beliefs about consequences, beliefs about capability, and motivation and goals). This may have been problematic as the data analysis indicated that 11 of the 12 TDF domains were relevant to PA for the youth who were interviewed. Therefore, using the TDF reduced the risk of omitting important areas when exploring factors, which may impact decision making regarding PA for youth with SB. As well, Michie et al. (2008) developed a model to inform the selection of behaviour change techniques that target the determinants described in the TDF. The approach to mapping behaviour change techniques to the 12 TDF domains has been incorporated into protocols for the development of complex interventions, such as tobacco counseling in dentistry (Amemori et al., 2011), and management of low back pain (French et al., 2012). Beyond the scope of this thesis, the mapping process provides a practical tool for selecting appropriate behaviour change techniques, as the components of behaviour change interventions are mapped out clearly for future studies (see appendix F for an example of the mapping process).

Secondly, the TDF is descriptive in nature since it does not specify relationships between domains, and thus does not generate testable hypotheses. Considering this as a limitation of the TDF, further research needs to be conducted which tests the relationships between the theoretical factors that are specific to youth with SB and their influence on objectively and/or subjectively measured PA behaviour. Future theory-based intervention work can then be carried out to effectively increase PA participation within this population, through the identification of the most salient modifiable theoretical constructs to intervene upon.

Finally, it is important to consider that some of the barriers, facilitators, and solutions discussed in this study might not reflect the experiences of youth with more severe form of SB. Taking 
this into consideration it is important to conduct more interviews with youth who have varying degrees of SB, as well as their parents, caregivers, and other sources of social support (e.g., teachers). This approach may give a more holistic understanding of the context within which youth operate in as well as the barriers and facilitators towards PA faced by youth with SB.

\subsection{Conclusion}

The current study is the first of its kind using the TDF as a framework to explore the knowledge and beliefs regarding PA participation among youth with SB. These findings provide useful avenues to guide future theory-based PA intervention research through the identification of potential theoretical correlates to target that are specific to youth with SB. 
Table 4: Perceived Influence of TDF domains on PA behaviour

\begin{tabular}{|c|c|c|}
\hline TDF Domain & Sub Themes & Perceived Influence on PA \\
\hline Nature of Behaviours & & 0 \\
\hline Knowledge & & - \\
\hline \multirow[t]{3}{*}{ Motivation and Goals } & Enjoyment & + \\
\hline & Social contact & + \\
\hline & Beneficial Effects & + \\
\hline Behavioural Regulation & Lack of independence & - \\
\hline \multirow{2}{*}{$\begin{array}{l}\text { Memory, Attention and Decision } \\
\text { Process }\end{array}$} & Mood & $+/-$ \\
\hline & Lack of Control over Decision Process & - \\
\hline Skills & & - \\
\hline \multirow[t]{5}{*}{ Beliefs about Consequences } & General Health & + \\
\hline & Mental Health & + \\
\hline & Competing Demands & - \\
\hline & Immediate adverse response to PA & 0 \\
\hline & Pain/Fatigue & - \\
\hline \multirow[t]{4}{*}{ Social Influences } & Family & $+/-$ \\
\hline & Friends/Teammates & + \\
\hline & Coaches & + \\
\hline & Health Care Professionals & + \\
\hline Emotion & Affect & $+/-$ \\
\hline \multirow{4}{*}{$\begin{array}{l}\text { Environmental Context and } \\
\text { Resources }\end{array}$} & Access & + \\
\hline & Cost & $0 /-$ \\
\hline & Built Environment & - \\
\hline & Physical Education Setting & $+/-$ \\
\hline Beliefs about capabilities & Self efficacy & + \\
\hline \multicolumn{2}{|c|}{$\begin{array}{l}\text { Social and professional role and } \\
\text { identity } \\
\text { Notes: } \\
\text { - perceived as negative influence on physical activity } \\
+ \text { perceived as positive influence on physical activity } \\
0 \text { No strong positive or negative beliefs/feelings }\end{array}$} & - \\
\hline
\end{tabular}




\section{Chapter 5}

\section{Considerations, Strengths and Personal Reflections}

\subsection{Considerations}

There are a few considerations when interpreting these study findings. The first relates to use of a selective sample. Although various methods of recruitment were used to achieve a more diverse range of participants (i.e., mail-out information packages, telephone calls), the majority of participants were female, ambulatory, and of white ethnicity, which therefore limits the transferability of the findings. Second, a large majority of the youth could not identify their level of SB, thus, it is important to consider that some of the barriers, facilitators, and solutions discussed in this study might not reflect the experiences of youth with more severe form of SB. Third, all participants were recruited from one location and therefore presumably received similar care. It is unclear if their experiences are similar to those who may have received care in other clinics and/or provinces and, therefore may place limits on the external validity of the study results. Fourth, the TDF is descriptive in nature, and thus does not generate testable hypotheses given the lack of directionality specified between the 12 domains and their quantifiable effects on PA. Finally, given the important role parent/caregivers play in youth's PA without their additional perspective our understanding of the barriers and facilitators described by youth may be limited by having only one perspective.

\subsection{Strength}

The use of the TDF provided a systematic approach to identifying and selecting the most relevant and useful theoretical constructs to investigate the behaviour in question (Francis et al., 2009). Thus, using the TDF presented a more efficient way of including all the domains specified, versus any individual theory. Using the TDF permitted wider consideration of potential explanations than would be possible if only one theoretical framework had been used (Francis et al., 2009). Moreover, there is evidence to support the use of the TDF in identifying behaviour-specific barriers which would not normally be reported using an atheoretical approach, but may have an important influence on behaviour (Dharni, 2011). The use of 
qualitative methods to gather and analyze the data offered a novel contribution to the TDF literature. The available literature using the TDF framework has primarily relied on the use of frequencies (counts of the individual domains) as the main method of data analysis to understand the saliency of each domain. However, within the current study the thematic analysis that was undertaken allowed for a rich and a more in depth exploration of each domain itself (through the use of inductive approach) and the domain's influence on PA. This is in-depth qualitative methodology is indeed one of the major strengths of the current study. Using a semi-structured interview guide to guide the individual interviews, can be considered to be an additional strength to this study given that the guide provided a natural interaction between the researcher and interviewee to obtain in-depth and general information on the key issues. It also gave the researcher an opportunity to explore areas beyond the interview guide and the 12 TDF domains if they arose.

Another study strength was the general description of PA provided to the youth (i.e., any activity that causes you to sweat and your heart to beat faster). This study was not only examining participation in sports, a sole focus in previous research, but also unstructured PA in daily life. Daily PA is an important factor for youth with SB to attain the recommended PA guidelines and gain health benefits, versus participation in sports alone. Additionally, PA in daily life is an important factor for reducing sedentary behaviour. Research has shown a positive relationship between sedentary behaviour and markers of adiposity in many studies of school-aged TD children, regardless of PA levels (Tremblay et al., 2011). Understanding the current PA trends in daily life within youth with SB will help to increase PA, as well as to reduce sedentary behaviour within this population

Finally, due to time and travel constraints, the majority of participants could not commute to Holland Bloorview Kid's Rehabilitation Hospital and therefore the majority of interviews were completed by telephone. Qualitative researchers generally rely on face-to-face interviewing; some may therefore argue that telephone interviews do not provide the same richness in data because researchers cannot see those very important non-verbal cues such as facial expressions and gestures (Novick, 2008). However, there may be advantages to conducting telephone interviews for this particular population. First, given the nature of the topic and sensitive issues regarding SB (i.e., bowel and bladder care) that may have been discussed, or topics that may be embarrassing (i.e., negative experiences with PA), respondents may have preferred the relative 
anonymity of the telephone, and therefore will be more open and honest in their responses which may increase data quality (Fenig and Levav, 1993). Secondly, telephone interviews may allow researchers to access hard-to-reach groups (i.e., those who do not live in the Greater Toronto Area), making it possible to obtain data from individuals who would not otherwise have their views represented (Miller, 1995). Researchers who have compared telephone interviewing with field (face-to-face) interviewing have generally concluded that telephone interviewing was an acceptable and valuable method of data collection (Sturges \& Hanrahan, 2004).

\subsection{Personal Reflections}

The qualitative study was a wonderful and challenging new experience for me. The TDF and the information gained from the interviewees were very informative in understanding the perspectives and experiences of youth with SB.

I have not changed my positionality through this research process. I examined the data through a relativist lens and I understood that realities exist in the form of multiple, intangible, mental constructions that are socially and experientially based, and dependent on their form and content of the individual holding the constructions. The experiences that youth described in relation to their PA are a very personal account of their experience and are context and situation specific. To interpret and understand the meaning of a youth's subjective experience of participating in PA, I positioned myself within a constructivist epistemological paradigm. This meant that it was understood that the participants and myself were linked, and therefore the findings that emerged are the creation of a process of interaction between the two (Guba and Lincoln, 2005). I found this to be most true with the experience using the TDF framework to guide the interviews. My interview guide was set up in a semi-structured fashion; the TDF domain in question drove each inquiry. Participants were asked questions relating to each domain, which elicited specific responses in relation to that domain, and therefore both myself and the participant were linked in the construction of this knowledge. If the guide was not driven by the TDF framework, but rather a different theoretical approach, the results may have been different.

Reflecting on the process of conducting interviews with the youth, I gained experience with each interview and each one generally went more smoothly as I went along. I also relaxed a little more with every interview as I gained more experience and got closer to completing data collection. 
The most demanding and time-consuming requirement was that of transcribing and analyzing the interviews. As I conducted more and more interviews and was able to reflect on what I had observed using my field notes, I became more and more confident in my interpretation of the events and behaviours as I understood them. Through the process of both collecting and analyzing data, I reflected on my own biases towards PA. Firstly, completing my master's degree in exercise science, I have spent the past three years exploring and understanding the benefits of PA for a variety of populations. Secondly, working as an aquatics instructor for a large majority of my adult life, I see the benefits swimming has on children and youth of all abilities. Additionally, throughout my own life I have had mostly positive experiences with PA and sport. My academic background, personal hobbies, and aquatics training have instilled notions of the benefits (both mental and physical) of PA. When conducting interviews, I consciously tried to maintain neutral reactions to either positive or negative experience youth might have had in their lifetimes. This allowed the participants to speak freely without feeling any judgment from my tone of voice. Additionally, if I found a participant to be reluctant in talking about negative experiences they may have had, I often relayed stories of negative experiences of other youth I had interacted with. While analyzing the data, I stuck closely to my reflexive journal, in order to distinguish between positive and negative factors that affected a youth's PA participation. Reflecting on a participant's tone of voice, the inflections, or even eye contact (for those who were interviewed in person) helped me to categorize each factor that was mentioned as positive or negative from their perspectives (even if mine differed).

Throughout the research process, I encountered many hills and valleys that have taught me a great deal about the scientific process of inquiry. I know now that understanding human behaviour is a complicated process and changing human behaviour is an even greater task. This process has left me with more questions than answers, and through the valleys, I never lost sight of my intentions when embarking on this project and making a contribution to our society in any small way that I can. 
Appendices

\title{
6.1 Appendix A
}

Examining youth's perceptions and experience with physical activity participation

\author{
Research Team: \\ Amy McPherson, Bloorview Research Institute (Principal Investigator) \\ Zlata Volfson, University of Toronto \\ Kelly Arbour-Nicitopoulos, University of Toronto
}

$<$ April 12, 2015>

Dear Parent/Guardian and Participant,

The research team of Amy Mcpherson, Zlata Volfson and Kelly Arbour-Nicitopoulos at Holland Bloorview Kids Rehabilitation Hospital are doing a research study called "Examining youth's perceptions and experience with physical activity participation" and are inviting you to participate. They are interested in learning about youth with spina bifida's perceptions and experience with physical activity participation. You have received this letter because you/your child is 12-17 years old and attending Spina Bifida clinic at Holland Bloorview.

If you have any questions or want to hear more about the study, you can contact the research team at 416-978-4795 or email Zlata Volfson at z.volfson@mail.utoronto.ca.

If you have questions about your rights as a research participant, please contact the Holland Bloorview Research Ethics Board Office at 416-425-6220 x3507.

Thank you for your time.

Yours truly,

Julia Lyons, RN 


\subsection{Appendix B}

- Examining youth's perceptions and experience with physical activity participation $<$ April 22, 2015>

\section{Dear Parent/Participant,}

My name is Zlata Volfson. I am a $2^{\text {nd }}$ year Masters Student from the Faculty of Kinesiology and Physical Education at the University of Toronto. I am working with Dr. Amy McPherson, a scientist from the Bloorview Research Institute and Dr. Kelly ArbourNicitopoulos, an Assistant Professor from the University of Toronto on a study that explores youth with spina bifida's perceptions and experience with physical activity participation. We would like to invite your child to take part in a research study to tell us about their thoughts and experiences with physical activity. Before agreeing to take part in this study, it is important that you understand how your child will be involved.

\section{What is the study about?}

Physical activity can be defined as any activity that makes one's heart beat fast and may make you sweat. Physical activity has been shown to provide a wide range of health benefits including lowering risk of cardiovascular diseases, diabetes, obesity and depression. But despite the known health benefits of physical activity, youth with Spina Bifida are at risk of an inactive lifestyle. Our research team is interested in exploring the reasons behind this inactivity and how we can better promote physical activity among youth with spina bifida.

In this study, 12 youth with spina bifida will be asked to participate in one face-to-face interview at the Holland Bloorview Rehabilitation Hospital, where they can talk about their perceptions and experiences with physical activity.

\section{How will my child and I be involved in this study?}

We want to invite you and your child to Holland Bloorview to meet with Ms. Volfson. Your child will be asked to participate in a one to one interview where they will be asked through a series of questions about their experiences with physical activity. Parents or guardians will be given the option to sit in on the interview.

This research session at Holland Bloorview will last 60 minutes.

\section{Will anyone know what I say?}

We will use a tape recorder to record what your child says during the meeting. We need to use the recording to review what your child did in more detail. Only researchers on the project will have access to the material recorded during this session. We will destroy the recording after all data has been analyzed. 
All the information we collect about your child/youth will be kept confidential. A unique identifier number will be assigned and pseudo ("fictitious") names will be used. We will not make public anything that might identify you, unless legally required to do so. This legal obligation includes a number of circumstances, such as suspected child abuse, where research documents are ordered to be produced by a court of law and where researchers are obliged to report to the appropriate authorities.

If the results of the study are published, your child's name will not be used and no information that discloses your child's identity will be released or published without your prior agreement. A summary report will be prepared for you once all the data are analyzed, this report will provide an overall summary of the findings and potential future research directions. This report will be e-mailed to you. We must keep the research data we collect for 7 years as required by Holland Bloorview.

\section{What are the risks and benefits?}

The harms and risks associated with this study are minimal, and are no greater than those your child may experience discussing sensitive topics on a daily basis. Participants may experience some emotional distress when discussing sensitive topics related to their daily lives, for example asking participants to recall a negative experience relating to physical activity participation.

You and your child may not directly benefit from this research. However, we think that you and your child will help to inform the development of future community-based programs for children and youth with physical disabilities.

You will not waive your legal rights in the event of research-related harm if you decide to take part in this study.

\section{Do I have to do this?}

You and your child do not need to do this study. It's okay if you decide not to take part. If you decide to take part, you can change your mind at any time. Whatever you decide will not affect the services you and your child get from Holland Bloorview.

If you DO NOT wish to participate in this study and do not wish to be contacted again about this study, please call the confidential study voice mail at 416-XXX- XXXX and leave a message with you name in order to opt out.

If we do not here from you within $\mathbf{1 0}$ days a study team member will contact you by phone to follow up and answer any questions. 


\section{What if I have questions?}

If you would like to learn more about this study or would like to talk to us directly please call the research team at 416-978-4795. If you leave a message, I will return your call within 48 hours.

We will pay your parking expenses so you can attend. Your child will receive a \$10 gift card as tokens of appreciation for participating in this study.

We will send you a letter at the end of the study to share what we learned.

If you have any questions about your rights as a research participant, please contact the Holland Bloorview Research Ethics Board at 416-425-6220 ext. 3507.

Thank you thinking about helping us with this project.

Yours truly,

Amy McPherson

Main Researcher,

Holland Bloorview Kids Rehabilitation Hospital

Phone: 416-425-6220 ext. 6378 


\section{CONSENT FORM \\ HOLLAND BLOORVIEW KIDS REHABILITATION HOSPITAL}

\section{Re: Physical Activity Participation Study}

Please complete this form below and return it to the researcher. You will receive a signed copy of this form.

$<$ Ms. Zlata Volfson > explained this study to me. I read the attached Information Letter dated and understand what this study is about.

I understand that my child or I may drop out of the study at any time.

I agree to participate in this study and allow my child to participate.

I agree to be audiotaped

Parent's Name (please print)

Signature

Date

I have explained this study to the above participant/parent and have answered all their questions.

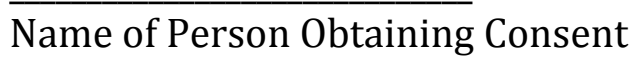

Signature

Date 


\title{
6.3 Appendix C
}

\section{Examining your thoughts and experiences with Physical Activity}

\begin{abstract}
Why did you want to talk with me?
I asked you to see me because I am inviting you to participate in a research study. I would like to meet with you to ask you some questions about your thoughts and experiences with physical activity. Physical activity is any activity that you do that makes makes your heart beat faster and you get out of breath or sweaty.
\end{abstract}

\section{What do I need to do?}

I was wondering whether you would like to tell me about what you know about physical activity, if you like or dislike participating in these activities and what you think about when you decide if you want to participate. Your parents will bring you to see me one time. I will ask you a few questions about the activities you do or do not participate in that make your heart beat faster and you get out of breath.

\section{What are the good and bad things about doing this?}

I don't think that there are any bad things about being involved. Some topics may be sensitive and might make you upset. If you don't want to talk about your experience that's okay. You don't need to do this. If you or your parents decide not to participate, I won't ask you again.

The good thing about this study is that you will help us to make a better recreation programs for youth with spina bifida.

\section{Will anyone know that I did this study?}

We won't share anything you said with anyone who is not part of this study. We will record our meeting but a false name will be used so no one will know you are talking. No one else will know it was you who said these things.

\section{Do I have to do this?}

If you do not want to talk about anything, that's okay. You can tell your parents or me that you don't want to take part in this study. That will be okay. This will not affect how I treat you the next time you see me. If you say yes now, you can change your mind later. You can still say no. That will be okay.

\section{What if I am not sure?}

Your parents know about this study. Ask them questions if you don't understand what this is about. You can also talk to me about the study before you decide whether or not you want to be involved.

Thanks for thinking about being a part of this study. 


\section{ASSENT FORM \\ HOLLAND BLOORVIEW KIDS REHABILITATION HOSPITAL \\ Examining your thoughts and experiences with Physical Activity}

I discussed this form with and $\mathrm{s} / \mathrm{he}$ agreed to participate and to be audiotaped.

Name of Person Who Obtained Assent

Signature

Date 


\section{CONSENT FORM}

\section{HOLLAND BLOORVIEW KIDS REHABILITATION HOSPITAL}

\section{Examining your experiences with Physical Activity}

Please complete this form below and return it to the researcher. You will receive a signed copy of this form.

$<$ Ms. Zlata Volfson > explained this study to me. I read the attached Information Letter dated and understand what this study is about.

I understand that I may drop out of the study at any time.

I agree to participate in this study.

I agree to be audiotaped.

Youth Name (please print)

Signature

Date

I have explained this study to the above participant and have answered all their questions.

Name of Person Obtaining Consent

Signature

Date 


\subsection{Appendix D}

Introduction: I am going to be asking you some questions today to help us understand some of the reasons behind why youth with spina bifida participate or do not participate in PA.

For the purpose of this interview, physical activity will be defined as "any activity that makes your heart beat faster and you get out of breath or sweaty."

We want to know what influences you when you are thinking about or participating in physical activity. There are no right or wrong answers here; we are trying to understand how youth with spina bifida think about and participate in physical activity, so please answer as best as you can.

You don't have to answer any question you don't want to just say "skip" if you would like to move on to the next question.

Are you ready to get started?

Great! Now first can you tell me a little bit about yourself

(interviewer to administer the Participant Profile questionnaire)

\begin{tabular}{|l|l|}
\hline (1) Knowledge & $\begin{array}{c}\text { What do you know about physical activity? } \\
\text { - Alternative: What are your thoughts about physical } \\
\text { activity? (prompt: easy, challenging, good, bad) }\end{array}$ \\
What have you been told about PA? \\
$\begin{array}{c}\text { How much PA do you think you should you be doing every day? } \\
\text { Could you perhaps tell me how often you think you should be } \\
\text { active for? }\end{array}$ \\
$\begin{array}{c}\text { (12) Nature of the } \\
\text { behaviours }\end{array}$ \\
$\begin{array}{c}\text { What do you currently do in your spare time? } \\
\text { when your not in school; what do you spend you time doing. } \\
\text { O Houkes your heart beat faster and you get out of breath or sweaty." } \\
\text { - Alternative: Do you do any activities that make you out } \\
\text { of breath and sweaty? (i.e. physical activities) }\end{array}$ \\
- Prompt: type \\
Participants:
\end{tabular}




\begin{tabular}{|c|c|}
\hline & $\begin{array}{l}\text { - How long do you usually do your activities for? } \\
\text { - What type of physical activities do you take part in? } \\
\text { - Give examples if they are stuck e.g. pushing themselves } \\
\text { fast wheelchair basketball } \\
\text { - How often do you do those activities? } \\
\text { - On a scale of 1-10, how much effort do the activities require... } \\
\text { At what intensity would you say you typically take part in these } \\
\text { physical activities? } \\
\text { low intensity - physical activities that require minimal } \\
\text { effort. Like light walking. That would be a } 1 \text { or a } 2 \text { out of } \\
10 \text { (and so on...). } \\
\text { Moderate-intensity - physical activities that cause you } \\
\text { to sweat a little and to breathe harder. Like skating and } \\
\text { bike riding } \\
\text { Vigorous-intensity - physical activities that cause you to } \\
\text { sweat and be 'out of breath. Like running, heavy wheeling, } \\
\text { rollerblading. } \\
\text { Non-Participants: } \\
\text { If you could do anything you wanted to what physical } \\
\text { activities would you want to do. }\end{array}$ \\
\hline (2) Skills (Skills) - & $\begin{array}{l}\text { What types of skills do you think you need to have to participate in } \\
\text { PA? } \\
\text { - E.g., Throwing, kicking, FMS } \\
\text { - What do you need to be able to do to participate in PA } \\
\text { Why do you think you need these skills? }\end{array}$ \\
\hline $\begin{array}{l}\text { (5) Beliefs about } \\
\text { consequences } \\
\text { (Anticipated } \\
\text { outcomes/attitude) }\end{array}$ & $\begin{array}{l}\text { What do you think are some of the good things about taking part in } \\
\text { physical activity? What might some bad things be? Can you think of a } \\
\text { situation where that has happened to you? Explain this situation } \\
\text { What do you like about PA/ dislike PA } \\
\text { What do you think might happen if you chose not to take part in PA? } \\
\text { Can you think of a time that has happened to you? } \\
\text { Do you think you can personally benefit from being physically } \\
\text { active? How so? } \\
\text { how do you benefit from being physically active what do you gain } \\
\text { Why don't you take part in PA }\end{array}$ \\
\hline $\begin{array}{l}\text { (6) Motivation and } \\
\text { goals (Intention) }\end{array}$ & $\begin{array}{l}\text { What makes you want to take part in physical activity? } \\
\text { - How will you achieve that (i.e getting at goals) } \\
\text { What makes you not want to take part in Physical activity? } \\
\text { What motivates you to be PA } \\
\text { Think about how else you can ask about incentives/rewards. }\end{array}$ \\
\hline
\end{tabular}




\begin{tabular}{|c|c|}
\hline & $\begin{array}{l}\text { - Are there any incentives or rewards that make you want to } \\
\text { participate or increase your participation in PA? Explain. } \\
\text { How committed are you to remain physically active (become } \\
\text { physically active [for non-active participants])? (On a scale of } 1 \\
\text { [not at all committed] to } 10 \text { [completely committed]). } \\
\text { Tell me about your plans to participate in PA in the future. } \\
\text { - Do you have any PA goals you want to achieve? What are } \\
\text { these goals? }\end{array}$ \\
\hline $\begin{array}{l}\text { (11) Behavioural } \\
\text { regulation }\end{array}$ & $\begin{array}{l}\text { How do you get ready to take part in PA (i.e plan to get there, find a } \\
\text { ride, tell mom and dad, find friends to go on a run/wheel with etc..)? } \\
\text { NOTE: earlier you told me you like to go swimming.. what are some } \\
\text { steps that you need to do } \\
\text { Prompt: others/ personal } \\
\text { Can you think of any strategies that you use to help you to participate } \\
\text { in PA? If so, can you describe these strategies to me? } \\
\text { - I.e. Do you write things down when your going to be active? } \\
\text { Do you keep track of what you are going to do? } \\
\text { Non-Participants: } \\
\text { - If you wanted to start doing PA/increasing your PA, describe how } \\
\text { you would go about doing this. }\end{array}$ \\
\hline $\begin{array}{l}\text { (7) Memory, attention } \\
\text { and decision processes }\end{array}$ & $\begin{array}{l}\text { What do you think about when deciding if you are going to participate } \\
\text { in PA? } \\
\text { - Do you find it easy or difficult to make the decision to be } \\
\text { physically active or participate in PA? Why or why not? } \\
\text { Earlier you said you liked to do X in your spare time... would you } \\
\text { rather do this activity than participate in PA. Why? (i.e competing } \\
\text { tasks) } \\
\text { Active Participants Only: } \\
\text { You mentioned you do PA X many times a week... are there any } \\
\text { things you do to remember to do those activities? }\end{array}$ \\
\hline $\begin{array}{l}\text { (9) Social influences } \\
\text { (Norms) }\end{array}$ & $\begin{array}{l}\text { Do your friends do any physical activity? } \\
\text { - What do they do? } \\
\text { - How often do they do this activity? } \\
\text { - Do you want to participate with them? Why or why not? } \\
\text { - Do they make it easy or hard for you to take part in PA? }\end{array}$ \\
\hline
\end{tabular}




\begin{tabular}{|c|c|}
\hline & $\begin{array}{l}\text { Why/why not? } \\
\text { What about your family? } \\
\qquad \text { What do they do? } \\
\text { - How often? } \\
\text { - Do you want to participate with them? Why or why not } \\
\text { Why/why not? } \\
\text { Is there anyone else that makes you want to (or not) participate in PA? } \\
\text { If so, whom? } \\
\text { Are there any times that someone has made you feel like you take part in PA? } \\
\text { shouldn't be physically active? Can you describe this experience for } \\
\text { me? }\end{array}$ \\
\hline $\begin{array}{l}\text { (10) Emotion } \\
\text { (Emotion) }\end{array}$ & $\begin{array}{l}\text { How do you feel when you take part in PA? } \\
\quad \text { - If they give emotion... eg: Happy } \\
\text { - Prompt: negative/positive } \\
\text { How do you feel during activity X } \\
\text { How do you feel after you do activity X } \\
\text { How do you feel when you've missed a session of X } \\
\text { Do any of these feelings affect whether you take part in PA? } \\
\text { How? Explain? }\end{array}$ \\
\hline $\begin{array}{l}\text { (8) Environmental } \\
\text { context and resources } \\
\text { (Environmental } \\
\text { constraints) }\end{array}$ & $\begin{array}{l}\text { Thinking about where you live lets talk about all those places where } \\
\text { you could be PA } \\
\text { - } \text { sidewalks/crosswalk/parks/rec centres } \\
\text { - built env. } \\
\text { How easy is it for you to access places where PA takes place? } \\
\text { - Explore whatever they say (i.e. if it's easy or hard) } \\
\text { Are there people who are available that can help/teach you X } \\
\text { Is there anything in your environment that has helped you or made it } \\
\text { difficult for you to participate in PA? } \\
\text { - What/Who has helped/would help you overcome these } \\
\text { difficulties? }\end{array}$ \\
\hline & What resources do you think are important for you to have available \\
\hline
\end{tabular}




\begin{tabular}{|l|l|}
\hline & $\begin{array}{l}\text { in order to be physically active? Maybe provide them with some } \\
\text { examples (e.g., accessible facilities, coaches, etc.) }\end{array}$ \\
& $\begin{array}{l}\text { Are there resources you wish you had access to? Please describe these } \\
\text { to me. } \\
\text { - What else do you wish was close by for being physically active }\end{array}$ \\
\hline $\begin{array}{l}\text { (4) Beliefs about } \\
\text { capabilities (Self- } \\
\text { efficacy) }\end{array}$ & $\begin{array}{c}\text { How easy or difficult is it for you to participate in PA? } \\
\text { Follow up... Why X and not Y }\end{array}$ \\
$\begin{array}{l}\text { Please tell me about anything that has made your participation in PA } \\
\text { easy or helped you participate in PA? } \\
\text { What are some things that make it difficult for you to take part in PA? } \\
\text { Alterative: Have you had any problems when participating in } \\
\text { PA? } \\
\text { - Earlier you mentioned X as a barrier... }\end{array}$ \\
$\begin{array}{l}\text { Have you used any strategies to help you overcome any of these } \\
\text { barriers? If so, can you describe to me these strategies? }\end{array}$ \\
\hline
\end{tabular}

(3) Social/professional role and identity (Selfstandards)
How important do you think it is to take part in PA? For you? For other people? For other people with spina bifida?

- Why/why not?

- Is it important for YOU to take part in physical activity? Why/why not?

- Prompt: for gender and age group

- For different mobility level, and type of SB

Do you think physical activity plays an important role in your daily life? If so then can you describe the role it plays? 


\subsection{Appendix E}

\section{Participant Profile Questionnaire}

This questionnaire will be administered orally by the interviewer

\section{PART A: Please tell us about yourself:}

1. Please indicate your sex?

$\square$ Male

$\square$ Female

2. Please indicate your age?:

3. What is your primary ethnic background?

$\square$ Chinese

$\square$ Latin American

$\square$ White

$\square$ Arabic

$\square$ Black or African American $\square$ South Asian (e.g., Indian, Pakistani, Sri Lanka)

$\square$ West Asian (e.g., Afghan, Iranian)

$\square$ Southeast Asian (e.g., Cambodian, Indonesian, Laotian, Vietnamese)

$\square$ Other:

$\square$ Prefer not to answer

4. What type of Spina Bifida do you have?

$\square \quad$ Myelomeningocele

$\square \quad$ Lipomeningocele

$\square \quad$ Other

5. Has your doctor ever told you have hydrocephalus? __ Yes ___ No

6. Do you use a mobility Aid? __ Yes __ No

7. Which of the following mobility aids or devices do you typically use (check all that apply)?

$\square$ Cane
$\square$ Walker
$\square$ Braces
$\square$ Wheelchair - $\square$ Manual OR $\square$ Electric
$\square$ Scooter
$\square$ Other




\subsection{Appendix F}

\section{Example of Mapping Behaviour Change Techniques}

\begin{tabular}{|c|c|c|c|}
\hline TDF domain & $\begin{array}{l}\text { Examples of barriers or } \\
\text { facilitators }\end{array}$ & $\begin{array}{l}\text { Possible Theory } \\
\text { That aligns with that TDF }\end{array}$ & $\begin{array}{l}\text { Techniques judged to be effective } \\
\text { in changing the domain } \\
\text { (Michie, 2008) }\end{array}$ \\
\hline Beliefs about consequences & $\begin{array}{l}\text { Beliefs about perceived } \\
\text { pain or fatigue }\end{array}$ & Theory of planned behaviour & $\begin{array}{l}\text { - Self-monitoring; Information } \\
\text { regarding behaviour, outcome; } \\
\text { - Persuasive communication; } \\
\text { - Feedback }\end{array}$ \\
\hline Beliefs about capabilities & $\begin{array}{l}\text { Self-efficacy towards PA } \\
\text { activity }\end{array}$ & Social cognitive theory & $\begin{array}{l}\text { - Graded tasks; } \\
\text { - Increasing skills: problem solving, } \\
\text { decision making, goal setting; } \\
\text { - Social process; } \\
\text { - Feedback; } \\
\text { - Self talk; } \\
\text { - Motivational interviewing }\end{array}$ \\
\hline Knowledge & $\begin{array}{l}\text { Little knowledge } \\
\text { regarding physical activity } \\
\text { guidelines, as well as } \\
\text { community programs that } \\
\text { exist. }\end{array}$ & & $\begin{array}{l}\text { Information regarding behaviour } \\
\text { outcome }\end{array}$ \\
\hline
\end{tabular}




\section{References}

Abresch, R. T., McDonald, D. A., Widman, L. M., McGinnis, K., \& Hickey, K. J. (2007). Impact of spinal cord dysfunction and obesity on the health-related quality of life of children and adolescents. The journal of spinal cord medicine,30.(Suppl 1), S112.

Ajzen, I. (1991). The theory of planned behavior. Organizational behavior and human decision processes, 50(2), 179-211.

Allison, K. R., Adlaf, E. M., Dwyer, J. J., Lysy, D. C., \& Irving, H. M. (2007). The decline in physical activity among adolescent students: a cross-national comparison. Canadian Journal of Public Health/Revue Canadienne de Sante'e Publique, 97-100.

Allender, S., Cowburn, G., \& Foster, C. (2006). Understanding participation in sport and physical activity among children and adults: a review of qualitative studies. Health education research, 21(6), 826-835.

Alvord, M. K., \& Grados, J. J. (2005). Enhancing Resilience in Children: A Proactive Approach. Professional psychology: research and practice, 36(3), 238.

Bandura, A. (1989). Human agency in social cognitive theory. American psychologist, 44(9), 1175.

Bandura A. Health promotion by social cognitive means. Health Educ Behav. 2004;31(2):143164.

Barf, H. A., Verhoef, M., Jennekens-Schinkel, A., Post, M. W. M., Gooskens, R. H. J. M., \& Prevo, A. J. H. (2003). Cognitive status of young adults with spina bifida. Developmental Medicine \& Child Neurology, 45(12), 813-820.

Bauman, A. E., Reis, R. S., Sallis, J. F., Wells, J. C., Loos, R. J., Martin, B. W., \& Lancet Physical Activity Series Working Group. (2012). Correlates of physical activity: why are some people physically active and others not?. The lancet, 380(9838), 258-271.

Bellin, M. H., Zabel, T. A., Dicianno, B. E., Levey, E., Garver, K., Linroth, R., \& Braun, P. (2010). Correlates of depressive and anxiety symptoms in young adults with spina bifida. Journal of pediatric psychology. 35(7), 778-789.

Biddle S, Whitehead S, O'Donovan T, Nevill M. (2005). Correlates of participation in physical activity for adolescent girls: a systematic review of recent literature. Journal of Physical Activity and Health. 2(4), 423-424.

Bloemen, M. A., Backx, F. J., Takken, T., Wittink, H., Benner, J., Mollema, J., \& Groot, J. F. (2015). Factors associated with physical activity in children and adolescents with a physical disability: a systematic review. Developmental Medicine \& Child Neurology, 57(2), 137-148.

Boot, C. R. L., van Langen, H., \& Hopman, M. T. E. (2003). Arterial vascular properties in individuals with spina bifida. Spinal cord, 41(4), 242-246.

Botto, L. D., Moore, C. A., Khoury, M. J., \& Erickson, J. D. (1999). Neural-tube defects. New England Journal of Medicine, 341(20), 1509-1519.

Boulet, S. L., Gambrell, D., Shin, M., Honein, M. A., \& Mathews, T. J. (2009). Racial/ethnic differences in the birth prevalence of spina bifida-United States, 1995-2005. Morbidity and Mortality weekly report, 57(53), 1409-1413.

Bowman, R. M., McLone, D. G., Grant, J. A., Tomita, T., \& Ito, J. A. (2001). Spina bifida outcome: a 25-year prospective. Pediatric neurosurgery, 34(3), 114-120.

Braun, V., \& Clarke, V. (2006). Using thematic analysis in psychology. Qualitative Research in Psychology, 3, 77-101. 
Brooks, R., \& Goldstein, S. (2001). Raising Resilient Children: Fostering Strength, Hope, and Optimism in Your Child. Contemporary Books, 4255 West Touhy Avenue, Lincolnwood, IL $60712-1975$.

Brunton, L. K., \& Bartlett, D. J. (2010). Description of exercise participation of adolescents with cerebral palsy across a 4-year period. Pediatric Physical Therapy, 22(2), 180-187.

Buffart, L. M., Berg-Emons, R. J. V. D., Meeteren, J. V., Stam, H. J., \& Roebroeck, M. E. (2009). Lifestyle, participation, and health-related quality of life in adolescents and young adults with myelomeningocele. Developmental Medicine \& Child Neurology, 51(11), 886-894.

Buffart, L. M., van der Ploeg, H. P., Bauman, A. E., Van Asbeck, F. W., Stam, H. J., Roebroeck, M. E., \& van den Berg-Emons, R. J. (2008). Sports participation in adolescents and young adults with myelomeningocele and its role in total physical activity behaviour and fitness. Journal of Rehabilitation Medicine, 40(9), 702-708.

Buran, C. F., Sawin, K. J., Brei, T. J., \& Fastenau, P. S. (2004). Adolescents with myelomeningocele: activities, beliefs, expectations, and perceptions.Developmental Medicine \& Child Neurology, 46(4), 244-252.

Canadian Society for Exercise Physiology (CSEP). (2011). Canadian Phsyical Activity Guidelines for Youth (12- 17 years).

Canadian Sport for Life. (2016). Active for Life: Durable by Design

Cavet, J., \& Sloper, P. (2004). Participation of disabled children in individual decisions about their lives and in public decisions about service development. Children \& Society, 18(4), 278-290.

Cavanagh, S. (1997). Content analysis: concepts, methods and applications.Nurse researcher, 4(3), 5-13.

Charmaz, K. (2004). Premises, principles and practices in qualitative research: Revisiting the foundations. Qualitative Health Research, 14, 976-993.

Cohen, J. (1992). Statistical power analysis. Current directions in psychological science, 1(3), 98-101.

Clancy, C. A., McGrath, P. J., \& Oddson, B. E. (2005). Pain in children and adolescents with spina bifida. Developmental Medicine \& Child Neurology,47(1), 27-34.

Cragg, J. J., Noonan, V. K., Krassioukov, A., \& Borisoff, J. (2013). Cardiovascular disease and spinal cord injury Results from a national population health survey. Neurology, 81(8), 723-728.

Craggs, C., Corder, K., van Sluijs, E. M., \& Griffin, S. J. (2011). Determinants of change in physical activity in children and adolescents: a systematic review. American journal of preventive medicine, 40(6), 645-658.

Craig, P., Dieppe, P., Macintyre, S., Michie, S., Nazareth, I., \& Petticrew, M. (2008). Developing and evaluating complex interventions: the new Medical Research Council guidance. $B m j, 337$, a1655.

Crytzer, T. M., Dicianno, B. E., \& Kapoor, R. (2013). Physical Activity, Exercise, and Healthrelated Measures of Fitness in Adults With Spina Bifida: A Review of the Literature. $P M \& R, 5(12), 1051-1062$.

De Vivo, M. J., Stuart Krause, J., \& Lammertse, D. P. (1999). Recent trends in mortality and causes of death among persons with spinal cord injury. Archives of physical medicine and rehabilitation, 80(11), 1411-1419. 
De Wals, P., Tairou, F., Van Allen, M. I., Uh, S. H., Lowry, R. B., Sibbald, B., \& Niyonsenga, T. (2007). Reduction in neural-tube defects after folic acid fortification in Canada. New England Journal of Medicine, 357(2), 135-142.

De Wals, P., Van Allen, M. I., Lowry, R. B., Evans, J. A., Van den Hof, M. C., Crowley, M., \& Niyonsenga, T. (2008). Impact of folic acid food fortification on the birth prevalence of lipomyelomeningocele in Canada. Birth Defects Research Part A: Clinical and Molecular Teratology, 82(2), 106-109.

Dharni, N. 2011, "Division of Health Psychology annual Conference 2011", Recent developments in applying the theoretical domains Framework to understanding behaviour change, ed. N. Dharni, The british Psychological Society, Southampton, 14-16 Sep 2011.

DiClemente, C. C., \& Prochaska, J. O. (1998). Toward a comprehensive, transtheoretical model of change: Stages of change and addictive behaviors.

Dosa, N. P., Foley, J. T., Eckrich, M., Woodall-Ruff, D., \& Liptak, G. S. (2009). Obesity across the lifespan among persons with spina bifida. Disability and rehabilitation, 31(11), 914920.

Duffy, C. M., Hill, A. E., Cosgrove, A. P., Carry, I. S., \& Graham, H. K. (1996). Energy consumption in children with spina bifida and cerebral palsy: a comparative study. Developmental Medicine \& Child Neurology, 38(3), 238-243.

Durstine JL, Painter P, Franklin BA, Morgan D, Pitetti KH, Roberts SO. Physical activity for the chronically ill and disabled.Sports Med.2000;30 (3), 207-219.

Dykens, E. M., Rosner, B. A., \& Butterbaugh, G. (1998). Exercise and sports in children and adolescents with developmental disabilities. Positive physical and psychosocial effects. Child and Adolescent Psychiatric Clinics of North America,7(4), 757-71.

Dyson, J., Lawton, R., Jackson, C., \& Cheater, F. (2010). Does the use of a theoretical approach tell us more about hand hygiene behaviour? The barriers and levers to hand hygiene. Journal of Infection Prevention, 10.1177/1757177410384300

Ekkekakis, P., Parfitt, G., \& Petruzzello, S. J. (2011). The pleasure and displeasure people feel when they exercise at different intensities. Sports Medicine, 41(8), 641-671.

Ekkekakis, P., \& Petruzzello, S. J. (1999). Acute aerobic exercise and affect.Sports Medicine, 28(5), 337-347.

Esterberg, K. G. (2002). Qualitative methods in social research. Boston, MA: McGraw Hill.

Equit, M., Hill, J., Hübner, A., \& Von Gontard, A. (2014). Health-related quality of life and treatment effects on children with functional incontinence, and their parents. Journal of pediatric urology, 10(5), 922-928.

Farry, A., \& Baxter, D. (2010). The incidence and prevalence of spinal cord injury in Canada: overview and estimates based on current evidence. Rick Hansen Institute.

Fein, A. J., Plotnikoff, R. C., Wild, T. C., \& Spence, J. C. (2005). An examination of adolescents' perceptions of the school physical environment related to physical activity. International Journal of Sport and Exercise Psychology, 3(2), 179-195.

Fenig, S., Levav, I., Kohn, R., \& Yelin, N. (1993). Telephone vs face-to-face interviewing in a community psychiatric survey. American Journal of Public Health, 83(6), 896-898.

Field, S. J., \& Oates, R. K. (2001). Sport and recreation activities and opportunities for children with spina bifida and cystic fibrosis. Journal of Science and Medicine in Sport, 4(1), 7176. 
Finlay, L. (2002). "Outing” the researcher: The provenance, process, and practice of reflexivity. Qualitative health research, 12(4), 531-545.

France, A., Bendelow, G. Williams, S. (2000) “A 'risky'business': researching the health beliefs of children and young people" in eds. Ann Lewis and Geoff Lindsay, Researching Children's Perspectives, pp. 150-161, Buckingham: Open University Press.

Francis, J. J., O'Connor, D., \& Curran, J. (2012). Theories of behaviour change synthesized into a set of theoretical groupings: introducing a thematic series on the theoretical domains framework. Implement Sci, 7(1), 35.

Francis, J. J., Stockton, C., Eccles, M. P., Johnston, M., Cuthbertson, B. H., Grimshaw, J. M., ... \& Stanworth, S. J. (2009). Evidence-based selection of theories for designing behaviour change interventions: Using methods based on theoretical construct domains to understand clinicians' blood transfusion behaviour. British Journal of Health Psychology, 14(4), 625-646.

French, S. D., Green, S. E., O’Connor, D. A., McKenzie, J. E., Francis, J. J., Michie, S., ... \& Grimshaw, J. M. (2012). Developing theory-informed behaviour change interventions to implement evidence into practice: a systematic approach using the Theoretical Domains Framework.Implementation Science, 7(1), 38.

French, D., \& Hainsworth, J. (2001)., There aren't any buses and the swimming pool is always

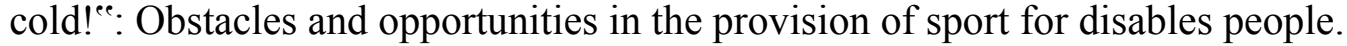
Managing Leisure, 6, 35-49.

Fowler, E. G., Kolobe, T. H. A., Damiano, D. L., Thorpe, D. E., Morgan, D. W., Brunstrom, J. E.,...Stevenson, R. D. (2007). Promotion of physical fitness and prevention of secondary conditions for children with cerebral palsy: Section on pediatrics research summit proceedings. Physical Therapy, 87, 1495-1510.

Garth, B., \& Aroni, R. (2003). 'I value what you have to say'. Seeking the perspective of children with a disability, not just their parents. Disability \& Society, 18(5), 561-576.

Giblin, S., Collins, D., \& Button, C. (2014). Physical literacy: importance, assessment and future directions. Sports Medicine, 44(9), 1177-1184.

Goodwin, D.L. \& Compton, S.G.(2004). Physical activity experiences of women aging with disability. Adapted Physical Activity Quarterly, 21, 122-138.

Gordon-Larsen, P., McMurray, R. G., \& Popkin, B. M. (2000). Determinants of adolescent physical activity and inactivity patterns. Pediatrics, 105(6), 1-8.

Griffiths, L. J., Cortina-Borja, M., Sera, F., Pouliou, T., Geraci, M., Rich, C., et al. (2013). How active are our children? Findings from the Millennium Cohort Study. Br. Med. J. Open 3:e002893. doi: 10.1136/bmjopen-2013-002893

Guba, E. G., \& Lincoln, Y. S. (2005). Paradigmatic controversies, contradictions, and emerging confluences. In N. K. Denzin \& Y. S. Lincoln (Ed.), The Sage Handbook of Qualitative Research ( $3^{\text {rd }}$ Ed.) (pp. 191-215). Thousand Oaks, CA: Sage.

Hagger, M. S., Chatzisarantis, N. L. D., \& Biddle, S. J. H. (2002). A meta-analytic review of the theories of reasoned action and planned behavior in physical activity: Predictive validity and the contribution of additional variables. Journal of Sport and Exercise Psychology, 24, 3-32.

Health Canada. Congenital Anomalies in Canada - A Perinatal Health Report, 2002. Ottawa: Minister of Public Works and Government Services Canada, 2002.

Helms, C., Leask, J., Robbins, S. C., Chow, M. Y. K., \& McIntyre, P. (2011). Implementation of 
mandatory immunisation of healthcare workers: observations from New South Wales, Australia. Vaccine, 29(16), 2895-2901.

Hetrick, S., Álvarez-Jiménez, M., Parker, A., Hughes, F., Willet, M., Morley, K., ... \&

Thompson, A. (2010). Promoting physical health in youth mental health services: ensuring routine monitoring of weight and metabolic indices in a first episode psychosis clinic. Australasian Psychiatry, 18(5), 451-455.

Hesse-Biber, S. N., \& Leavy, P. (2004). Distinguishing qualitative research. Approaches to Qualitative Research, 1-15.

Higgs, C., Balyi, I., Bluechard, M., Cardinal, C., Norris, S., \& Way, R. (2005). Developing Physical Literacy. Canadian Sport Centre Pacific, Vancouver.

Hoffer MM, Feiwell E, Perry R, Perry J, Bonnett C. (1973). Functional ambulation in patients with myelomeningocele. J Bone Joint Surg Am, 55(1),137-48.

Horst K, Paw MJ, Twisk JW, van Mechelen W. A brief review on correlates of physical activity and sedentariness in youth. Med Sci Sports Exerc. 2007;39(8):1241-1250.

Hunt, G. M., \& Poulton, A. (1995). Open spina bifida: a complete cohort reviewed 25 years after closure. Developmental Medicine \& Child Neurology,37(1), 19-29.

Hutzler, Y., Fliess, O., Chacham, A., \& Van den Auweele, Y. (2002). Perspectives of children with physical disabilities on inclusion and empowerment: Supporting and limiting factors. Adapted Physical Activity Quarterly, 19(3), 300-317.

Isomaa, B. O., Almgren, P., Tuomi, T., Forsén, B., Lahti, K., Nissen, M., ... \& Groop, L. (2001). Cardiovascular morbidity and mortality associated with the metabolic syndrome. Diabetes care, 24(4), 683-689.

Jackson, S.A \& Csikszentmihalyi (1999). Flow in Sports: The key to optimal experiences and performances. Illinois: Human Kinetics.

Janssen, I., \& LeBlanc, A. G. (2010). Review Systematic review of the health benefits of physical activity and fitness in school-aged children and youth.International Journal of Behavioral Nutrition and Physical Activity, 7(40), 1-16

Janssen, T. W., Van Oers, C. A. J. M., van Kamp, G. J., Ten Voorde, B. J., van der Woude, L. H., \& Peter Hollander, A. (1997). Coronary heart disease risk indicators, aerobic power, and physical activity in men with spinal cord injuries.Archives of physical medicine and rehabilitation, 78(7), 697-705.

Kaczynski AT, Robertson-Wilson J, Decloe M. Interaction of perceived neighborhood walkability and self-efficacy on physical activity. $J$ Phys Act Health. 2012;9(2):208-217.

King, G., Law, M., Hurley, P., Petrenchik, T., \& Schwellnus, H. (2010). A developmental comparison of the out-of-school recreation and leisure activity participation of boys and girls with and without physical disabilities. International Journal of Disability, Development \& Education, 57, 77-107.

King, G., Lawm, M., King, S., Rosenbaum, P., Kertoy, M. K., \& Young, N. L. (2003). A conceptual model of the factors affecting the recreation and leisure participation of children with disabilities. Physical \& occupational therapy in pediatrics, 23(1), 63-90.

Kirchner, C. E., Gerber, E. G., \& Smith, B. C. (2008). Designed to deter: Community barriers to physical activity for people with visual or motor impairments. American Journal of Preventive Medicine, 34, 349-352. doi:10.1016/j.amepre. 2008.01.005

Kondracki, N. L., Wellman, N. S., \& Amundson, D. R. (2002). Content analysis: review of methods and their applications in nutrition education.Journal of nutrition education and behavior, 34(4), 224-230. 
Law, M., Haight, M., Milroy, B., Williams, D., Stewart, D., \& Rosenbaum, P. (1999). Environmental factors affecting the occupations of children with physical disabilities. Journal of Occupational Science, 6, 102-111.

Law, M., Petrenchik, T., King, G., \& Hurley, P. (2007). Perceived environmental barriers to recreational, community, and school participation for children and youth with physical disabilities. Archives of Physical Medicine and Rehabilitation, 88, 1636- 1642.

Lidal, I. B., Snekkevik, H., Aamodt, G., Hjeltnes, N., Stanghelle, J. K., \& Biering-Sørensen, F. (2007). Mortality after spinal cord injury in Norway. Journal of Rehabilitation Medicine, 39(2), 145-151.

Lincoln, Y. S., \& Guba, E. G. (1985). Naturalistic Inquiry. Newbury Park, CA: Sage.

Lindquist, C. H., Reynolds, K. D., \& Goran, M. I. (1999). Sociocultural determinants of physical activity among children. Preventive Medicine, 29, 305-312.

Lutkenhoff, M. (Ed.). (2008). Children with Spina Bifida: A parents' guide. Woodbine House.

Mackey, M. C. (2012). Evaluation of Qualitative Research. In P. Munhall (Eds.), Nursing Research: A qualitative perspective $\left(5^{\text {th }}\right.$ Ed.) (pp. 517-531). Toronto: Jones and Bartlett.

MacNamara, Á., Collins, D., \& Giblin, S. (2015). Just let them play? Deliberate preparation as the most appropriate foundation for lifelong physical activity. Frontiers in psychology, 6 .

McPherson, A. C., Swift, J. A., Yung, E., Lyons, J., \& Church, P. (2013). The assessment of weight status in children and young people attending a spina bifida outpatient clinic: a retrospective medical record review. Disability \& Rehabilitation, 35(25), 2123-2131.

Maher, C. A., Williams, M. T., Olds, T., \& Lane, A. E. (2007). Physical and sedentary activity in adolescents with cerebral palsy. Developmental Medicine \& Child Neurology, 49(6), 450457.

Marques, A., Maldonado, I., Peralta, M., \& Santos, S. (2014). Exploring psychosocial correlates of physical activity among children and adolescents with spina bifida. Disability and health journal.

Meland, E., Haugland, S., \& Breidablik, H. J. (2007). Body image and perceived health in adolescence. Health Education Research, 22(3), 342-350.

Michie, S., Johnston, M., Abraham, C., Lawton, R., Parker, D., \& Walker, A. (2005). Making psychological theory useful for implementing evidence based practice: a consensus approach. Quality and safety in health care, 14(1), 26-33.

Michie, S., Johnston, M., Francis, J., Hardeman, W., \& Eccles, M. (2008). From theory to intervention: mapping theoretically derived behavioural determinants to behaviour change techniques. Applied psychology, 57(4), 660-680.

Michie, S., van Stralen, M. M., \& West, R. (2011). The behaviour change wheel: a new method for characterising and designing behaviour change interventions. Implementation Science, 6(1), 42.

Miller, C. (1995) 'In-depth Interviewing by Telephone: Some Practical Considerations', Evaluation and Research in Education 9(1), 29-38

Morrow, V., \& Richards, M. (1996). The ethics of social research with children: An overview1. Children \& society, 10(2), 90-105.

Murphy, N. A., \& Carbone, P. S. (2008). Promoting the participation of children with disabilities in sports, recreation, and physical activities.Pediatrics, 121(5), 1057-1061.

Nelson, M. D., Widman, L. M., Abresch, R. T., Stanhope, K., Havel, P. J., Styne, D. M., \& McDonald, C. M. (2007). Metabolic syndrome in adolescents with spinal cord dysfunction. The journal of spinal cord medicine, 30(Suppl 1), S127. 
Noar, S. M., Benac, C. N., \& Harris, M. S. (2007). Does tailoring matter? Meta-analytic review of tailored print health behavior change interventions.Psychological bulletin, 133(4), 673.

Novick, G. (2008). Is there a bias against telephone interviews in qualitative research?. Research in nursing \& health, 31(4), 391-398.

Oakeshott, P., \& Hunt, G. M. (2003). Long-term outcome in open spina bifida.British Journal of General Practice, 53(493), 632-636.

Oliveira, A., Jácome, C., \& Marques, A. (2014). Physical fitness and exercise training on individuals with Spina Bifida: A systematic review. Research in developmental disabilities, 35(5), 1119-1136.

Paffenbarger, R.S., Hyde, R.T., Wing, A.L., \&Hsieh, C. (1986). Physical activity, all- cause mortality and longevity of college alumni. New England Journal of Medicine, 314(10), 605-613.

Paluska, S. A., \& Schwenk, T. L. (2000). Physical activity and mental health.Sports medicine, 29(3), 167-180.

Patel, D. R., \& Greydanus, D. E. (2002). The pediatric athlete with disabilities.Pediatric Clinics of North America, 49(4), 803-827.

Patey, A. M., Islam, R., Francis, J. J., Bryson, G. L., \& Grimshaw, J. M. (2012). Anesthesiologists' and surgeons' perceptions about routine pre-operative testing in lowrisk patients: application of the Theoretical Domains Framework (TDF) to identify factors that influence physicians' decisions to order pre-operative tests. Implement Sci, $7(1), 52$.

Patton, M. Q. (2002). Qualitative evaluation and research methods ( $3^{\text {rd }}$ ed.). Thousand Oaks, CA: Sage.

Pemberton, C. and Swegin, P.J. (1989). Goal Setting and Motivation. Journal of Physical Education, Recreation, and Dance. 60(1), 39-41.

Peny-Dahlstrand, M., Krumlinde-Sundholm, L., \& Gosman-Hedstrom, G. (2013). Patterns of participation in school-related activities and settings in children with spina bifida. Disability and rehabilitation, 35(21), 1821-1827.

Petersen, J. C., \& Piletic, C. K. (2006). Facility accessibility: Opening the door to all. The Journal of Physical Education, Recreation, and Dance, 77(5), 38-46.

Powers, L. E., Sowers, J. A., \& Stevens, T. (1995). An exploratory, randomized study of the impact of mentoring on the self-efficacy and community-based knowledge of adolescents with severe physical challenges. Journal of Rehabilitation, 61(1), 33.

Plotnikoff, R. C., Costigan, S. A., Karunamuni, N., \& Lubans, D. R. (2013). Social cognitive theories used to explain physical activity behavior in adolescents: A systematic review and meta-analysis. Preventive medicine,56(5), 245-253.

Public Health Agency of Canada. Congenital Anomalies in Canada 2013 : A Perinatal Health Surveillance Report. Ottawa, 2013.

Rimmer, J. H. (2005). The conspicuous absence of people with disabilities in public fitness and recreation facilities: Lack of interest or lack of access? American Journal of Health Promotion, 19, 327-329.

Rimmer, J. H., Riley, B., Wang, E., \& Rauworth, A. (2005). Accessibility of Health Clubs for People with Mobility Disabilities and Visual Impairments.American Journal of Public Health, 95(11), 2022-2028.

Rimmer, J. A., \& Rowland, J. L. (2008). Physical activity for youth with disabilities: a critical need in an underserved population. Developmental Neurorehabilitation, 11(2), 141-148. 
Rimmer, J. H., Wang, E., Yamaki, K., \& Davis, B. (2010). Documenting disparities in obesity and disability. Focus: A Publication of the National Center for the Dissemination of Disability Research (NCDDR), 24, 1-16.

Rintoul, N. E., Sutton, L. N., Hubbard, A. M., Cohen, B., Melchionni, J., Pasquariello, P. S., \& Adzick, N. S. (2002). A new look at myelomeningoceles: functional level, vertebral level, shunting, and the implications for fetal intervention. Pediatrics, 109(3), 409-413.

Ritchie, J. \& Lewis, J. (eds) 2003, Qualitative research Practice: A Guide for Social Sciences Student and researchers., sage publication Inc, London.

Robertson, S. \& Way, R. (2005). Long-term athlete development. Coaches report, 11(3), 6-12.

Roebroeck, M. E., Hempenius, L., Van Baalen, B., Hendriksen, J. G. M., Van Den Berg-Emons, H. J. G., \& Stam, H. J. (2006). Cognitive functioning of adolescents and young adults with meningomyelocele and level of everyday physical activity. Disability \& Rehabilitation, 28(20), 1237-1242.

Rothenberg, S. P., da Costa, M. P., Sequeira, J. M., Cracco, J., Roberts, J. L., Weedon, J., \& Quadros, E. V. (2004). Autoantibodies against folate receptors in women with a pregnancy complicated by a neural-tube defect. New England Journal of Medicine, 350(2), 134-142.

Sallis, J. F., \& Saelens, B. E. (2000). Assessment of physical activity by self-report: Status, limitations, and future directions. Research Quarterly for Exercise and Sport, 71, 1-14.

Schoenmakers, M. A., de Groot, J. F., Gorter, J. W., Hillaert, J. L., Helders, P. J., \& Takken, T. (2009). Muscle strength, aerobic capacity and physical activity in independent ambulating children with lumbosacral spina bifida. Disability \& Rehabilitation, 31(4), 259-266.

Schneider, M., Dunn, A. L., \& Cooper, D. (2009). Affective, Exercise and Physical Activity among Healthy Adolescents. Journal of sport \& exercise psychology, 31(6), 706.

Schleien, S.J., Miller, K. D. (2010). Diffusion of Innovation: A roadmap for inclusive community recreation services. Research \& Practice for Persons with Severe Disabilities, 35(3-4), 93-101

Shepherd, K., Roberts, D., Golding, S., Thomas, B. J., \& Shepherd, R. W. (1991). Body composition in myelomeningocele. The American journal of clinical nutrition, 53(1), 1-6.

Sherman, M. S., Kaplan, J. M., Effgen, S., Campbell, D., \& Dold, F. (1997). Pulmonary dysfunction and reduced exercise capacity in patients with myelomeningocele. The Journal of pediatrics, 131(3), 413-418.

Shields, N., Synnot, A. J., \& Barr, M. (2012). Perceived barriers and facilitators to physical activity for children with disability: a systematic review. British journal of sports medicine, 46(14), 989-997.

Shilts, M. K., Horowitz, M., \& Townsend, M. S. (2004). Goal setting as a strategy for dietary and physical activity behavior change: a review of the literature. American Journal of Health Promotion, 19(2), 81-93.

Short, K. R., \& Frimberger, D. (2012). A review of the potential for cardiometabolic dysfunction in youth with spina bifida and the role for physical activity and structured exercise. International journal of pediatrics, 2012.

Simeonsson, R. J., McMillen, J. S., \& Huntington, G. S. (2002). Secondary conditions in children with disabilities: spina bifida as a case example. Mental retardation and developmental disabilities research reviews, 8(3), 198-205.

Singh, D. K. (2003). Families of children with spina bifida: A review. Journal of Developmental and Physical Disabilities, 15(1), 37-55. 
Sit, C. H., Lindner, K. J., \& Sherrill, C. (2002). Sport participation of Hong Kong Chinese children with disabilities in special schools. Adapted Physical Activity Quarterly, 19(4), 453-471.

Sparkes, A. C., \& Smith, B. (2013). Qualitative research methods in sport, exercise and health: From process to product. Routledge.

Spina Bifida Association of America (2011). Fact Sheets: Obesity. Retrieved from: http://www.spinabifidaassociation.org/site/c.liKWL7PLLrF/b.2700287/k.C25F/O besity.htm

Stankov, I., Olds, T., \& Cargo, M. (2012). Overweight and obese adolescents: what turns them off physical activity. Int J Behav Nutr Phys Act,9(1), 53.

Sturges, J. E., \& Hanrahan, K. J. (2004). Comparing telephone and face-to-face qualitative interviewing: a research note. Qualitative research, 4(1), 107-118.

Talamonti G, D'Aliberti G, Collice M. Myelomeningocele: long-term neurosurgical treatment and follow-up in 202 patients. J Neurosurg 2007;107,368-86.

Tavender, E. J., Bosch, M., Gruen, R. L., Green, S. E., Knott, J., Francis, J. J., ... \& O’Connor, D. A. (2014). Understanding practice: the factors that influence management of mild traumatic brain injury in the emergency department-a qualitative study using the Theoretical Domains Framework. Implementation Science, 9(1), 8.

Telama, R., Yang, X., Viikari, J., Välimäki, I., Wanne, O., \& Raitakari, O. (2005). Physical activity from childhood to adulthood: a 21-year tracking study.American journal of preventive medicine, 28(3), 267-273.

Trost, S. G., Pate, R. R., Dowda, M., Ward, D. S., Felton, G., \& Saunders, R. (2002). Psychosocial correlates of physical activity in white and African-American girls. Journal of Adolescent Health, 31(3), 226-233.

Tremblay, M. S., LeBlanc, A. G., Carson, V., Choquette, L., Connor Gorber, S., Dillman, C., Spence, J. C. (2012). Canadian sedentary guidelines for the early years (aged 0-4 years). Applied Physiology, Nutrition and Metabolism, 37(2), 370-380.

Thomas H, Irwin J: What is a healthy body weight? Perspectives of overweight youth. Can J Diet Pract Res 2009, 70(3):110-116.

Van den Berg-Emons, H. J., Bussmann, J. B., Brobbel, A. S., Roebroeck, M. E., van Meeteren, J., \& Stam, H. J. (2001). Everyday physical activity in adolescents and young adults with meningomyelocele as measured with a novel activity monitor. The Journal of pediatrics, 139(6), 880-886.

Van den Berg-Emons, H., Bussmann, J., Meyerink, H., Roebroeck, M., \& Stam, H. (2003). Body fat, fitness and level of everyday physical activity in adolescents and young adults with meningomyelocele. Journal of rehabilitation medicine, 35(6), 271-275.

Van der Ploeg, H. P., van der Beek, A. J., van der Woude, L. H. C., \& van Mechelen, W. (2004). Physical activity for people with disabilities. Sports Medicine, 34, 638- 649.

Vanhala, M., Vanhala, P., Kumpusalo, E., Halonen, P., \& Takala, J. (1998). Relation between obesity from childhood to adulthood and the metabolic syndrome: population based study. Bmj, 317(7154), 319-320.

Verhoef, M., Barf, H. A., Post, M. W. M., Asbeck, F. W. A., Gooskens, R. H. J. M., \& Prevo, A. J. H. (2004). Secondary impairments in young adults with spina bifida. Developmental Medicine \& Child Neurology, 46(6), 420-427.

Verhoef, M., Barf, H. A., Post, M. W., Asbeck, F. W., Gooskens, R. H., \& Prevo, A. J. (2006). Functional independence among young adults with spina bifida, in relation to 
hydrocephalus and level of lesion. Developmental Medicine \& Child Neurology, 48(2), 114-119.

Verhoef, M., Post, M. W. M., Barf, H. A., Van Asbeck, F. W. A., Gooskens, R. H. J. M., \& Prevo, A. J. H. (2007). Perceived health in young adults with spina bifida. Developmental Medicine \& Child Neurology, 49(3), 192-197.

Verschuren, O., Ketelaar, M., Gorter, J. W., Helders, P. J., Uiterwaal, C. S., \& Takken, T. (2007). Exercise training program in children and adolescents with cerebral palsy: a randomized controlled trial. Archives of pediatrics \& adolescent medicine, 161(11), 1075-1081.

Wai, E. K., Owen, J., Fehlings, D., \& Wright, J. G. (2000). Assessing physical disability in children with spina bifida and scoliosis. Journal of Pediatric Orthopaedics, 20(6), 765 770.

Washburn, R. A., Zhu, W., McAuley, E., Frogley, M., \& Figoni, S. F. (2002). The physical activity scale for individuals with physical disabilities: Development and evaluation. Archives of Physical Medicine and Rehabilitation, 83, 193-200. doi: 10.1053/apmr.2002.27467

White, L., Volfson, Z., Faulkner, G., \& Arbour-Nicitopoulos, K. (2015). Reliability and Validity of Physical Activity Instruments Used in Children and Youth with Physical Disabilities: A Systematic Review. Pediatric exercise science.

Whiteneck, G. G., Charlifue, S. W., Frankel, H. A., Fraser, M. H., Gardner, B. P., Gerhart, K. A., ... \& Silver, J. R. (1992). Mortality, morbidity, and psychosocial outcomes of persons spinal cord injured more than 20 years ago.Spinal Cord, 30(9), 617-630.

Winnick, J. P., \& Short, F. X. (1984). The physical fitness of youngsters with spinal neuromuscular conditions. Adapted Physical Activity Quarterly.

Wolf, Z. R. (2012). Ethnography: The method. In P. Munhall (Eds.), Nursing Research: A qualitative perspective ( $5^{\text {th }} \mathrm{Ed}$.) (pp. 285-338). Toronto: Jones and Bartlett Learning.

World Health Organization. (2001). International Classification of Functioning, Disability, and Health. Geneva: WHO

Zimmerman R.D, Breckbill D, Dennis M.W, et al. Cranial C.T findings in patients with meningomyelocele. AJR Am J Roentgenol 1979;132:623-9. 